Prepared in cooperation with the Bureau of Reclamation

\title{
Technical Evaluation of a Total Maximum Daily Load Model for Upper Klamath Lake, Oregon
}

Open-File Report 2013-1262

U.S. Department of the Interior U.S. Geological Survey 



\section{Technical Evaluation of a Total Maximum Daily Load Model for Upper Klamath Lake, Oregon}

By Tamara M. Wood, Susan A. Wherry, James L. Carter, James S. Kuwabara, Nancy S. Simon, and Stewart A. Rounds

Prepared in cooperation with the Bureau of Reclamation

Open-File Report 2013-1262

U.S. Department of the Interior

U.S. Geological Survey 


\section{U.S. Department of the Interior \\ SALLY JEWELL, Secretary}

\section{U.S. Geological Survey \\ Suzette M. Kimball, Acting Director}

U.S. Geological Survey, Reston, Virginia 2013

For more information on the USGS-the Federal source for science about the Earth its natural and living resources, natural hazards, and the environment: World Wide Web: http://www.usgs.gov

Telephone: 1-888-ASK-USGS

For an overview of USGS information products, including maps, imagery, and publications, visit http://www.usgs.gov/pubprod

To order this and other USGS information products, visit http://store.usgs.gov

Any use of trade, product, or firm names is for descriptive purposes only and does not imply endorsement by the U.S. Government.

Although this report is in the public domain, permission must be secured from the individual copyright owners to reproduce any copyrighted material contained within this report.

Suggested citation:

Wood, T.M., Wherry, S.A., Carter, J.L., Kuwabara, J.S., Simon, N.S., and Rounds, S.A., 2013, Technical evaluation of a total maximum daily load model for Upper Klamath and Agency Lakes, Oregon: U.S. Geological Survey Open-File Report 2013-1262, 75 p, http://dx.doi.org/10.3133/ofr20131262

ISSN 2331-1258 (online) 


\section{Contents}

Executive Summary

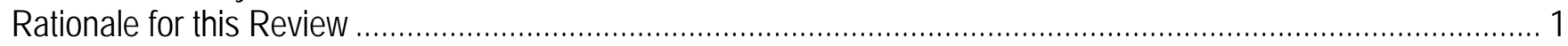

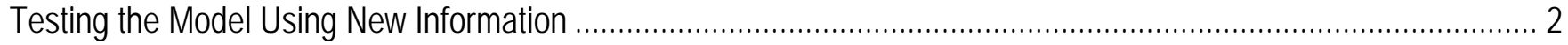

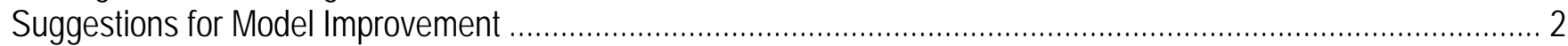

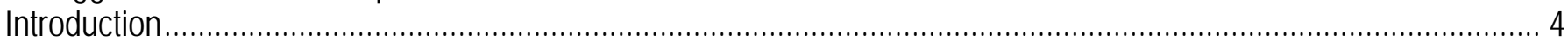

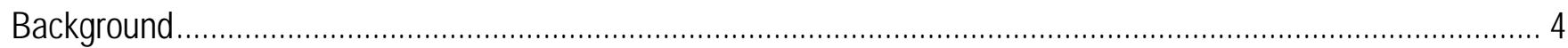

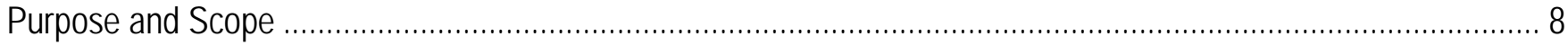

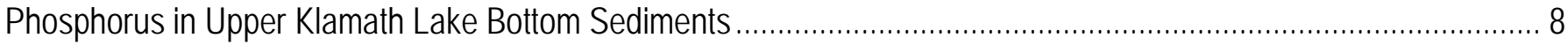

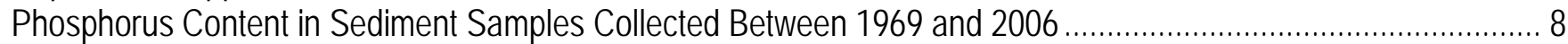

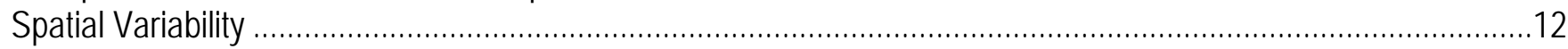

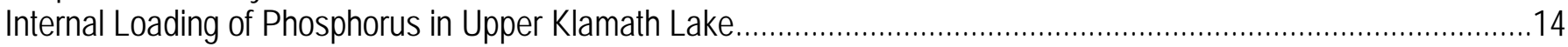

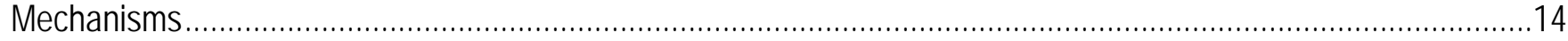

Possible Role of Benthic Invertebrates in Internal Loading in Upper Klamath Lake ...............................................17

Verification of the Upper Klamath Lake Phosphorus TMDL Model.................................................................22

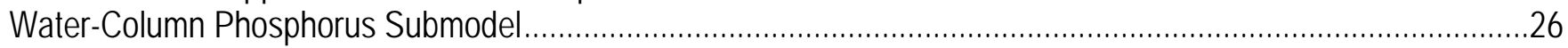

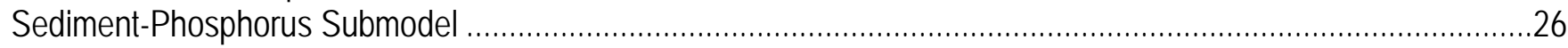

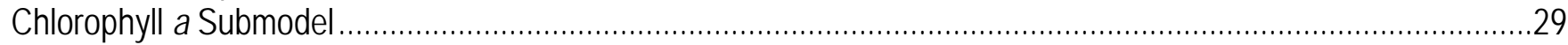

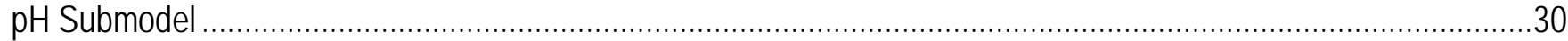

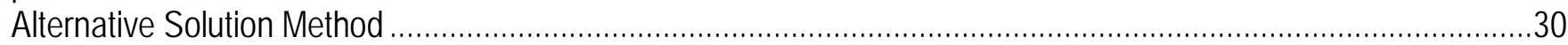

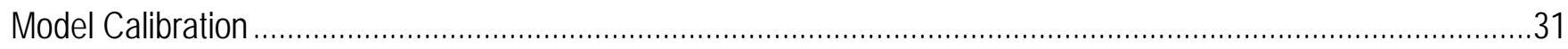

Step 1-pH Regression Model Parameters..........................................................................................

Step 2 -Algal Settling Rate ...........................................................................................................

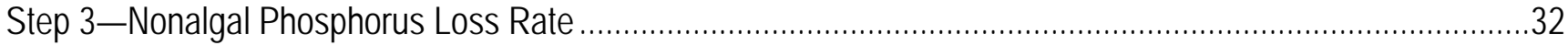

Step 4-Internal Recycling Parameters ………………………….....................................................32

Comparison of Original to Recalibrated Model Performance......................................................................33

Sensitivity of Calibration Parameters to Model Modifications..........................................................................4

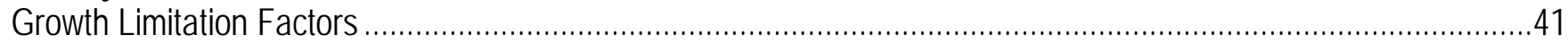

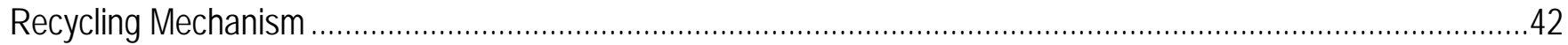

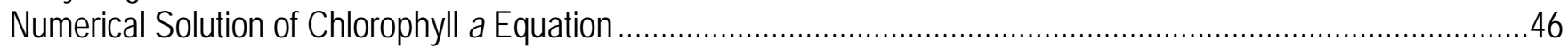

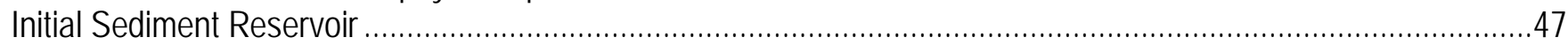

Long-Term Model Simulation and Implications for TMDL .........................................................................49

Summary, Conclusions, and Suggestions for Improvements to the TMDL Model ................................................60

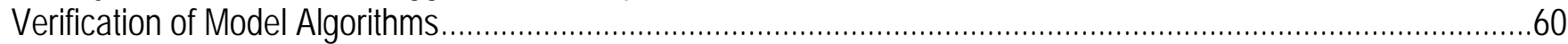

Sensitivity of Calibration Parameters to Model Assumptions ...........................................................................60

Effect of Calibration Parameters on Long-Term Model Simulations....................................................................61

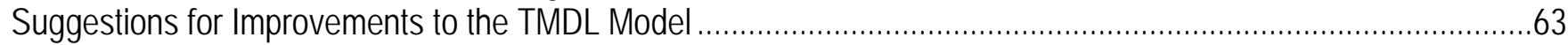

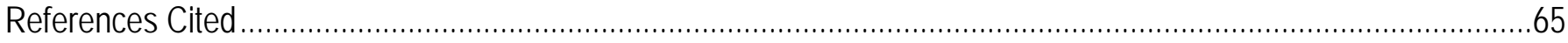

Appendix A. R-Script Code for Upper Klamath Lake Phosphorus Model ..............................................................71 


\section{Figures}

Figure 1. Map showing sampling sites for benthic flux and sediment core and grab sample collection in Upper Klamath Lake, Oregon.

Figure 2. Graphs showing average concentration of phosphorus fractions as a function of depth in sediment from 26 cores collected from Upper Klamath Lake, Oregon, 2006.

Figure 3. Graphs showing average concentration of carbon, nitrogen, and trace elements as a function of depth in sediment from 26 cores collected from Upper Klamath Lake, Oregon, 2006.

Figure 4. Diagrams showing varimax rotated principal component scores for all constituents in cores collected from Upper Klamath Lake, Oregon, integrated to 10 centimeter depth.

Figure 5. Graph showing calculated whole-lake average of internal loading to Upper Klamath Lake, Oregon, April 1991-September 1998.

Figure 6. Diagram showing original total maximum daily load (TMDL) model dependence loops.

Figure 7. Diagrams showing simulated and observed water column $(A)$ total phosphorus concentration, $(B)$ chlorophyll a concentration, and (C) pH, Upper Klamath Lake, Oregon, April 1991-September 1998.

Figure 8. Diagrams showing simulated and observed water column $(A)$ total phosphorus concentration, $(B)$ chlorophyll a concentration, and (C) pH in Upper Klamath Lake, Oregon, April 1991-April 1998.

Figure 9. Graph showing mass of phosphorus recycled from sediments, calculated from observations of water column phosphorus and external loads, Upper Klamath Lake, Oregon, May-July 1991-1998, as a function of lake temperature.

Figure 10. Graphs showing simulated and observed water column $(A)$ total phosphorus concentration, $(B)$ chlorophyll a concentration, and (C) pH, Upper Klamath Lake, Oregon, April 1991-September 1998.

Figure 11. Graphs showing simulated and observed water column $(A)$ total phosphorus concentration, $(B)$ chlorophyll a concentration, and (C) pH, Upper Klamath Lake, Oregon, April 1991-September 1998.

Figure 12. Graphs showing simulated and observed water column $(A)$ total phosphorus concentration, $(B)$ chlorophyll a concentration, and (C) pH, Upper Klamath Lake, Oregon, April 1991-September 1998.

Figure 13. Graphs showing average $(A)$ concentration of total phosphorus, $(B)$ size of the sediment reservoir, $(C)$ concentration of chlorophyll a during the final 7 years of a 203-year simulation for Upper Klamath Lake, Oregon, as a function of the average ratio of recycled mass to settled mass during the first 7 years of a 203-year simulation. (D) Total phosphorus concentration from graph $A$ as a function of the sediment reservoir from graph $B$.

Figure 14. Graphs showing comparison of long-term simulated concentration of water column phosphorus, under conditions of $(A) 0$ and $(B) 40$ percent reductions in external loads to Upper Klamath Lake, Oregon.

Figure 15. Graphs showing comparison of long-term simulated concentration of sediment phosphorus reservoir in Upper Klamath Lake, Oregon, under conditions of $(A) 0$ and $(B) 40$ percent reductions in external loads.

Figure 16. Graphs showing comparison of long-term simulated concentration of water column phosphorus in Upper Klamath Lake, Oregon, under conditions of $(A) 0$ and $(B) 40$ percent reductions in external loads.

Figure 17. Graphs showing comparison of long-term simulated concentration of sediment phosphorus reservoir in Upper Klamath Lake, Oregon, under conditions of $(A) 0$ and $(B) 40$ percent reductions in external loads......

Figure 18. Graphs showing simulated chlorophyll a concentration during the last 7 years of a 203-year simulation under conditions of $(A) 0$ percent and $(B) 40$ percent reductions in external loads to Upper Klamath Lake, Oregon. . 58 Figure 19. Graphs showing simulated total phosphorus concentration during the last 7 years of a 203-year simulation under conditions of $(A) 0$ percent and $(B) 40$ percent reductions in external loads to Upper Klamath Lake, Oregon. . 59 


\section{Tables}

Table 1. Comparison of concentrations of total and inorganic phosphorus in sediment cores collected October 2006 from Upper Klamath Lake, Oregon, to reported concentrations prior to 2006.

Table 2. Loadings of sediment variables onto varimax rotated principal components for all constituents in cores collected from Upper Klamath Lake, Oregon, integrated to 10 centimeter depth.

Table 3. Comparison of mass-specific excretion of phosphorus by benthic invertebrates from Upper Klamath Lake,

Oregon...... 20

Table 4. Values and sources of parameters used in the Upper Klamath Lake, Oregon, phosphorus TMDL modelcontinued 23

Table 5. Definitions of symbols used in this report

Table 6. Comparison of simulated model variables obtained from the original, semi-analytical and Runge-Kutta models used in the review of the original model used to establish a TMDL for Upper Klamath Lake, Oregon. 31

Table 7. Comparison of $\mathrm{pH}$ model coefficients and statistics between the original TMDL model for Upper Klamath Lake, Oregon, and the model recalibration.

Table 8. Comparison of descriptive statistics between observed and calculated non-algal mass lost to sedimentation during March-May 1991-1998. 32

Table 9. Comparison of performance statistics for total phosphorus obtained over a validation period including all months in 1991-1993 and August-April in 1994-1998 from model versions discussed in the report. 35

Table 10. Comparison of performance statistics for chlorophyll a obtained over a validation period including all months in 1991-1993 and August-April in 1994-1998 from model versions discussed in the report.

Table 11. Comparison of performance statistics for pH obtained over a validation period including all months in 19911993 and August-April in 1994-1998 from model versions discussed in the report.

Table 12. Comparison of performance statistics for total phosphorus over a validation period including May-July 1991-1993 obtained from various model versions discussed in the report.

Table 13. Comparison of performance statistics for chlorophyll a obtained over a validation period including May-July 1991-1993 from model versions discussed in the report.

Table 14. Comparison of performance statistics for pH obtained over a validation period including May-July 19911993 from various model versions discussed in the report.

Table 15. Comparison of metrics describing the long-term simulations for model versions discussed in the report. .. 51 


\section{Conversion Factors and Datums}

\section{Conversion Factors}

\begin{tabular}{|c|c|c|}
\hline Multiply & By & To obtain \\
\hline \multicolumn{3}{|c|}{ Length } \\
\hline meter $(\mathrm{m})$ & 3.281 & foot $(\mathrm{ft})$ \\
\hline centimeter $(\mathrm{cm})$ & $2.54 \mathrm{x}$ & inch (in.) \\
\hline kilometer (km) & 0.6214 & mile (mi) \\
\hline \multicolumn{3}{|c|}{ Area } \\
\hline square kilometer $\left(\mathrm{km}^{2}\right)$ & 247.1 & acre \\
\hline square kilometer $\left(\mathrm{km}^{2}\right)$ & 0.3861 & square mile $\left(\mathrm{mi}^{2}\right)$ \\
\hline square meter $\left(\mathrm{m}^{2}\right)$ & 10.7639 & square foot (ft2) \\
\hline \multicolumn{3}{|c|}{ Volume } \\
\hline cubic meter $\left(\mathrm{m}^{3}\right)$ & 35.31 & cubic foot $\left(\mathrm{ft}^{3}\right)$ \\
\hline \multicolumn{3}{|c|}{ Flow rate } \\
\hline meter per second $(\mathrm{m} / \mathrm{s})$ & 3.281 & foot per second (ft/s) \\
\hline meter per day $(\mathrm{m} / \mathrm{d})$ & 3.281 & foot per day (ft/d) \\
\hline cubic meter per day $\left(\mathrm{m}^{3} / \mathrm{d}\right)$ & 35.31 & cubic foot per day $\left(\mathrm{ft}^{3} / \mathrm{d}\right)$ \\
\hline \multicolumn{3}{|c|}{ Mass } \\
\hline $\operatorname{gram}(\mathrm{g})$ & 0.03527 & ounce avoirdupois (oz) \\
\hline milligram (mg) & $3.527 \times 10^{-5}$ & ounce avoirdupois (oz) \\
\hline kilogram $(\mathrm{kg})$ & 2.205 & pound avoirdupois (lb) \\
\hline metric ton & $2,205.00$ & pound avoirdupois (lb) \\
\hline \multicolumn{3}{|c|}{ Concentration } \\
\hline parts per billion (ppb) & 1.0 & micrograms per liter $(\mu \mathrm{g} / \mathrm{L})$ \\
\hline
\end{tabular}

Temperature in degrees Celsius $\left({ }^{\circ} \mathrm{C}\right)$ may be converted to degrees Fahrenheit $\left({ }^{\circ} \mathrm{F}\right)$ as follows: ${ }^{\circ} \mathrm{F}=\left(1.8 x^{\circ} \mathrm{C}\right)+32$.

Concentrations of chemical constituents in water are given in milligrams per liter (mg/L), micrograms per liter $(\mu \mathrm{g} / \mathrm{L})$, or milligrams per gram dry weight (mg/g DW).

\section{Datums}

Vertical coordinate information is referenced to the Bureau of Reclamation datum, which is 1.78 feet above National Geodetic Vertical Datum of 1929 (NGVD 29). 


\title{
Technical Evaluation of a Total Maximum Daily Load Model for Upper Klamath and Agency Lakes, Oregon
}

\author{
By Tamara M. Wood, Susan A. Wherry, James L. Carter, James S. Kuwabara, Nancy S. Simon, \\ and Stewart A. Rounds
}

\section{Executive Summary}

\section{Rationale for this Review}

We reviewed a mass balance model developed in 2001 that guided establishment of the phosphorus total maximum daily load (TMDL) for Upper Klamath and Agency Lakes, Oregon. The purpose of the review was to evaluate the strengths and weaknesses of the model and to determine whether improvements could be made using information derived from studies since the model was first developed. The new data have contributed to the understanding of processes in the lakes, particularly internal loading of phosphorus from sediment, and include measurements of diffusive fluxes of phosphorus from the bottom sediments, groundwater advection, desorption from iron oxides at high $\mathrm{pH}$ in a laboratory setting, and estimates of fluxes of phosphorus bound to iron and aluminum oxides. None of these processes in isolation, however, is large enough to account for the episodically high values of wholelake internal loading calculated from a mass balance, which can range from 10 to 20 milligrams per square meter per day for short periods.

The possible role of benthic invertebrates in lake sediments in the internal loading of phosphorus in the lake has become apparent since the development of the TMDL model. Benthic invertebrates can increase diffusive fluxes several-fold through bioturbation and biodiffusion, and, if the invertebrates are bottom feeders, they can recycle phosphorus to the water column through metabol- ic excretion. These organisms have high densities (1,822-62,178 individuals per square meter) in Upper Klamath Lake. Conversion of the mean density of tubificid worms (Oligochaeta) and chironomid midges (Diptera), two of the dominant taxa, to an areal flux rate based on laboratory measurements of metabolic excretion of two abundant species suggested that excretion by benthic invertebrates is at least as important as any of the other identified processes for internal loading to the water column.

Data from sediment cores collected around Upper Klamath Lake since the development of the TMDL model also contributed to this review. Cores were sequentially extracted to determine the distribution of phosphorus associated with several matrices in the sediment (freely exchangeable, metal-oxides, acid-soluble minerals, and residual). The concentrations of phosphorus in these fractions varied around the lake in patterns that reflect transport processes in the lake and the ultimate deposition of organic and inorganic forms of phosphorus from the water column. Both organic and inorganic phosphorus had higher concentrations in the northern part of the lake, in and just west of Goose Bay. At the time that these cores were collected, prior to restoration of the Williamson River Delta, this area was close to the shoreline of the lake and east of the Williamson River mouth. This contrasts with erosional inputs, which, in addition to being high to the east of the pre-restoration Williamson River mouth, were higher in the middle of the lake than at the northern end. Organic forms of phos- 
phorus had particularly high concentrations in the northern bays. When these cores were used to calculate a new estimate of the whole-lakeaveraged concentration of total phosphorus in the top 10 centimeters of the lake sediments, the estimate was about one-third of the best estimate available when the TMDL model was developed.

\section{Testing the Model Using New Information}

Verification of the original TMDL model and its calibration identified three readily implemented changes in model algorithms that improve the model: (1) integrating the light limitation function over depth, (2) replacing the phosphorus limitation function with a MichaelisMenten formulation, and (3) removing the assumption that chlorophyll $a$ reaches instantaneous equilibrium with light and nutrients.

When these changes were made and the model was recalibrated, the calibration parameters associated with phosphorus recycling changed substantially, resulting in quantitative differences such as higher predicted total phosphorus and chlorophyll $a$ concentrations in the long term (203-year) simulations that were used to predict the steady-state response of the lakes to the implementation of the TMDL. The improved model also predicted that, at steady state, chlorophyll $a$ concentration would exceed 100 parts per billion ( $\mathrm{ppb}$, the units used in the original model documentation; equivalent to micrograms per liter) in 4 of 7 years, instead of 2 of 7 years. Qualitatively, however, the predictions of the improved model were consistent with those of the previous model in simulating a long-term reduction in total phosphorus and chlorophyll $a$ concentrations relative to current conditions and in predicting that severe blooms (peak chlorophyll $a$ concentration greater than $(>) 100 \mathrm{ppb}$ ) would no longer happen every year.

We used a sensitivity analysis to examine the result of changing the estimate of the initial sediment phosphorus reservoir to about one-third the value used in the original TMDL simulations, based on concentration data from the more re- cently collected sediment cores. Using the new estimate and updating the model calibration parameters caused the long-term predictions of the model to change because the calibrated recycling rates increased. The new recycling rates increased predicted water column total phosphorus and chlorophyll $a$ concentrations in the long term (203-year) simulations, a consequence of the result that, for a given a set of boundary conditions (percent reduction in external load) and initial conditions (size of sediment-phosphorus reservoir), the steady-state water-column phosphorus concentration generally was negatively correlated with the steady-state sediment reservoir.

The model equations describe a coupled water column/sediment system in which the two compartments are inter-dependent. In such a system, as long as external inputs to the system continue, the sediment compartment will not trend independently toward depletion until it is gone. Rather, phosphorus concentrations in the water column will reach a steady state in equilibrium with the sediment reservoir over time and the calibration parameters (not the magnitude of the sediment phosphorus reservoir) will determine the steady-state conditions. In most simulations, the sediment reservoir decreased over time to a steady-state value less than the initial condition. In some simulations, however, the size of the sediment-phosphorus reservoir stayed mostly steady or increased slightly over time as equilibrium was approached.

\section{Suggestions for Model Improvement}

We developed a temperature-dependent recycling term for the model that is based on the hypothesis that benthic invertebrate activity is an important driver of internal phosphorus loading and that higher temperature stimulates that activity. We substituted this term for the $\mathrm{pH}$-dependent recycling term in the original model to investigate the behavior of the model when the feedback inherent in the $\mathrm{pH}$-dependent recycling term was removed. Although the predictions of the modified model were consistent with previous results in simulating a long-term reduction in total phos- 
phorus and chlorophyll $a$, over the 203-year timeframe the differences in the two approaches became apparent: At steady state, the $\mathrm{pH}$ dependent recycling approach simulated large blooms (defined as greater than 100 ppb chlorophyll $a$ ) in only 2 of every 7 years, whereas the temperature-dependent approach simulated large blooms every year. Therefore, the form of the recycling term has a strong influence on model predictions. Because $\mathrm{pH}$-dependent desorption of phosphorus from iron oxyhydroxides is only one of several mechanisms for the internal loading of phosphorus in the lake, adding more realistic complexity to the recycling term would improve the model.

The calibrated settling velocity of algal phosphorus varied 51 percent over the implemented model modifications, indicating that the calibrated parameter did not represent a true physical or chemical process, but rather was compensating for overly simplistic formulations of complex phenomena. The model likely, therefore, could be improved by reducing uncertainty in the sedimentation and recycling terms through a combination of field programs and modeling or empirical techniques that could better predict sedimentation and recycling as functions of other readily available environmental variables. For example, two explanatory variables for macroinvertebrate-dependent recycling might be water temperature and time elapsed since the start of the growing season. A field program could include the collection of density, body-size, and excretion stoichiometry data for benthic invertebrates over a few growing seasons. Because many quantities, such as recycling rate, sedimentphosphorus content, benthic invertebrate density, and sedimentation vary around the lake, a spatially explicit phosphorus transport model of the lake could be used to appropriately "scale up" the spatial variability from site-dependent estimates for use in a whole-lake model. The model could be further improved through the incorporation of a mortality term that would move algal phosphorus from a viable (nonsettling) to a detrital (settling) physiological state.
The final improvement would be to use a longer dataset (in terms of number of years) to calibrate and validate the model. Water-quality data from 1991 to 1998 were used to calibrate the model, and the behavior of the model over the long term depends on the calibration parameters derived from fitting the earliest part of the simulation to the available calibration data. The simulations from our model modifications were consistent in that all achieved a steady state within about 25-75 years, during which total phosphorus and chlorophyll $a$ concentrations in the lakes were decreased, and most models simulated severe blooms (chlorophyll $a>100 \mathrm{ppb}$ ) happening less often after steady state is achieved. The consistency of this result can be tested in the context of potential changes to calibrated parameters based on a longer calibration dataset, when that becomes available. The performance of the calibrated model with a longer validation dataset also can be evaluated. 


\section{Introduction}

\section{Background}

Upper Klamath and Agency Lakes (fig. 1) are the primary components of a large, shallow, freshwater lake system in south-central Oregon that has a surface area of $260 \mathrm{~km}^{2}$ and a mean depth of $2.8 \mathrm{~m}$ at full pool. The main tributaries include the Williamson, Sprague, and Wood Rivers. Most water leaves the lake through Link Dam into the Link River, a $1.6-\mathrm{km}$ reach that leads to the head of the Klamath River. Water from the lakes provides essential waterfowl and fish habitat and is used for irrigation, power generation, and to enhance and sustain downstream flows in the Klamath River. A restoration project completed in 2009 added $28 \mathrm{~km}^{2}$ around the mouth of the Williamson River (shown as Tulana and Goose Bay in figure 1) to the Agency Lake/Upper Klamath Lake hydrologic system, and formed a single water body from the two lakes that had previously been connected only through Agency Straits (fig. 1). In this report, "Upper Klamath Lake" refers to the combined lake system, before or after restoration of the Williamson River Delta, as appropriate.

Water currents in the Upper Klamath Lake system are primarily wind driven. Prevailing north to northwest winds move the water in a generally clockwise direction around the lake in a broad, north-to-south flow on the shallow eastern side of the lake and a narrow, south to north return flow in the deepest part of the lake, a trench along the western shoreline with a maximum depth of about $15 \mathrm{~m}$ (Wood and others, 2008). Dense blooms dominated by the filamentous cyanobacterium Aphanizomenon flos-aquae occur in the lake every summer. Thermal stratification establishes in the afternoon, and the resulting water column stability allows the large, buoyant colonies of $A$. flos-aquae to accumulate in the upper water column. Because the lake is so shallow, the water column in most of the lake mixes daily when wind increases, usually in the afternoon, although in deeper parts of the lake stratification can sometimes persist for several days. Conditions at the sediment/water interface do not routinely become completely anoxic, although this can happen in association with a bloom decline in the deep trench along the western shoreline or other deep parts of the lake when mixing does not occur for several days (Wood and others, 2006), or in the bays, where particularly high concentrations of planktonic biomass can occur before senescence (Wood, 2001). Normal summer stratification, particularly during periods of low wind, does, however, result in low dissolved oxygen and high ammonia concentrations in the near-bottom water column during bloom declines (Kann and Welch, 2005). These episodes of poor water quality negatively affect fish in the lake, including shortnose sucker (Chasmistes brevirostris) and Lost River sucker (Deltistes luxatus), both endangered species (Perkins and others, 2000; Banish and others, 2009).

During the rapid growth phase of the bloom, generally May-July, dissolved oxygen typically is supersaturated in the near-surface water column, and photosynthetically elevated $\mathrm{pH}$ routinely exceeds 9.5 (Hoilman and others, 2008). The probability of exceeding a specific $\mathrm{pH}$ value in this phase can be predicted from concentrations of the biomass surrogate chlorophyll $a$ (Kann and Smith, 1999). A. flos-aquae is a nitrogen-fixing cyanobacterium, and consequently, phosphorus is the primary limiting nutrient, at least during the growth phase of the first bloom (Lindenberg and others, 2009; Kann, 2011a), which is initiated and sustained by tributary phosphorus and by phosphorus stored in the bottom sediments that is transferred to the water column in the spring and summer through a process known as "internal loading" or "internal recycling" (Kann, 1998).

A Total Maximum Daily Load (TMDL) for Upper Klamath and Agency Lakes was completed in 2002 to address chlorophyll $a, \mathrm{pH}$, and dissolved-oxygen levels that did not meet waterquality standards (Oregon Department of Environmental Quality, 2002). The TMDL analysis 


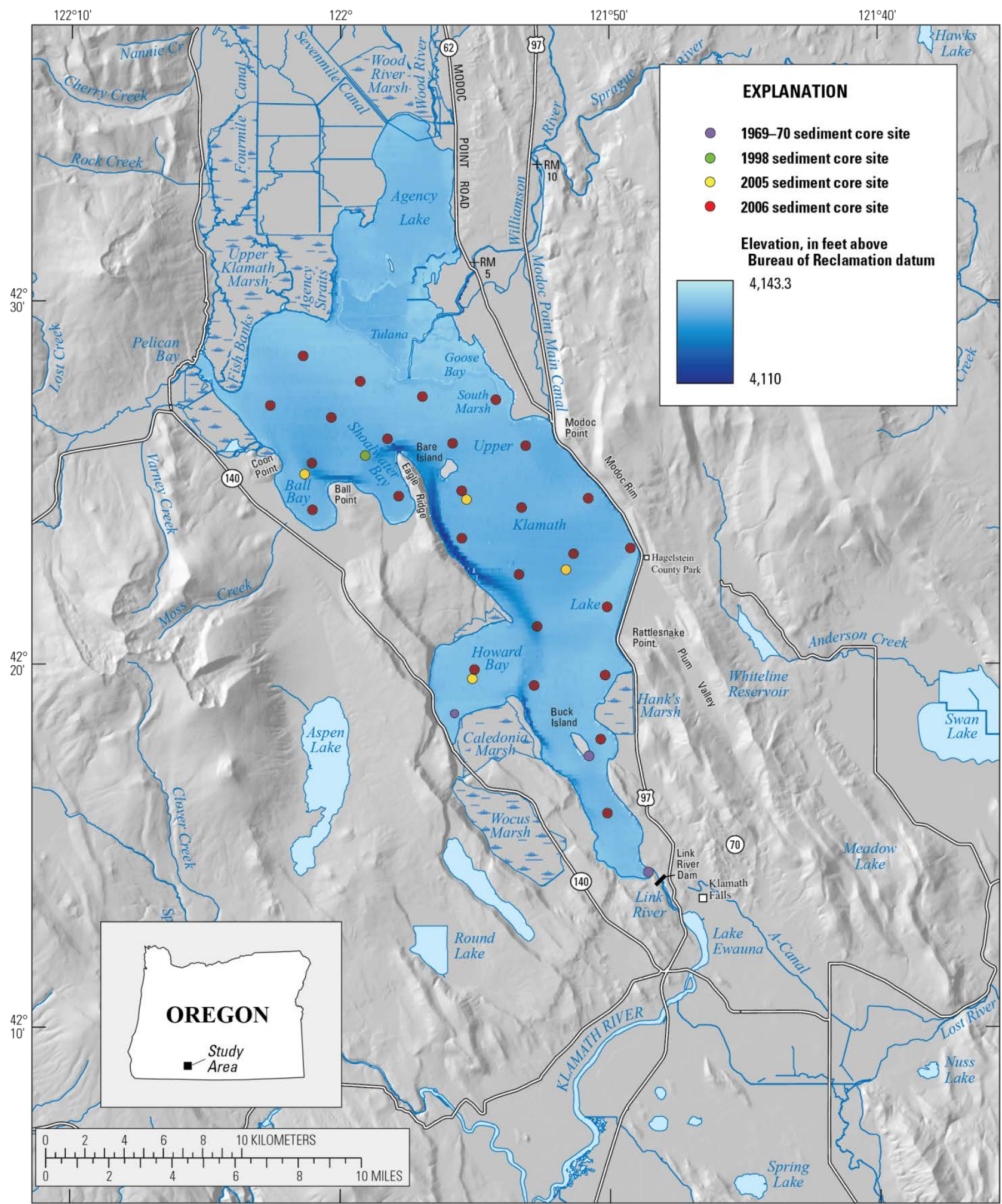

Base modified from USGS and other digital sources, various scales.

Coordinate system is UTM, Zone 10N; North American Datum of 1927.

Figure 1. Map showing sampling sites for benthic flux and sediment core and grab sample collection in Upper Klamath Lake, Oregon. 
was partly based on a dynamic mass-balance model that simulates the combined Upper Klamath and Agency Lakes as a continuously stirred tank reactor (CSTR) and predicts lake total phosphorus, chlorophyll $a$, and $\mathrm{pH}$ as a function of phosphorus loading (external and internal) and other factors (Walker, 2001). The model tracks phosphorus in the water column and sediment. It simulates lake-mean phosphorus concentrations (is not spatially explicit) and performs massbalance simulations on a biweekly time step. The model is programmed into a Microsoft ${ }^{\circledR}$ Excel $^{\circledR}$ spreadsheet.

The mass-balance model also was used to develop boundary conditions for naturalconditions scenarios for the Klamath River TMDL models (Oregon Department of Environmental Quality, 2010). The Oregon Department of Environmental Quality acknowledged that the modeled boundary conditions are one of the greatest sources of uncertainty in the development of the Klamath River TMDLs. As the basis for load allocations and regulatory actions that would affect point and nonpoint discharges downstream, operation of irrigation and hydropower systems, and attainment of beneficial uses in more than $320 \mathrm{~km}$ of the Klamath River to the ocean, the effects of the boundary conditions on the Klamath River TMDL came under scrutiny when reviewers of the Klamath River models questioned whether the Upper Klamath Lake TMDL model was sufficiently detailed and physically based to support these critical boundary conditions (Rounds and Sullivan, 2009; 2010).

Further research, water-quality monitoring, and wetland restoration has occurred in and around the lake since the Upper Klamath Lake TMDL model was originally developed. The TMDL model was calibrated and validated using a whole-lake mass balance (Kann and Walker, 2001) derived from biweekly, year-round, in-lake water column profiles and tributary data collected by the Klamath Tribes from 1991 through 1998. Another decade of monitoring has occurred since the model was completed, including a continuation of the Klamath Tribes' dataset, which is documented in a series of reports (for example, Kann, 2011a, b). The U.S. Geological Survey (USGS) has operated continuous water-quality monitors and collected water chemistry data in the lake since 2002, and the results are documented in a series of reports (for example Eldridge and others, 2012).

Additionally, research has led to a better mechanistic understanding of water-quality processes in the lake, including processes that affect the internal loading of phosphorus that is critical to the cycling of nutrients and the stimulation of algal growth:

- Laboratory experiments by USGS (Fisher and Wood, 2004) demonstrated that the mechanism of desorption of phosphorus at high $\mathrm{pH}$ may not be the most important mechanism of sediment phosphorus recycling.

- Direct measurements of diffusive fluxes through the sediment have been made in Upper Klamath Lake (Kuwabara and others, 2007; 2009) and the restored Williamson River Delta (Kuwabara and others, 2012a).

- Samples of benthic invertebrate communities collected in the lake and delta have revealed high densities of benthic invertebrates in the sediment (Kuwabara and others, 2012a) that could contribute to internal loading through metabolic cycling.

- A study of the phosphorus in the top $2 \mathrm{~cm}$ of sediment before and after the $A$. flos aquae bloom in 2005 was equivocal, in that two of four sites showed no significant change, one site showed a significant increase in residual phosphorus, and one site showed a significant decrease in iron-associated phosphorus (Simon and others, 2009).

- In 2006, 26 sediment cores were collected and analyzed for nutrients and metals in 10 vertical layers, which provided a better description of the amount and forms of phosphorus in the bottom sediments of the lake than was available previously (Simon and Ingle, 2011). 
- A hydrodynamic and heat transport model of the lake has provided insight into the role of the wind-driven circulation in transporting water quality constituents (Wood and others, 2008).

The phased restoration of deltaic wetlands surrounding the mouth of the Williamson River was a significant development. The alterations of the shoreline associated with this restoration were completed in 2009, but maturation of vegetation is expected to continue for many years (Elsroad and others, 2011), and soil accretion in the wetlands can be expected to occur on the time scale of decades (Graham and others, 2005). The newly flooded wetlands increased nutrient and DOC fluxes to the water column in the months after inundation (Wong and others, 2011) as was expected based on preliminary laboratory experiments with wetland soils (Aldous and others, 2005; 2007).

Over time, however, these lands have adjusted and will continue to adjust on time scales that are solute specific. Nitrate and dissolved organic carbon (DOC) fluxes to the water column dissipated over 3 years, whereas orthophosphate, ammonia, iron, and manganese fluxes continue to be significant relative to riverine sources (Kuwabara and others, 2012b). Flux of orthophosphate and ammonia is declining (Wong and Hendrixson, 2011), but over a longer time scale than nitrate and DOC. The long-term role of the deltaic wetlands in processing water from the Williamson River is not certain (over the long term the wetland may be a sink for phosphorus [Graham and others, 2005]), but it is clear that these wetlands create spatial heterogeneity of water and sediment quality within the present-day shoreline.

Because of the additional research and data collection since the establishment of the Upper Klamath Lake TMDL and the reliance of the Klamath River TMDL on results from the Upper Klamath Lake TMDL, many agencies that have a role in the regulation and management of Upper Klamath Lake have agreed that it is appropriate to review the status and technical basis of the model that informed establishment of the Upper Klamath Lake TMDL. As a Designated Management Agency for the TMDL process, the Bureau of Reclamation, the cooperator on this study, wants to determine whether the tools used to build the TMDL are consistent with the most up-to-date scientific information and understanding of the major hydrological and biogeochemical processes that occur in the lake. Further, periodic review of new scientific information related to a TMDL is an explicit part of Oregon Department of Environmental Quality's adaptive management approach (Oregon Department of Environmental Quality, 2002).

This review begins with a description of the most current information about phosphorus fractions in the bottom sediments of the lake, followed by a summary of the possible mechanisms of internal loading and how those relate specifically to Upper Klamath Lake. The evaluation of the TMDL model is in two parts: verification and sensitivity analysis. The verification step assures that (1) the equations provided in the documentation are error-free and consistent with basic physical, chemical, and biological principles such as mass balance and descriptions of algal growth, (2) the solution technique can be understood and is numerically sound, (3) the spreadsheet is consistent with the documentation supplied by the developers and does not contain coding errors, and (4) the calibration described in the documentation can be duplicated and the same calibration parameters obtained independently.

We determined the sensitivity of the calibration parameters to the following factors: (1) the mathematical forms of the terms that limit algal growth based on the availability of light and phosphorus, (2) the assumption that chlorophyll $a$ achieves equilibrium with ambient light and nutrients during the time step, (3) the assumed mechanism for recycling phosphorus from the sediments to the water column, and (4) the estimated size of the initial sediment reservoir. The first two factors were determined from an exami- 
nation of the model code during the initial verification step of the review, the third was based on a recognition that recent work has identified several other mechanisms that are likely to be at least as important as the single, $\mathrm{pH}$-dependent mechanism that was incorporated into the model, and the fourth was the result of recognizing that calculations based on new sediment cores produced an estimate of the phosphorus content in the sediments that differed substantially from the value used when the TMDL was developed. Finally, the report ends with an assessment of where the TMDL model is weakest and suggestions for improvements.

\section{Purpose and Scope}

This report presents the results of a technical review of the existing Upper Klamath Lake TMDL mass-balance model, including an assessment of the technical competency of the model and an evaluation of model assumptions in light of information from studies that have been done since it was implemented.

The review had the following objectives:

1. Check the model code for consistency with the model documentation, and identify, implement, and test any easily made improvements to the model code.

2. Revisit the calibration process and determine whether and to what extent calibration parameters would change with implementation of improvements identified in the first objective or when reasonable and easily implemented changes were made in other process-based model assumptions.

3. Quantify the performance of the model through a validation process and determine the extent to which the performance of the model changed with the changes in calibration parameters that were determined in meeting the second objective.

4. Evaluate the sensitivity of long-term model simulations to changes made in the process of meeting objectives 1 and 2 to assess the con- sistency of the model results that informed the establishment of the Upper Klamath Lake and Klamath River TMDLs.

5. Suggest improvements or enhancements of model algorithms based on updated data and published research.

\section{Phosphorus in Upper Klamath Lake Bottom Sediments}

\section{Phosphorus Content in Sediment Samples Col- lected Between 1969 and 2006}

Simon and Ingle (2011) collected 26 sediment cores in October 2006 throughout the main body of Upper Klamath Lake, inside of the shoreline as it existed prior to restoration of the Williamson River Delta, for the purpose of quantifying the amount of phosphorus $(\mathrm{P})$ stored in the components of the bottom sediments (fig. 1). The cores were sampled at 1-cm intervals to a depth of $5 \mathrm{~cm}$, and at $5-\mathrm{cm}$ intervals between depths of 5 and $30 \mathrm{~cm}$. Samples were analyzed for total concentration of phosphorus, iron ( $\mathrm{Fe}$ ), titanium (Ti), aluminum (Al), and calcium ( $\mathrm{Ca}$ ) using sample digestion with nitric and hydrofluoric acids. Total concentrations of carbon (C) and nitrogen $(\mathrm{N})$ were determined using flash oxidation of each sample followed by separation of the gaseous products using a Carlo Erba EA 1108 Elemental Analyzer (Simon and Ingle, 2011). A sequential extraction was used to quantify (1) the loosely sorbed and interstitial water phosphorus (LP), (2) phosphorus bound to poorly crystalline iron oxides (Fe-P), and (3) phosphorus bound to carbonates and acid-soluble minerals (AP), which also includes phosphorus bound to aluminum hydroxides. The residual fraction of phosphorus (RP), which can include organic phosphorus and refractory phosphorus in minerals, was calculated by subtracting the phosphorus fractions recovered by the sequential extraction from the total $\mathrm{P}$. The methods of collection and analysis, as well as the data, are reported in Simon and Ingle (2011).

Results of averaging mass concentrations at each depth across all cores showed that phospho- 
rus fractions were surface intensified - total phosphorus at $1 \mathrm{~cm}$ depth was about 1.7 times the value at $30 \mathrm{~cm}$ depth (fig. 2). The most surfaceintensified fraction was the Fe-P fraction, which had a surface concentration about 3.4 times the value at $30 \mathrm{~cm}$, and the least surface-intensified fraction was the AP fraction, which had a concentration about 1.1 times greater at $1 \mathrm{~cm}$ than at 30 $\mathrm{cm}$. Compared to a core collected in 1998 (Eilers and others, 2004), the average total phosphorus concentration of the 26 cores collected in 2006 was lower (maximum and minimum concentration over $30 \mathrm{~cm}$ depth was 0.5 and $0.3 \mathrm{mg} / \mathrm{g} \mathrm{DW}$, respectively, for the 2006 cores [fig. 2], and maximum and minimum concentration over $30 \mathrm{~cm}$ depth was 1.2 and $0.7 \mathrm{mg} / \mathrm{g} \mathrm{DW}$, respectively, for the 1998 core (Eilers and others, 2004, fig. 4), but the enrichment between the surface and $30 \mathrm{~cm}$ depth is about the same. The 2006 core collected closest to the site of the 1998 core (fig. 1) ranged in concentration from $0.45 \mathrm{mg} / \mathrm{g}$ DW at $0.5 \mathrm{~cm}$ to $0.2 \mathrm{mg} / \mathrm{g}$ DW at $30 \mathrm{~cm}$. The difference in absolute concentrations attributable to the different methods used (microwave digestion in both cases, with $\mathrm{HNO}_{3}+\mathrm{HF}$ for the 2006 cores and $\mathrm{HNO}_{3}+\mathrm{HF}+\mathrm{HCl}+\mathrm{H}_{3} \mathrm{BO}_{3}$ for the 1998 core) is minor.

Eilers and others (2004) noted that the surface intensification of titanium and aluminum (40 percent for titanium and more than 200 percent for aluminum compared to the concentrations in the deepest part of the core) in the 1998 core indicated increased erosional inputs to Upper Klamath Lake in the 20th century. The 26 cores collected in 2006 show similar surface intensification (fig. 3). Tephra and charcoal increases in the upper layers of an additional sediment core collected in 1996 also indicated increased erosional inputs to the lake due to river channelization and other wetland and watershed disturbances over the past 100 years (Bradbury and others, 2004). Eilers and others (2004) also noted a decrease in the ratio of nitrogen to phosphorus (N:P) in the upper $18 \mathrm{~cm}$ of sediment, which they interpreted as likely due to an increase in phosphorus loading relative to nitrogen loading in the 20th century, although increased nitrogen loss processes over the same period also could have been partly responsible. The average of the 26 cores collected in 2006 shows a similar decrease in the N:P ratio from 26.1 at $30 \mathrm{~cm}$ to 14.3 near the surface. Broadly speaking, therefore, the results of Simon and Ingle (2011) are consistent with the recent paleolimnological evidence presented by Eilers and others (2004).

To investigate the possibility of a long-term trend in the sediment phosphorus content, we compared results from the 2006 cores to those from two previous studies. The first of these studies analyzed grab samples collected from three sites over 16 months during 1969-70 (Wildung and Schmidt, 1973; Wildung and others, 1977). For each of the sites, the concentration (averaged over the top $10 \mathrm{~cm}$ ) in cores collected nearby in 2006 was less than the minimum concentration in the 12-13 samples collected in $1969-70$ by as much as $0.13 \mathrm{mg} / \mathrm{g} \mathrm{DW}$ at the southern end of the lake (Pelican Marina) and as little as $0.02 \mathrm{mg} / \mathrm{g}$ DW at Howard Bay (table 1). The overall variability, however, at each site where samples were collected in 1969-70 was large in comparison: $0.27 \mathrm{mg} / \mathrm{g}$ DW at Pelican Marina and $0.66 \mathrm{mg} / \mathrm{g}$ DW at Howard Bay (table 1). The total inorganic phosphorus concentration in the cores collected in 2006 was equal to the minimum total inorganic phosphorus concentration in nearby samples collected from Howard Bay in 1969-70 and was less than the minimum total inorganic phosphorus concentration in samples collected from the other two sites by as much as $0.1 \mathrm{mg} / \mathrm{g} \mathrm{DW}$ at the third site, Buck Island (table 1). Thus, the concentrations measured in 2006 were lower than those measured 36 years earlier at nearby sites, and at two of three sites most of the difference between the two studies was in the residual (total phosphorus minus sum of extracted inorganic phosphorus) fraction. 

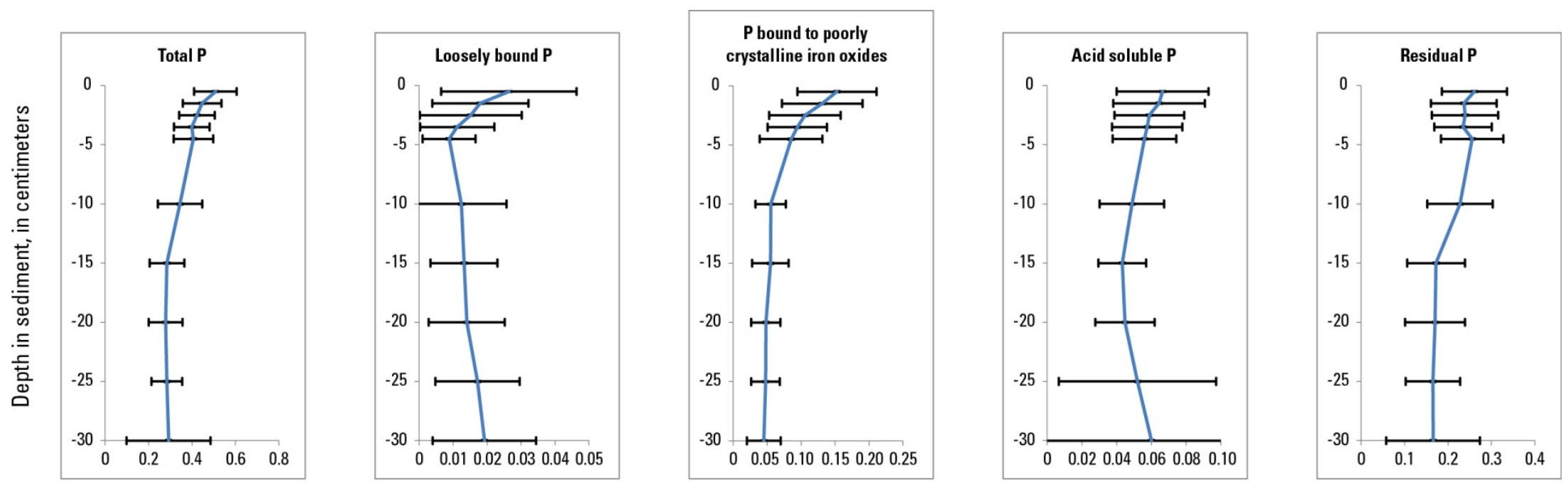

Concentration, in milligrams per gram dry weight

Figure 2. Graphs showing average concentration of phosphorus fractions as a function of depth in sediment from 26 cores collected from Upper Klamath Lake, Oregon, 2006.
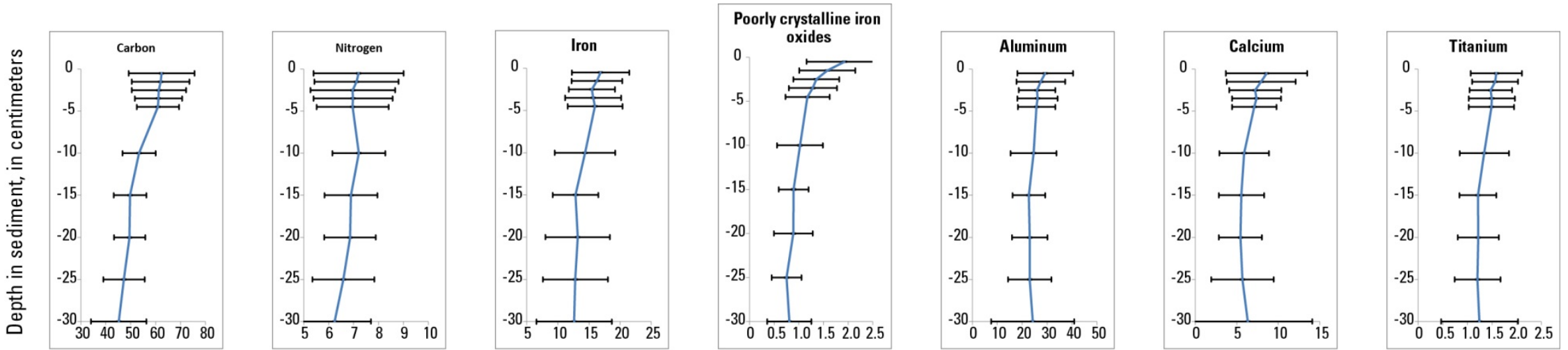

Concentration, in milligrams per gram dry weight

Figure 3. Graphs showing average concentration of carbon, nitrogen, and trace elements as a function of depth in sediment from 26 cores collected from Upper Klamath Lake, Oregon, 2006. 
Table 1. Comparison of concentrations of total and inorganic phosphorus in sediment cores collected October 2006 from Upper Klamath Lake, Oregon, to reported concentrations prior to 2006.

[Data from 2005 and 2006 were averaged over the top 10 centimeters of sediment; samples were collected in 1969-70 with an Ekman dredge to an approximate depth of $10 \mathrm{~cm}$ and homogenized. This table is modified from table 1 in Simon and Ingle (2011). $\mathrm{mg} / \mathrm{g}$ DW, milligrams per gram of dry weight;

Reference 1, Wildung and Schmidt, 1973, 13-15 samples collected over 24 months at each site; analysis method for total phosphorus: high temperature ignition, extraction method for inorganic phosphorus: $\mathrm{H}_{2} \mathrm{SO}_{4}$; Reference 2, Simon and others (2009), samples collected twice at each site, in April and July; analysis method for total phosphorus: microwave digestion, $\mathrm{HNO}_{3}$ and $\mathrm{HF}$, extraction method for inorganic phosphorus: sum of $\mathrm{MgCl}_{2}(1.0 \mathrm{M})$, bicarbonatecitrate plus dithionite, and $\mathrm{HCl}(1.0 \mathrm{M})$; analysis and extraction methods of Simon and Ingle (2011) same as Kuwabara and others (2007). Italicized values were read from a graph and are approximate.]

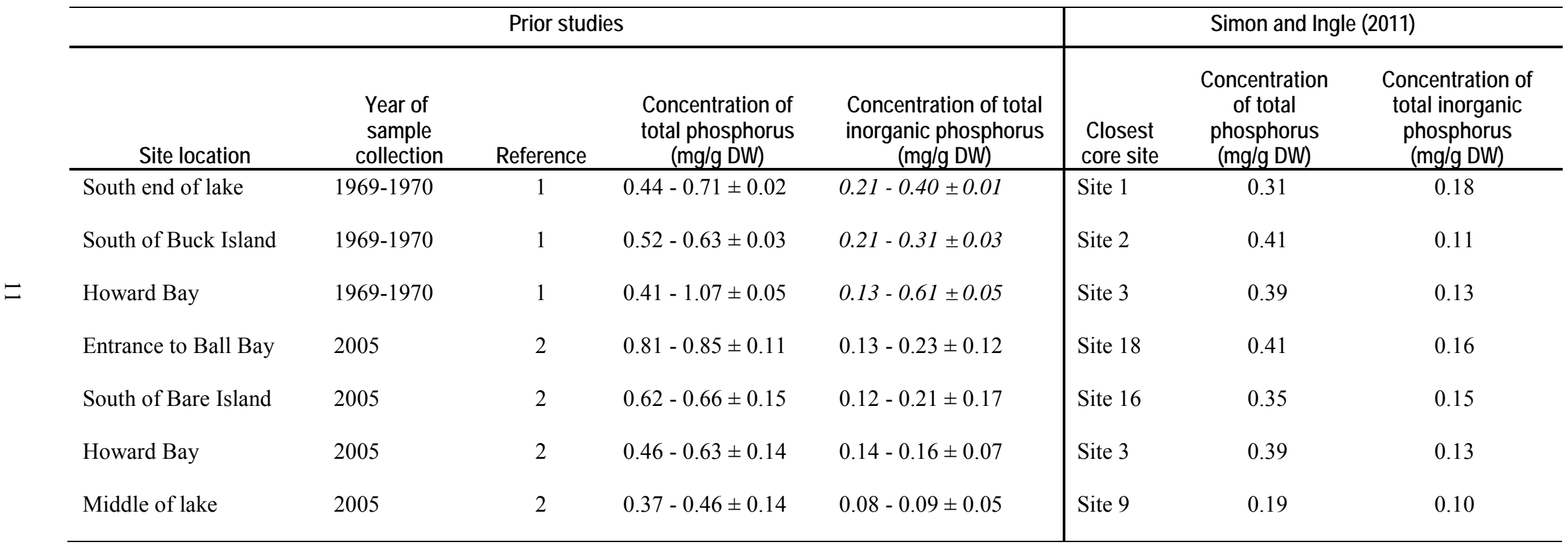


To investigate further whether the difference between the two studies represents a true longterm trend, we compared the concentration in cores collected in 2006 to concentrations in cores collected from four nearby sites in April and July 2005 (Simon and others, 2009). The total phosphorus concentration in cores from those sites was lower in 2006 than in April or July 2005 by as much as $0.4 \mathrm{mg} / \mathrm{g} \mathrm{DW}$ at the entrance to Ball Bay, or as little as $0.07 \mathrm{mg} / \mathrm{g}$ DW at Howard Bay. The total inorganic phosphorus concentration was comparable between the 2 years (slightly higher in 2006 than in 2005 at three of the four sites, slightly lower at the fourth site [table 1]). Thus, the concentrations measured in April and June 2005 were higher than concentrations measured in October 2006 at nearby sites by an amount comparable to or greater than the difference between the concentrations measured in 1969-70 and 2006, and, again, most of the difference was in the residual fraction.

The 2005 cores were collected carefully by divers to prevent loss of sediment at the sediment-water interface, whereas the 2006 cores were collected with a gravity corer; therefore, the collection method could account for part of the higher total phosphorus concentration in 2005 compared to 2006. Samples were collected with an Ekman dredge in 1969-70, which likely did not preserve the integrity of the sediment/water interface as much as diver-collected cores; it is also unclear how the depth sampled by the Ekman dredge compares to the top $10-\mathrm{cm}$ of a core. Therefore, although the comparison of samples collected 36 years apart and others collected 1 year apart did not provide evidence of a longterm trend in sediment concentration that exceeds seasonal and interannual variability, differences in sampling methods make quantitative comparisons between these studies tentative.

\section{Spatial Variability}

A limitation in using a CSTR model to simulate a large shallow lake is that all lake quantities are averaged, and appropriate averaging requires detailed information regarding the spatial variability in those quantities. The whole-lake averaged concentrations that provide the calibration and validation data for the CSTR model were from samples collected at 11 sites around the lake (Kann and Walker, 2001). Little information is available, however, on the spatial variability of processes that affect the mass balance, like cyanobacterial growth and mortality, and phosphorus sedimentation to and recycling from the sediments.

One factor determining the magnitude of phosphorus recycling from the sediments is the sediment phosphorus concentration. The 26 cores analyzed by Simon and Ingle (2011) provided previously unavailable information about the spatial variability of the various phosphorus fractions in the lake sediment. The data in each core were numerically integrated over $10 \mathrm{~cm}$, the assumed depth of the active sediment layer in the TMDL model. The study used Principal Components Analysis (PCA, Haykin, 1999) with varimax rotation (Kaiser, 1958) to reduce the dimensionality of the dataset and aid in interpretation. With varimax rotation, the principal component axes are rotated to maximize loading of a single component onto each variable and minimize loading of other components onto this variable, making it easy to associate each variable with a single component on which it has a high loading. The final set of principal components was selected on the basis of the Kaiser criterion, which retains components corresponding to eigenvalues greater than one (Kaiser, 1960). Principal component analyses were accomplished with the psych package of subroutines ("principal" function) from the R software (R Core Team, 2012). The PCA reduced the original 12 sediment constituents to 3 principal components that explained 82.4 percent of the variance in the $10-\mathrm{cm}$ integrated data (fig. 4 , table 2). 


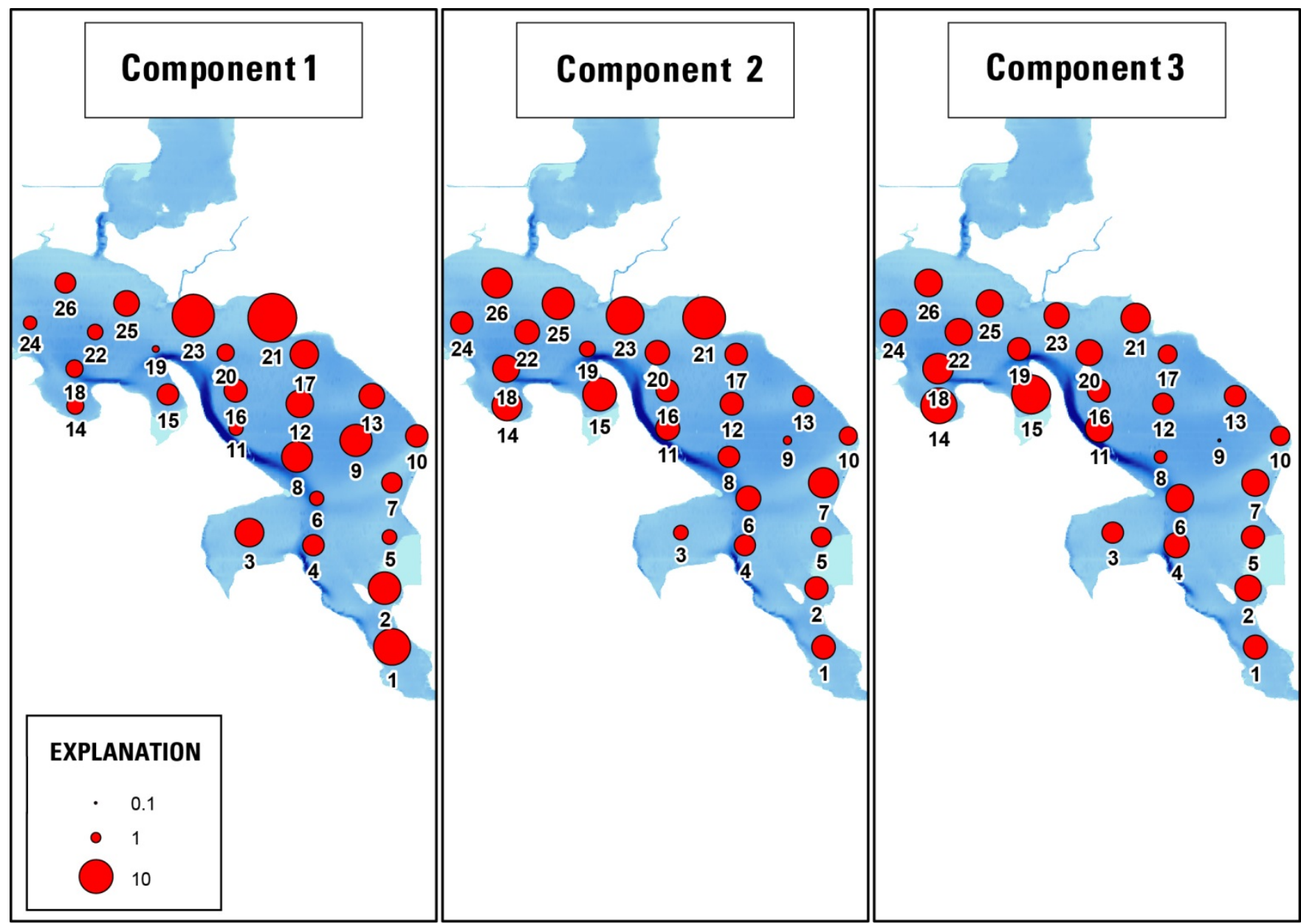

Figure 4. Diagrams showing varimax rotated principal component scores for all constituents in cores collected from Upper Klamath Lake, Oregon, integrated to 10 centimeter depth.

Table 2. Loadings of sediment variables onto varimax rotated principal components for all constituents in cores collected from Upper Klamath Lake, Oregon, integrated to 10 centimeter depth.

[TP, total phosphorus; RP, residual phosphorus; LP, loosely bound phosphorus; AP, phosphorus bound to acid-soluble minerals; Fe-P, phosphorus bound to poorly crystalline iron oxides; Fe-cryst, poorly crystalline iron oxides]

\begin{tabular}{|c|c|l|}
\hline $\begin{array}{c}\text { Component } \\
\text { number }\end{array}$ & $\begin{array}{c}\text { Variance } \\
\text { Explained } \\
\text { (percent) }\end{array}$ & \multicolumn{1}{|c|}{$\begin{array}{c}\text { Variables with } \\
\text { loading }>\mathbf{0 . 5}\end{array}$} \\
\hline $\mathrm{VC} 1$ & 37.8 & $\mathrm{AP}, \mathrm{Fe}, \mathrm{Al}, \mathrm{Ca}, \mathrm{Ti}$ \\
\hline $\mathrm{VC} 2$ & 20.2 & $\mathrm{C}, \mathrm{N}, \mathrm{LP}$ \\
\hline $\mathrm{VC} 3$ & 24.4 & $\mathrm{TP}, \mathrm{RP}, \mathrm{Fe}-\mathrm{P}, \mathrm{Fe}$-cryst \\
\hline
\end{tabular}

Iron, titanium, calcium, and aluminum are indicators of erosional inputs from the basin; these metals have similar variability in the bottom sediments. This variability is captured by the first principal component (VC1), which largely represents the spatial variability in the deposition of erosional material. Sites 21 and 23 east of the pre-restoration mouth of the Williamson River have high scores on this component, reflecting erosional inputs from the Williamson River. Under prevailing northwesterly winds, currents flow southeastward along the eastern shoreline and traverse the lake from east to west between Modoc Rim and Buck Island (Wood and others, 2008). High scores at sites $17,12,8$, and 9 indi- 
cate deposition of erosional inputs along this pathway. High scores in Howard Bay and at thesouthern end of the lake (sites 1, 2, and 3; fig. 4) indicate inorganic sediment inputs to these areas from runoff or anthropogenic loadings. Phosphorus associated with carbonates and aluminum hydroxides (AP), also has high loading on $\mathrm{VC} 1$.

Carbon and nitrogen have similar variability that is captured by component 2 (VC2), which, therefore, largely represents the spatial variability in the organic fraction of the sediments. LP also is associated with VC2, perhaps because mineralization of organic material results in high dissolved phosphorus concentrations in pore water and high concentrations of loosely sorbed phosphorus in the sediment matrix. The sites that scored highest on this component were along the northern shoreline of the lake and in the northern bays (fig. 4), indicating that these are areas characterized by high deposition of organic matter. Site 7 near Rattlesnake Point also has a notably high score on VC2. VC2 was roughly inverse to $\mathrm{VC} 1$, in that sites in the central part of the lake had minimum scores on $\mathrm{VC} 2$, but maximum scores on $\mathrm{VCl}$.

The third component, VC3, captures the spatial variability in total phosphorus and its largest fractions, Fe-P and RP. The spatial pattern of $\mathrm{VC} 3$ site scores is more similar to that of $\mathrm{VC} 2$ site scores than to that of VC1 site scores (fig. 4), which is largely because the RP fraction, which contains organic phosphorus, is the largest fraction of the total phosphorus. The site scores for VC3 are highest in the northern and southern parts of Upper Klamath Lake and lowest in the central part; the highest scores of all are in the northern bays. The score in Howard Bay, which had a low VC2 score, is notably low in comparison.

\section{Internal Loading of Phosphorus in Upper Klamath Lake}

\section{Mechanisms}

Internal loading of phosphorus (loading directly from bottom sediment to the water column) is an important component of phosphorus cycling and a primary driver of massive cyanobacterial blooms in Upper Klamath Lake (Barbiero and Kann, 1994; Kann, 1998). An understanding of phosphorus cycling in the lake requires a good estimate of the magnitude of the internal loading and its temporal and spatial variability. The model estimated whole-lake internal loading from the residual of the phosphorus mass balance of the lake on a 2-week time step for the calibration period of April 1991-September 1998 (Kann and Walker, 2001). Internal loading (recycling) was estimated to be, on average, 60 percent of the total loading to the lake (Kann and Walker, 2001). The time series of the whole-lake internal load over 14 days from the original dataset was converted to an areal flux (fig. 5). In each of the eight growing seasons, the lake-average internal load exceeded 10 milligrams per square meter per day $\left[\left(\mathrm{mg} / \mathrm{m}^{2}\right) / \mathrm{d}\right]$ and in some years exceeded 20 $\left(\mathrm{mg} / \mathrm{m}^{2}\right) / \mathrm{d}$. Because internal loading varies spatially (fig. 4), localized values of internal loading could be many times greater than indicated by the whole-lake average.

Several mechanisms contribute to nutrient fluxes from the sediments to the water column. Resuspension of the sediments can contribute to internal loading in shallow lakes (Sondergaard and others, 1992; Koski-Vahala and Hartikainen, 2001; Niemisto and others, 2011). No direct connection between episodes of resuspension and internal loading for Upper Klamath Lake has been established, although resuspension can result when wind speed exceeds $4.5 \mathrm{~m} / \mathrm{s}$, a relatively common occurrence (Laenen and LeTourneau, 1996). Further, resuspended sediments from Upper Klamath Lake did not release more phosphorus in the long-term than sediments at a stable interface in laboratory experiments, 


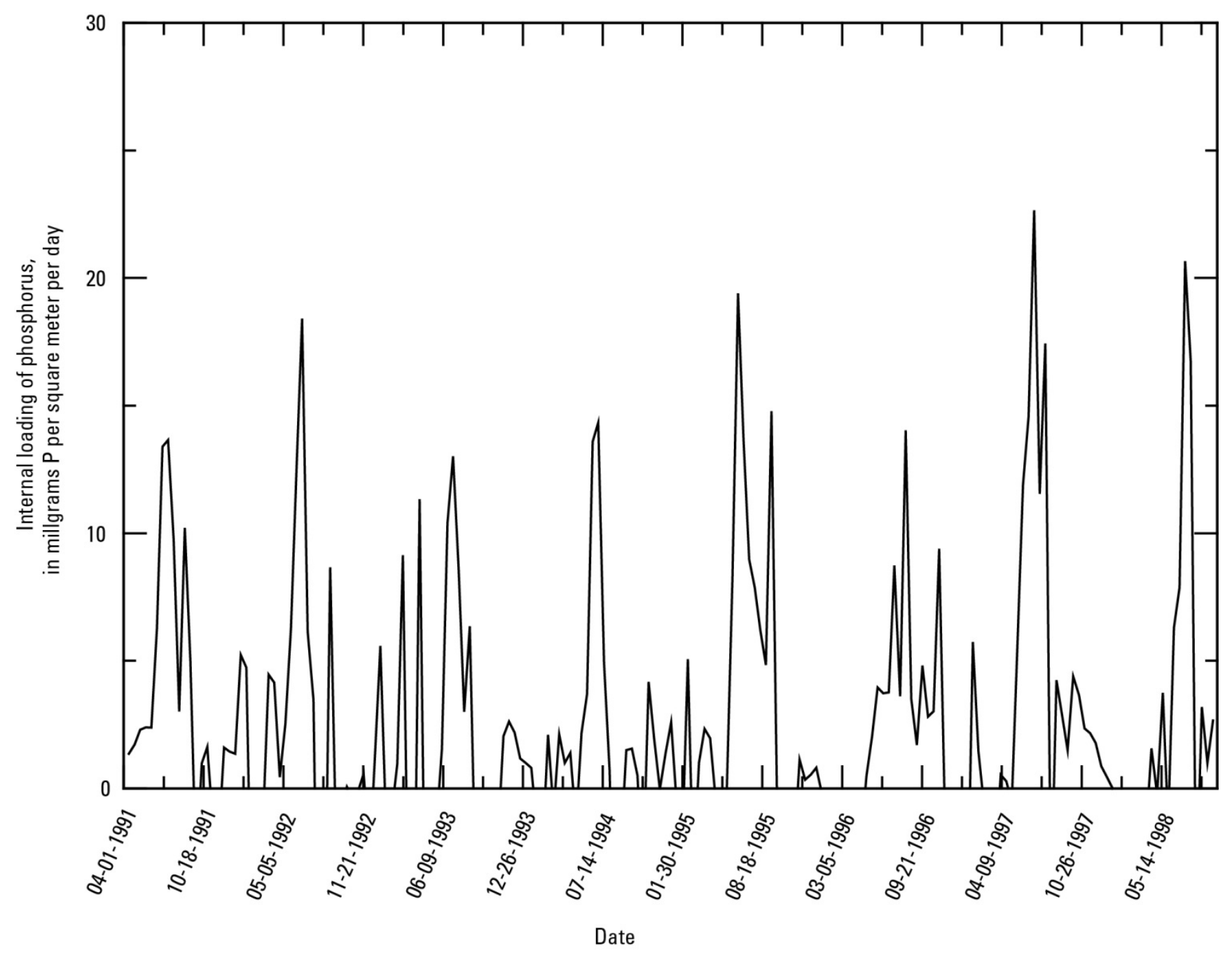

Figure 5. Graph showing calculated whole-lake average of internal loading to Upper Klamath Lake, Oregon, April 1991-September 1998. Only positive values, representing a flux of phosphorus from the sediments to the water column, are shown. Calculation of the average flux is based on data from Kann and Walker (2001).

and in the short-term had the capacity to sorb phosphorus (Fisher and Wood, 2004). Likely, resuspension in Upper Klamath Lake adds primarily sorbed (not bioavailable) phosphorus to the water column that does not directly promote the growth of cyanobacterial blooms or chlorophyll $a$ production. Therefore, fluxes of dissolved phosphorus from the bottom of Upper Klamath Lake also must occur through pore water pathways by means of physical transport, either by molecular diffusion or advection (by groundwater from below or by surface water flowing horizontally and entering interstitial spaces).
Phosphorus in the solid phase, measurements of which were described by Simon and Ingle (2011), can be made available for transport in the aqueous phase through various means, and the phosphorus fraction that is the primary source of dissolved phosphorus varies accordingly. The origin of pore water phosphorus can be chemical desorption (primarily from the LP fraction) or, in deeper, reducing sediments, dissolution of iron oxides (source is Fe-P fraction). Desorption can also occur from iron oxides in oxic conditions when $\mathrm{pH}$ exceeds 9 and hydroxide ions begin to displace phosphate ions from sorption sites (source is Fe-P fraction; Jacoby and others, 1982; 
Sondergaard, 1988). In the process of mineralization, bacteria convert organic sediment phosphorus to biologically available dissolved inorganic phosphorus (source is RP fraction).

Benthic macroinvertebrates can contribute to benthic fluxes by enhancing diffusion through bioturbation, which increases the surface area in contact with pore water and creates macro-scale pathways for pore water transport (primary source is the LP fraction), and by excretion (primary source is the RP fraction), either to pore water or directly to the overlying water column. Fluxes of solid phase phosphorus can occur through biotranslocation of akinetes (dormant cyanobacteria cells) or invertebrates that undergo episodic recruitment (source is the RP fraction). Many or all of these processes may overlap in time and space in shallow lakes like Upper Klamath Lake; the key to constructing a successful model is to have a good quantitative understanding of the most important processes.

Direct measurements, or estimates by other means, of some of these processes have been made in Upper Klamath Lake:

- Kuwabara and others $(2007 ; 2009)$ measured diffusive fluxes across the sediment-water interface before, during, and after the rapid expansion of the cyanobacterial bloom in 2006, using a pore water profiler that obtained pore water concentration profiles at the centimeter scale. Benthic fluxes of phosphorus measured in this way were consistently positive (from the sediments to the overlying water column) and ranged from 0.4 to 6.1 $\left(\mathrm{mg} / \mathrm{m}^{2}\right) / \mathrm{d}$.

- Kuwabara and others (2009) also used heatflux modeling to estimate fluxes due to groundwater advection of $1.1\left(\mathrm{mg} / \mathrm{m}^{2}\right) / \mathrm{d}$.

- Fisher and Wood (2004) mimicked the process of desorption from iron oxides at high $\mathrm{pH}$ in a laboratory using sediment from Upper Klamath Lake. In the study of Fisher and Wood (2004), the estimated flux was 1.9 $\left(\mathrm{mg} / \mathrm{m}^{2}\right) / \mathrm{d}$ at $\mathrm{pH} 9.2$ and $1.3\left(\mathrm{mg} / \mathrm{m}^{2}\right) / \mathrm{d}$ at $\mathrm{pH}$ 10.3 .
- Additional estimated fluxes of Fe-P can be inferred from core studies. Using data from cores collected by Wildung and Schmidt (1973) to calculate the loss of phosphorus from the Fe-P fraction as an areal flux during 27 days between May 7 and June 3, 1969, gives an estimate of $1.8-2.5\left(\mathrm{mg} / \mathrm{m}^{2}\right) / \mathrm{d}$ (using sediment bulk densities at nearby sites from Simon and Ingle, 2011).

- Simon and others (2009) found a significant decrease in total phosphorus at one of their core sites during April-July 2005 that was associated primarily with iron oxyhydroxides. Averaging Fe-P over the top $10 \mathrm{~cm}$ of sediment and duplicate cores at that site (data provided in Kuwabara and others, 2007) gives an estimate of $0.73\left(\mathrm{mg} / \mathrm{m}^{2}\right) / \mathrm{d}$ for the loss of Fe-P during the 69 days between core collections.

- Assuming that the acid-soluble phosphorus fraction is composed primarily of phosphorus bound to aluminum hydroxides (Simon and Ingle, 2011), which is also subject to potential desorption at high $\mathrm{pH}$, then using data from the same site gives an estimate of the loss of Al-P of $0.45\left(\mathrm{mg} / \mathrm{m}^{2}\right) / \mathrm{d}$ during the 69 days between core collections.

- Barbiero and Kann (1994) measured the flux of phosphorus to the water column during cyanobacterial (A. flos aquae) recruitment at $3.56\left(\mathrm{mg} / \mathrm{m}^{2}\right) / \mathrm{d}$, which they concluded was about 27 percent of the concurrent increase in total water column phosphorus.

Each of these estimates indicates that the process involved could be episodically significant, but not likely to be the dominant process of internal loading, particularly during rapid, early spring $A$. flos-aquae growth, when calculations of internal loading can be between 10 and 20 $\left(\mathrm{mg} / \mathrm{m}^{2}\right) / \mathrm{d}$ on a whole-lake basis (fig. 5).

At the time of the development of the Upper Klamath Lake TMDL, the best available description of the composition of the phosphorus in the bottom sediments was by Wildung and Schmidt (1973) and Wildung and others (1977). Sediment 
samples used in these studies were collected approximately monthly between May 1969 and April 1970 from three sites at the southern end of Upper Klamath Lake - one near the outlet, one on the south side of Buck Island, and one in the southwest corner of Howard Bay. Wildung and Schmidt (1973) found that changes in total sediment phosphorus correlated with changes in total inorganic P. A subsequent serial extraction of various phosphorus fractions in a subset of the samples showed a decrease in phosphorus associated with hydrated iron oxides that coincided with a period of rapid growth of phytoplankton in spring 1969 at all three sites. Wildung and Schmidt (1973) concluded that it was primarily this fraction that provided bioavailable phosphorus to the water column. This conclusion was consistent with an identified mechanism for internal loading - desorption of Fe-bound phosphorus under oxic conditions at high $\mathrm{pH}$ (Jacoby and others, 1982) - and with observations that the recycling of phosphorus to the water column increased with pH (Kann, 1998), and this conclusion ultimately informed the way that internal loading was conceptualized and incorporated into the TMDL model.

The conclusion, however, was largely based on data from one site - the Howard Bay sitewhere sediment phosphorus concentrations were highest and most variable. For example, in sediment samples collected in April 1970, total phosphorus concentrations in Howard Bay, south of Buck Island, and near the lake outlet were $1.03 \pm 0.05,0.63 \pm 0.03$, and $0.66 \pm 0.02 \mathrm{mg} / \mathrm{g} \mathrm{DW}$, respectively, and total inorganic phosphorus concentrations at the same three locations were $0.57 \pm 0.05,0.30 \pm 0.03$, and $0.35 \pm 0.01 \mathrm{mg} / \mathrm{g}$ DW, respectively (table 3 in Wildung and Schmidt, 1973). The range in concentration during the 16 months of sample collection was $0.41-1.07 \mathrm{mg} / \mathrm{g}$ DW at Howard Bay, $0.52-0.63 \mathrm{mg} / \mathrm{g}$ DW near Buck Island, and $0.44-0.71 \mathrm{mg} / \mathrm{g}$ DW at the south end of the lake (table 1). The decrease between the two sample dates was greatest at the Howard Bay site, and inorganic phosphorus (as determined by $\mathrm{H}_{2} \mathrm{SO}_{4}$ extraction) accounted for
80 percent of the reduction in total phosphorus (determined by high temperature ignition).

The serial extractions that followed to distinguish which fraction of sediment phosphorus accounted for the loss of sediment phosphorus were incomplete, based on a comparison between the sum of the extracted fractions and the totals, as determined by high temperature ignition (used to determine total $\mathrm{P}$ ) and $\mathrm{H}_{2} \mathrm{SO}_{4}$ extraction (used to determine total inorganic $\mathrm{P}$ ). The residual organic fraction at the end of the serial extraction procedure ranged between 0.7 and 29 percent of the sum of the inorganic fractions. When the organic fraction was instead determined by difference between total phosphorus and total inorganic phosphorus, it was generally comparable to and often greater than the total inorganic phosphorus (Wildung and Schmidt, 1973). During most of the 16-month sampling period, and considering all three sites where samples were collected, changes in the total sediment phosphorus were correlated with changes in the both organic and inorganic fractions (based on visual inspection of figure 3 in Wildung and Schmidt, 1973). Therefore, it is consistent with these early studies to conclude that fractions other than ironbound phosphorus contributed substantially to changes in sediment $\mathrm{P}$, and that mechanisms of internal loading that utilize other phosphorus fractions as a source are as important as the single mechanism (desorption of iron-bound phosphorus under oxic conditions at high $\mathrm{pH}$ ) that was incorporated into the TMDL model. The importance of the organic phosphorus fraction, in particular, as a source for internal loading might have been underestimated.

\section{Possible Role of Benthic Invertebrates in Internal Loading in Upper Klamath Lake}

Benthic invertebrates in the bottom sediments of Upper Klamath Lake occur at densities that could influence diffusive fluxes through bioturbation and metabolism, both of which have the potential to be equally as important as the other physical and chemical processes discussed in the previous section (Andersson and others, 1988). 
During 2009 and 2010, we conducted a quantitative study of the distribution of benthic invertebrates in the northern part of the lake. Five samples were collected at five randomly selected sites on three dates (early June, mid-July, and early September) using a $0.023 \mathrm{~m}^{2}$ Ekman dredge. Samples were sieved using a $500 \mu \mathrm{m}$ mesh and sorted at 10X magnification. Mean density of all invertebrates sorted was 20,625 individuals $/ \mathrm{m}^{2} \pm 11,671$ ( \pm standard deviation, $\mathrm{N}=150$ ). The number of individuals per sample ranged from 1,822 to 62,178 individuals $/ \mathrm{m}^{2}$. Ninety-four (94) percent of all organisms comprised Oligochaeta (worms, 65 percent), Hirudinea (leeches, 17 percent), and Chironomidae (midges, 12 percent).

Benthic invertebrates can be sorted into functional groups based on a mechanistic assessment of their sediment mixing modes (Michaud and others, 2006). Differences in these modes likely influence the sediment chemistry and the solute distribution. For example, "upward conveyers" orient vertically with their heads down, and in the process of feeding remove sediment at depth and expel excrement at the sediment-water interface. "Gallery diffusers" dig extensive burrow systems and transport materials through the burrows by body movement. The bioturbation effects of the two groups are quite different. Gallery diffusers are effective at oxygenating the sediment to the maximum depth of their burrows, stimulating microbial processes. Michaud and others (2005) found that gallery diffusers increased oxygen uptake by a factor of two over uninhabited controls, and Michaud and others (2006) found that gallery diffusers were more effective at enhancing nutrient fluxes than another functional group"biodiffusers," which move particles randomly over short distances, thus enhancing sediment diffusion (bivalves belong to this group, but are rare in the open waters of Upper Klamath Lake). When a gallery diffuser and an upward conveyer were compared directly, the gallery diffuser was more effective than the upward conveyer in increasing the depth of oxygen penetration into the sediment (Zhang and others, 2010), but when an upward conveyer and a "downward conveyer" (surface feeder) were compared directly, the upward conveyer more effectively enhanced solute fluxes (Quintana and others, 2007).

Thus, the mode of feeding and sediment mixing must be considered on a taxon-specific basis to accurately assess the effect of each taxon on nutrient fluxes. For example, there are several species of tubificid worms (Oligochaeta) in Upper Klamath Lake, some of which create extensive galleries and move up and down through them, making them functionally gallery diffusers, whereas others simply feed head down without creating extensive galleries, making them functionally upward conveyers. The largest midge in Upper Klamath Lake, Chironomus plumosus, creates U-shaped tubes through which it brings water from the sediment surface at one end and expels it at the other end (functionally a mix of a downward conveyer and a gallery diffuser). At least one relatively common midge is predacious and moves about the sediment-water interface, acting functionally like a biodiffuser.

With respect to the flux of phosphorus in particular, the chemical composition of the sediments is also important. In iron-rich sediments, where much of the phosphorus is in the ironbound fraction, the increased oxidation of the sediment to the burrow depth can decrease the flux of phosphorus instead of increasing it by enhancing the precipitation of iron oxyhydroxides to which phosphate is adsorbed or with which phosphate is coprecipitated. Zhang and others (2010) reported that in Lake Taihu, China, both worms and chironomids inhibited phosphorus release from bottom sediments, but the concentration of iron in both sediments $(29.6 \mathrm{mg} / \mathrm{g} \mathrm{DW}$, top $4 \mathrm{~cm}$ ) and in pore water (maximum about 14 $\mathrm{mg} / \mathrm{L}$ ) in Zhang and others (2010) was greater than concentrations measured in Upper Klamath Lake. In contrast, sediment iron concentrations in Upper Klamath Lake were $16.1 \mathrm{mg} / \mathrm{g}$ DW in the top $4 \mathrm{~cm}$, averaged over 26 cores (Simon and Ingle, 2011), and maximum iron pore water concentrations were about $3 \mathrm{mg} / \mathrm{L}$ (Kuwabara and others, 2009). 
The influence of benthic invertebrates on nutrient fluxes also must be assessed in the context of the physical nature of the substrate and the hydrologic context of the environment (MermillodBlondin, 2011). In a comparison of tubificid worms and chironomids, only the worms were effective at reworking fine-grained sediment deposited by stormwater and river channels, and the effectiveness of the tubificids was dependent on high organic content in the sediment (Nogaro and others, 2009). Mermillod-Blondin and Rosenberg (2006) found that bioturbation could strongly affect fluxes at the sediment-water interface in a diffusion-dominated (lentic) system, but had a smaller influence in an advection-dominated (lotic) system. Much of Upper Klamath Lake has fine-grained sediments with moderately high organic content, and diffusion-dominated hydrologic processes; therefore, bioturbation could have the maximum possible effect under these conditions. There are areas of the lake, however, where wind-driven currents can reach tens of centimeters per second, and in those areas the effect of bioturbation on fluxes could be moderated.

The preceding discussion and reported measurements do not distinguish between the physical enhancement effects of bioturbation on diffusion and microbial degradation and the fluxes due to metabolic processing by the macroinvertebrates. Several studies have directly measured the phosphorus excretion of benthic invertebrates (table 3 ). Studies of two numerous benthic invertebrates in Upper Klamath Lakechironomids and tubificids - produced measurements of excretion that varied over a wide range, from 0.07 nanomoles phosphorus per milligram DW per hour (nmol P/mg DW/h) to $3.46 \mathrm{nmol}$ $\mathrm{P} / \mathrm{mg} \mathrm{DW} / \mathrm{h}$. Significant differences among studies in the rate of phosphorus excretion are likely a result of differences in the species (or, more commonly, groups of species within a higher taxon) evaluated, temperature, study location, and methods used for testing and analyses. There was a positive dependence on temperature, but with regard to differences between the two types of invertebrates, the results were equivocal. Gardner and others (1981), Fukuhara and Yasuda (1985) and Fukuhara and Sakamoto (1987) measured higher excretion rates in chironomids, whereas Devine and Vanni (2002) measured higher excretion rates in tubificids.

We measured excretion rates of phosphorus in Upper Klamath Lake resident fauna twice in the midge Chironomus plumosus and once in the tubificid worm Ilyodrilus frantzi. Animals were collected from Upper Klamath Lake on May 28, 2012, and experiments were completed within 2 days of collection using methods similar to Gardner and others (1981). Animals were kept with aeration in native sediment and at ambient lake temperature (approximately $12^{\circ} \mathrm{C}$ ) prior to each experiment. All animals were individually rinsed twice at the beginning of each experiment to remove adhered debris. The first rinse was in filtered lake water and the second was in low phosphorus artificial lake water (ALW). For each midge experiment, 25 fourth instar midges were placed separately in $5 \mathrm{~mL}$ of ALW in a $15 \mathrm{~mL}$ trace-contaminant-clean Teflon test vial and allowed to remain undisturbed at lake ambient temperature for $8 \mathrm{~h}$. In contrast to a single midge, for the tubificid experiment, five organisms were used per test vial because of their much lower mass.

After $8 \mathrm{~h}$, test water was filtered using 0.22 $\mu \mathrm{m}$ polycarbonate membranes and phosphorus was measured using U.S. Environmental Protection Agency (EPA) method 365.2 by batchautomated spectrophotometry (Aquakem ${ }^{\circledR} 250$, Thermo Scientific $\left.{ }^{\mathbb{B}}\right)$. Mean release rates were $0.035 \mu \mathrm{g} \mathrm{P} / \mathrm{midge} / \mathrm{h}( \pm 0.027, \mathrm{~N}=25), 0.030 \mu \mathrm{g}$ $\mathrm{P} /$ midge $/ \mathrm{h}( \pm 0.054, \mathrm{~N}=25)$, and $0.001 \mu \mathrm{g}$ $\mathrm{P} /$ tubificid/h $( \pm 0.0008, \mathrm{~N}=25)$ in the three experiments. Procedural blanks, which included a 1sec dipping of a previously rinsed midge in the blank ALW to account for remaining surface contamination, contained $0.001 \mathrm{mg} \mathrm{P} / \mathrm{L}( \pm 0.0012$, $\mathrm{N}=5$ ), which represented 2.4 percent of the mean phosphorus released $(0.053 \mathrm{mg} \mathrm{P} / \mathrm{L})$ by the $8-\mathrm{h}$ tested midges. Measurements of excretion rates 
Table 3. Comparison of mass-specific excretion of phosphorus by benthic invertebrates from Upper Klamath Lake, Oregon.

[nmole/mg DW/h = nanomole per milligram dry weight per hour, '-' = no data]

\begin{tabular}{|c|c|c|c|c|c|}
\hline \multirow[b]{2}{*}{ Taxon } & \multicolumn{5}{|c|}{ Mass-specific excretion rate } \\
\hline & $\begin{array}{c}\text { Temperature } \\
\left({ }^{\circ} \mathrm{C}\right)\end{array}$ & $\begin{array}{c}\text { Incubation } \\
\text { time } \\
\text { (hours) }\end{array}$ & $\begin{array}{c}\text { Nitrogen } \\
\text { (nmole/mg } \\
\text { DW/h) }\end{array}$ & $\begin{array}{c}\text { Phosphorus } \\
\text { (nmole/mg } \\
\text { DW/h) }\end{array}$ & Source \\
\hline $\begin{array}{l}\text { Chironomidae (Chironomus cf } \\
\text { plumosus) }\end{array}$ & 12 & 8 & - & 0.24 & This study \\
\hline $\begin{array}{l}\text { Chironomidae (Chironomus cf } \\
\text { plumosus) }\end{array}$ & 12 & 8 & - & 0.21 & This study \\
\hline Tubificidae (Ilyodrilus frantzi) & 12 & 8 & - & 0.05 & This study \\
\hline Chironomidae (July experiment) & 5 & 24 & - & 0.57 & Gardner and others (1981) \\
\hline $\begin{array}{l}\text { Chironomidae (September } \\
\text { experiment) }\end{array}$ & 5 & 24 & - & 0.27 & Gardner and others (1981) \\
\hline Tubificidae & 5 & 24 & - & 0.16 & Gardner and others (1981) \\
\hline Chaoborus sp. & 9 & 4 & 4.34 & 0.99 & Devine and Vanni (2002) \\
\hline Chironomidae & 9 & 4 & 4.48 & 0.28 & Devine and Vanni (2002) \\
\hline Tubificidae & 9 & 4 & 2.34 & 0.47 & Devine and Vanni (2002) \\
\hline Chaoborus sp. & 14 & 4 & 15.86 & 1.87 & Devine and Vanni (2002) \\
\hline Chironomidae & 14 & 4 & 13.08 & 0.56 & Devine and Vanni (2002) \\
\hline Tubificidae & 14 & 4 & 15.24 & 2.43 & Devine and Vanni (2002) \\
\hline Chaoborus sp. & 15 & 24 & - & 0.78 & $\begin{array}{l}\text { Fukuhara and Yasuda } \\
\text { (1985) }\end{array}$ \\
\hline Chironomidae ( Chironomus) & 15 & 4 & - & 0.19 & $\begin{array}{l}\text { Fukuhara and Yasuda } \\
\text { (1985) }\end{array}$ \\
\hline Chironomidae (Tokunagayusurika) & 15 & 4 & - & 0.10 & $\begin{array}{l}\text { Fukuhara and Yasuda } \\
\text { (1985) }\end{array}$ \\
\hline Tubificidae (Limnodrilus) & 15 & 7 & - & 0.07 & $\begin{array}{l}\text { Fukuhara and Yasuda } \\
\text { (1985) }\end{array}$ \\
\hline Chironomidae & 20 & 4 & 4.75 & 0.35 & $\begin{array}{l}\text { Fukuhara \& Sakamoto } \\
\text { (1987) }\end{array}$ \\
\hline Tubificidae & 20 & 4 & 5.10 & 0.10 & $\begin{array}{l}\text { Fukuhara \& Sakamoto } \\
\text { (1987) }\end{array}$ \\
\hline Tubificidae & 20 & 0.5 & - & 3.46 & Gardner and others (1981) \\
\hline Chironomidae & 20 & 24 & - & 0.81 & Gardner and others (1981) \\
\hline Tubificidae & 20 & 24 & - & 0.19 & Gardner and others (1981) \\
\hline Chaoborus sp. & 22 & 1 & 47.63 & 4.70 & Devine and Vanni (2002) \\
\hline Tubificidae & 22 & & 54.75 & 3.37 & Devine and Vanni (2002) \\
\hline Chironomidae & 25 & & 24.40 & 1.46 & Devine and Vanni (2002) \\
\hline
\end{tabular}


in molar units from the two midge experiments (0.241 and $0.207 \mathrm{nmol} \mathrm{P/mg} \mathrm{DW/h}$ ) and the single tubificid experiment $(0.054 \mathrm{nmol} \mathrm{P} / \mathrm{mg}$ $\mathrm{DW} / \mathrm{h}$ ) are similar to those tabulated by Devine and Vanni (2002).

To evaluate the contribution to internal loading of nutrient excretion by the benthos, the mass- and species-specific excretion rates were converted to an areal rate. The areal rate at any point in time and geographic location depends on the density of individuals and their body size, species present, life stage, and temperature. Nevertheless, to get an approximation of the importance of excretion by benthic invertebrates to internal loading in the lake, we used the overall estimated mean densities of tubificids and chironomids derived from sampling during the 2year period and mean values for the rate of phosphorus excretion per taxon. An estimate of phosphorus release through excretion based on mean densities by these two taxa is 3.8 $\left(\mathrm{mg} / \mathrm{m}^{2}\right) / \mathrm{d}$. This value represents an estimate of the metabolic addition of phosphorus to the water column by tubificid worms and chironomid midges, but does not address the influence of bioturbation nor the contribution of phosphorus by other abundant taxa (leeches, for example). Although there is likely an influence of bioturbation on phosphorus cycling given the overall density and behaviors of the resident benthic invertebrates, whether this influence enhances the release of phosphorus is a function of many other biological, chemical, and mechanical processes.

For the purposes of a numerical model, it is necessary to adequately estimate benthic invertebrate excretion rates of specific nutrients. These rates are influenced by the spatial and temporal variation in densities of individual species or higher taxa throughout Upper Klamath Lake. Seasonal variability in taxon presence and their growth rates are likely dependent on temperature (Vannote and Sweeney, 1980). The most important influence on interannual variability in spring nutrient release could be year-to-year differences in the spring progression of water temperature, because these temperatures likely influence the timing of the first midge emergence (Vannote and Sweeney, 1980). A cold spring would likely delay the emergence of the first midge cohorts relative to a warm spring. Measurements of water quality in the lake support the correlation of the onset of internal loading with spring temperatures and suggest a biological control on some of the important processes (Wood and others, 1996; Morace, 2007). In addition to temperature, year-to-year differences in food resources, predation, competition, and overwintering success also have a role in determining the size and distribution of Upper Klamath Lake benthic invertebrate populations.

The benthos affects not only the magnitude of fluxes of phosphorus and nitrogen from the sediments to the water column, but also the nutrient ratio in those fluxes. Alves and others (2010) found that mass-specific nitrogen and phosphorus body content varied among three species of benthic invertebrates, and that the mass-specific N:P excretion ratio varied among those species as well, such that it was positively related to mass specific body content N:P ratio. Thus, a more complete understanding of relative contributions of the three dominant benthic invertebrate taxa in Upper Klamath Lake would include a comparison of their body stoichiometries and how those vary with body size, which could be incorporated into growth-based models of excretion.

The possible influence of benthic invertebrates on the N:P ratio of fluxes from the sediments in the larger context of trophic level cycling must be considered. Sereda and Hudson (2011) noted that the N:P ratio in excretions of aquatic metazoans was generally below the Redfield ratio of 16:1 (a measure of the average N:P ration in aquatic phytoplankton [Redfield, 1934]). Hansen and others (1998) demonstrated that the effect of chironomids on nutrient sediment fluxes was not only an increase in fluxes, but also a lowering of the N:P ratio of those fluxes. In laboratory experiments, the N:P ratio of nutrient fluxes from unamended sediment cores was 14.3 without the addition of chironomids, and 6.8 with the addition of chironomids. The addition of fresh 
algal material stimulated mineralization processes and increased nutrient fluxes from sediment cores with and without chironomids, but in cores with chironomids, the N:P ratio of those fluxes was lower-8.1 in chironomid-inhabited versus 9.9 in cores without chironomids (Hansen and others, 1998). This implies that the N:P ratio of sediment fluxes into the water column of Upper Klamath Lake is possibly lower than it would be in the absence of the large benthic invertebrate densities. Thus, the role of the benthic invertebrates could include not only the efficient recycling of phosphorus from the sediments, but also the lowering of the N:P ratio to levels that favor the dominance of the nitrogen fixing cyanobacterium A. flos aquae over phytoplankton that are not capable of fixing nitrogen.

A final consideration regarding the role of benthic invertebrates is that their densities vary spatially as well as temporally. Because the concentration of phosphorus in various sediment fractions varies spatially as well (fig. 4), the overlay of the density of individuals on the spatial distribution of phosphorus is important to determining the magnitude of their contribution to internal phosphorus loading in the lake. Such spatial variability cannot be resolved with a CSTR model. Incorporation of invertebrates into a CSTR TMDL model requires an intermediate step designed to properly scale up from individual locations, and is not likely to be as simple as taking a straightforward average of the quantities involved.

\section{Verification of the Upper Klamath Lake Phosphorus TMDL Model}

The Upper Klamath Lake TMDL model simulates the lake as a continuously stirred tank reactor (CSTR) with a 2-week time step. It is programmed into an Excel ${ }^{\circledR}$ spreadsheet, and the datasets required to run the model from April 1991 to September 1998 (hereafter referred to as the 7.5-year calibration dataset [but includes eight summers]) are supplied with the spreadsheet. The model requires measured hydrologic and climato- logic inputs (external phosphorus loads, lake outflow, lake volume, solar radiation, air temperature, and water temperature), the sources of which are documented in Walker (2001). The model also requires several parameters that are determined through a calibration process or compiled from the literature. Those parameters also are documented in Walker (2001) and listed in table 4 .

The model has four component submodels: a water-column total phosphorus model, a sediment total phosphorus model, a chlorophyll a model, and a $\mathrm{pH}$ model. These four components are interconnected and interdependent at each time step (fig. 6) and are determined through an iterative process by intentionally allowing circular references and enabling the iterative calculation option in the spreadsheet. Required initial conditions include the initial water-column and sediment total phosphorus concentrations, determined from collected data. At each time step, the model evaluates total phosphorus in the water column, settled total phosphorus (algal and nonalgal components separately), buried total phosphorus, recycled total phosphorus from sediments, chlorophyll $a$ concentration, and $\mathrm{pH}$. The model can be run in two modes: the calibration model runs the model one time only through 7.5 years of measured hydrologic and climatologic conditions; the TMDL model chains together the first 7 years of these same measured conditions (mid-April 1991 to mid-April 1998), end to end. When running in "TMDL mode," the model continues to run through the same 7 years of measured conditions until a steady state (equilibrium) is reached. A short description of each submodel follows. 
Table 4. Values and sources of parameters used in the Upper Klamath Lake, Oregon, phosphorus TMDL model-

[For definitions of variables, see table 5. P, phosphorus, chl $a$, chlorophyll $a$, -, no units]

\begin{tabular}{|c|c|c|c|c|}
\hline Symbol & Description & $\begin{array}{l}\text { Value or value } \\
\text { range }\end{array}$ & Units & Source \\
\hline \multicolumn{5}{|c|}{ Values changed in one or more modified versions of the TMDL model } \\
\hline$K_{n a}$ & $\begin{array}{l}\text { Gross removal rate for non-algal } \\
\mathrm{P}\end{array}$ & $0.012-0.015$ & per day & $\begin{array}{l}\text { Calibrated using observed } \\
\text { mass balance and total } \mathrm{P} \\
\text { data }\end{array}$ \\
\hline$k_{\text {half }}$ & $\begin{array}{l}\text { Half-saturation constant for } \mathrm{P} \\
\text { limitation of algal growth }\end{array}$ & 0.06 & parts per million & $\begin{array}{l}\text { Calibrated within range pro- } \\
\text { vided by Bowie and others, } \\
1985\end{array}$ \\
\hline$u_{\text {alg }}$ & Net settling velocity for algal $\mathrm{P}$ & $0.001-0.116$ & meters per day & $\begin{array}{l}\text { Calibrated using observed } \\
\text { total } \mathrm{P} \text { and } \operatorname{chl} a \text { data }\end{array}$ \\
\hline$p H^{*}$ & $\begin{array}{l}\mathrm{pH} \text { at which the } \mathrm{P} \text { recycle rate is } \\
\text { one half the maximum }\end{array}$ & $8.1-9.1$ & - & $\begin{array}{l}\text { Calibrated using observed } \\
\text { total } \mathrm{P}, \text { chl } a \text { and } \mathrm{pH} \text { data }\end{array}$ \\
\hline$K_{R}$ & $\begin{array}{l}\text { Maximum } \mathrm{P} \text { recycle rate, } \mathrm{pH}- \\
\text { dependent }\end{array}$ & $0.26-1.48$ & per year & $\begin{array}{l}\text { Calibrated using observed } \\
\text { total } \mathrm{P}, \mathrm{chl} a \text { and } \mathrm{pH} \text { data }\end{array}$ \\
\hline$K_{T}$ & $\begin{array}{l}\text { Maximum } P \text { recycle rate, tem- } \\
\text { perature-dependent }\end{array}$ & 0.99 & per year & $\begin{array}{l}\text { Calibrated using observed } \\
\text { total } \mathrm{P}, \text { chl } a \text { and } \mathrm{pH} \text { data }\end{array}$ \\
\hline$T_{(\min , r e c)}$ & $\begin{array}{l}\text { The minimum temperature at } \\
\text { which temperature-dependent } \\
\text { recycling begins }\end{array}$ & 12.8 & degrees Celsius & $\begin{array}{l}\text { Calibrated using observed } \\
\text { total } \mathrm{P}, \mathrm{chl} a \text { and } \mathrm{pH} \text { data }\end{array}$ \\
\hline$T_{(\max , r e c)}$ & $\begin{array}{l}\text { The maximum temperature al- } \\
\text { lowing temperature-dependent } \\
\text { recycling }\end{array}$ & 23.7 & degrees Celsius & $\begin{array}{l}\text { Maximum water temperature } \\
\text { in observations provided } \\
\text { with model }\end{array}$ \\
\hline$P_{(\text {sed_new })}$ & $\begin{array}{l}\text { Initial sediment } \mathrm{P} \text { concentration, } \\
\text { updated based on cores collected } \\
\text { in } 2006\end{array}$ & 335 & $\begin{array}{l}\text { milligrams per } \\
\text { kilogram }\end{array}$ & Simon and Ingle, 2011 \\
\hline
\end{tabular}

\begin{tabular}{|c|c|c|c|c|}
\hline \multicolumn{5}{|c|}{ Values unchanged from original TMDL model } \\
\hline$\sigma_{o b s}$ & Spatial standard deviation of $\mathrm{pH}$ & 0.25 & - & $\begin{array}{l}\text { Calculated and reported in } \\
\text { Walker, } 2001\end{array}$ \\
\hline$\alpha$ & $\begin{array}{l}\text { Non-algal light extinction coef- } \\
\text { ficient }\end{array}$ & 1.32 & per meter & $\begin{array}{l}\text { Calculated and reported in } \\
\text { Walker, } 2001\end{array}$ \\
\hline$\beta$ & Algal light extinction coefficient & 0.0097 & $\begin{array}{l}\text { per }(\text { meter } \times \text { parts } \\
\text { per billion })\end{array}$ & $\begin{array}{l}\text { Calculated and reported in } \\
\text { Walker, } 2001\end{array}$ \\
\hline$I_{K}$ & Onset of light saturation & 214 & $\begin{array}{l}\text { microeinsteins per } \\
\text { square meter per } \\
\text { second }\end{array}$ & Talling, 1957 \\
\hline$f$ & Light reflectance fraction & 0.1 & - & Wetzel, 1975 \\
\hline$T_{\max }$ & $\begin{array}{l}\text { Temperature at which algal } \\
\text { growth rate is maximum }\end{array}$ & 20 & degrees Celsius & Bowie and others, 1985 \\
\hline
\end{tabular}


Table 4. Values and sources of parameters used in the Upper Klamath Lake, Oregon, phosphorus TMDL model-continued

[For definitions of variables, see table 5. P, phosphorus, chl $a$, chlorophyll $a,-$, no units]

\begin{tabular}{|c|c|c|c|c|}
\hline Symbol & Description & $\begin{array}{c}\text { Value or value } \\
\text { range }\end{array}$ & Units & Source \\
\hline$T_{\min }$ & Temperature at zero growth rate & 14 & degrees Celsius & Bowie and others, 1985 \\
\hline$K_{G}$ & $\begin{array}{l}\text { Maximum growth rate at refer- } \\
\text { ence temperature, } T_{X}\end{array}$ & 1.2 & per day & Bowie and others, 1985 \\
\hline$Y_{P}$ & Algal cell P quota & 0.6 & $\begin{array}{l}\text { milligrams P per } \\
\text { milligrams chl } a\end{array}$ & Bowie and others, 1985 \\
\hline$K_{\text {resp }}$ & $\begin{array}{l}\text { Maximum respiration rate at } \\
\text { reference temperature, } T_{X}\end{array}$ & 0.06 & per day & Bowie and others, 1985 \\
\hline$u_{\text {bur }}$ & $\begin{array}{l}\text { Burial velocity of } \mathrm{P} \text { in the sedi- } \\
\text { ment }\end{array}$ & 1.4 & $\begin{array}{l}\text { millimeters per } \\
\text { year }\end{array}$ & Eilers and others, 2001 \\
\hline$Z_{\text {sed }}$ & Active sediment thickness & 10 & $\mathrm{~cm}$ & Eilers and others, 2001 \\
\hline$\rho_{\text {bulk }}$ & Sediment bulk density & 0.12 & $\begin{array}{l}\text { grams per cubic } \\
\text { centimeter }\end{array}$ & Eilers and others, 2001 \\
\hline$P_{\text {sed }}$ & $\begin{array}{l}\text { Initial sediment } P \text { concentration, } \\
\text { as used in original model, based } \\
\text { on } 1996 \text { core }\end{array}$ & 1,000 & $\begin{array}{l}\text { milligrams per } \\
\text { kilogram }\end{array}$ & Eilers and others, 2001 \\
\hline
\end{tabular}




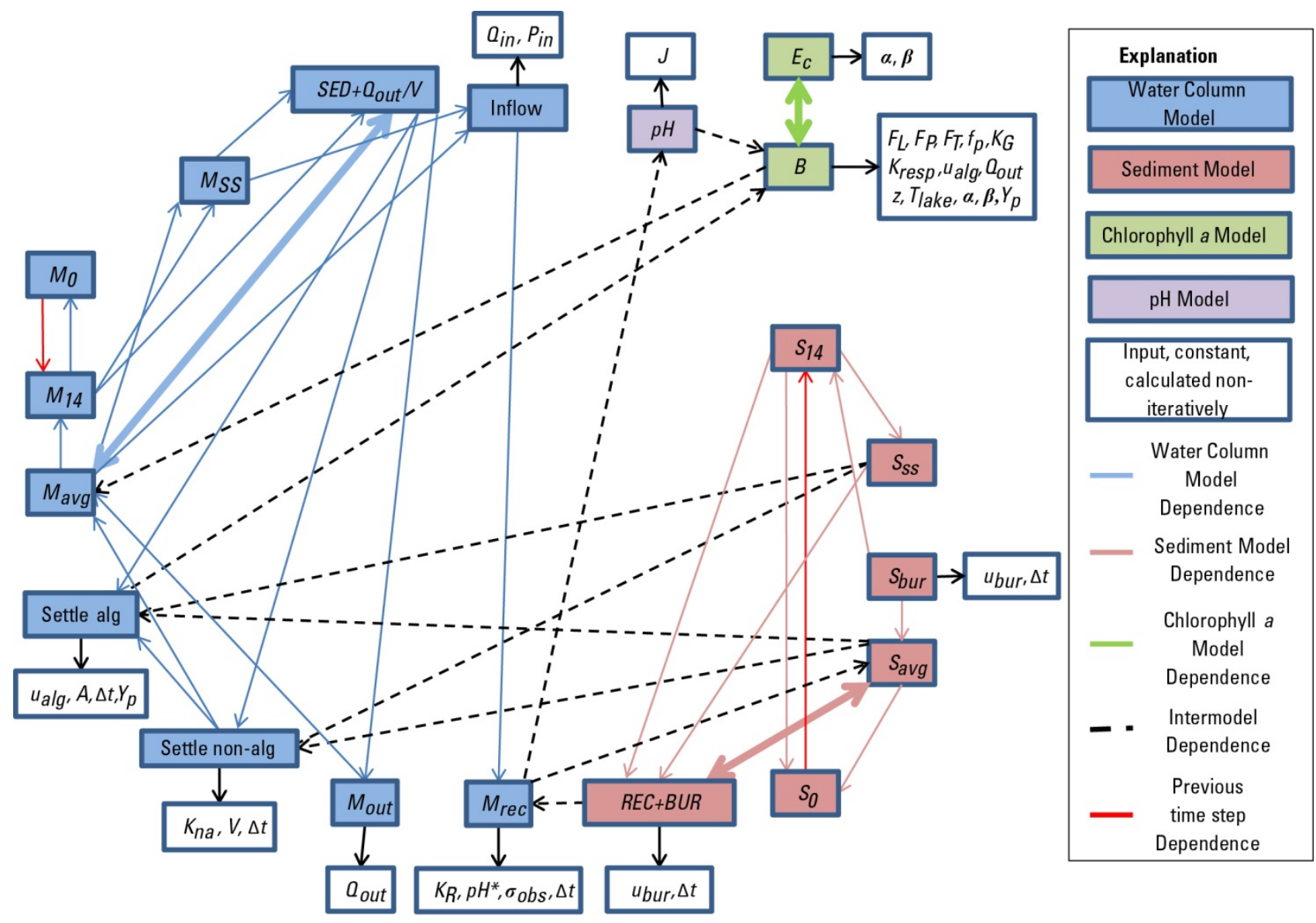

Figure 6. Diagram showing original total maximum daily load (TMDL) model dependence loops. Arrows point from the dependent variable to the independent variable and each filled box is a cell in the Excel model. Bold lines indicate cells using circular references.

To better understand and work with the algorithms of the TMDL model, an R-script version of the model was developed. The R-script enabled expedited duplication of model calibration, substitution of various recycling methods for sensitivity analysis, and user-friendly modeling of full future time periods. The R-script version of the model duplicated the results of the spreadsheet model, as indicated by statistics describing the comparison between the simulated data from both models - perfect correlation $\left(\mathrm{R}^{2}=1.0\right)$, zero bias, zero root mean square error (RMSE), and a

Nash-Sutcliffe statistic (NS) of 1.0 for all variables. Because the R-script model duplicated the results of the spreadsheet model, all of the modifications discussed in the rest of the document, as well as the duplication of model calibration and validation as presented in Walker (2001) were produced with the R-script model. 


\section{Water-Column Phosphorus Submodel}

The basis of the water-column phosphorus submodel is the following mass balance equation, excluding unit conversion factors which are included in the model:

$\frac{d M}{d t}=Q_{\text {in }} P_{\text {in }}+R E C \times S-\left(S E D+\frac{Q_{\text {out }}}{V}\right) \times M,(1)$

where $Q_{i n} P_{i n}$ and $R E C \times S$ are the external and internal load over the time step, respectively; $S E D \times M$ is the sedimentation rate of algal and nonalgal phosphorus, and $\left(\frac{Q_{\text {out }}}{V}\right) \times M$ is the export of phosphorus at the lake outlet. The $R E C$ and $S E D$ terms contain calibration parameters that are discussed below:

$R E C=K_{R} \operatorname{Prob}\left(\mathrm{pH}>p H^{*}\right)$,

where $K_{R}$ and $p H^{*}$ are calibration parameters (table 4) and $\operatorname{Prob}\left(\mathrm{pH}>p H^{*}\right)$ is the predicted probability of $\mathrm{pH}$ in the lake exceeding $p H^{*}$ as determined from a normal distribution with mean equal to $p H$ and standard deviation $\sigma_{o b s}$. The probabilistic relation was calibrated and verified with site-specific $\mathrm{pH}$ observations using (Walker, 2001): $\operatorname{Prob}\left(\mathrm{pH}>p H^{*}\right)=\operatorname{Freq}\left(p H_{\text {site }}>p H^{*}\right)$. The sedimentation term includes loss terms for algal and nonalgal phosphorus, assuming that the ratios of algal and nonalgal phosphorus to total phosphorus remain constant over a time step:

$S E D=K_{n a} r_{n a}+\frac{u_{a l g}}{z} r_{a l g}$,

where $K_{n a}$ and $u_{a l g}$ are calibration parameters. The solution to equation 1 over a time step takes the exponential form:

$$
M(t)=M_{S S}+\left(M_{0}-M_{S S}\right) e^{-\left(S E D+\frac{Q_{\text {out }}}{V}\right) t},
$$

where

$M_{S S}=\frac{Q_{\text {in }} P_{\text {in }}+R E C \times S}{S E D+\frac{Q_{\text {out }}}{V}}$.

All variables are defined in table 5 . The solution proceeds as follows: At each time step, the average mass $\left(M_{\text {avg }}\right)$ over the time step is calculated using the mass at the beginning $\left(M_{0}\right)$ and the mass at the end $\left(M_{14}\right)$ of the 14-day time step as defined by equation 4 . This value of $M_{a v g}$ is then used to calculate the sedimentation and recycle terms in the sediment and chlorophyll $a$ models (below), then the $\mathrm{pH}$ is calculated using the $\mathrm{pH}$ model (below). The new value of $\mathrm{pH}$ is then substituted back into equation (2) and the $R E C$ term then recalculated and substituted into equation 5 . This process repeats until the solution converges. Once the solution converges, $M_{14}$ becomes $M_{0}$ for the next time step, the initial time $\left(t_{0}\right)$ is reset to zero, and the iterative procedure begins again.

\section{Sediment-Phosphorus Submodel}

The basis of the sediment-phosphorus submodel is the mass balance equation for phosphorus contained in the sediment reservoir:

$\frac{d S}{d t}=S E D \times M-R E C \times S-B U R \times S$,

where

$B U R=u_{\text {bur }} z_{\text {sed }}$.

The solution to equation 6 over a time step takes the exponential form:

$S(t)=S_{s s}+\left(S_{0}-S_{s s}\right) e^{-(R E C+B U R) t}$,

where

$S_{S S}=\frac{S E D \times M}{R E C+B U R}$.

Equation 8 is used to determine the average sediment mass $\left(S_{\text {avg }}\right)$ over the time step. The new value of $S_{\text {avg }}$ is used to calculate a new value for the internal loading term in equation 1 , which leads to a new value of $M_{a v g}$. This process is repeated iteratively with each new value of $M_{\text {avg }}$ and $S_{\text {avg }}$ until the solution converges. 
Table 5. Definitions of symbols used in this report-

[For definitions and values of parameters, see table 4 . All mass, concentration, and $\mathrm{pH}$ variables (except $p H_{\text {site }}$ ) in the water column are lakewide averaged quantities. -, no units; $\mathrm{P}$, phosphorus]

\begin{tabular}{|c|c|c|}
\hline Symbol & Units & Description \\
\hline$A$ & square meters & Average lake surface area over the time step \\
\hline$B$ & parts per billion & Chlorophyll $a$ concentration \\
\hline$B_{o b s}$ & parts per billion & Observed chlorophyll $a$ concentration \\
\hline$B_{E Q}$ & parts per billion & Chlorophyll $a$ concentration evaluated by setting $d B / d t$ to 0 \\
\hline$B_{R K}$ & parts per billion & $\begin{array}{l}\text { Chlorophyll } a \text { concentration evaluated using a numerical Runge-Kutta } \\
\text { approach }\end{array}$ \\
\hline$E_{c}$ & per meter & Light extinction coefficient \\
\hline$F_{T}$ & - & Temperature adjustment factor \\
\hline$F_{P}$ & - & Phosphorus limitation factor \\
\hline$F_{P F S}$ & - & Forsberg Shapiro phosphorus limitation factor \\
\hline$F_{P 00}$ & - & Phosphorus limitation factor calculated as the percent of non-algal P \\
\hline$F_{P M M}$ & - & Phosphorus limitation factor calculated by Michaelis-Menten kinetics \\
\hline$F_{L}$ & - & Light limitation factor \\
\hline$F_{L A V G}$ & - & Light limitation calculated using the average light intensity \\
\hline$F_{L D I}$ & - & $\begin{array}{l}\text { Average light limitation calculated by depth-integrating the light limi- } \\
\text { tation equation }\end{array}$ \\
\hline$f_{p}$ & - & Photoperiod (fraction of day) \\
\hline$I$ & $\begin{array}{l}\text { microeinsteins per } \\
\text { square meter per } \\
\text { second }\end{array}$ & Light intensity at a particular depth \\
\hline$I_{0}$ & $\begin{array}{l}\text { microeinsteins per } \\
\text { square meter per } \\
\text { second }\end{array}$ & Light intensity at lake surface \\
\hline$I_{\text {mean }}$ & $\begin{array}{l}\text { microeinsteins per } \\
\text { square meter per } \\
\text { second }\end{array}$ & Average light intensity over the lake depth \\
\hline$J$ & _ & Julian day \\
\hline$K_{R}$ & per day & Recycle rate of $\mathrm{P}$ from the sediment \\
\hline$K_{G}$ & per day & Maximum algal growth rate \\
\hline$k_{s}$ & per day & Removal rate of algal $P$ \\
\hline$M$ & kilograms & Mass of total P in the water column \\
\hline$M_{\text {load }}$ & kilograms & Mass of external total P loading to the lake \\
\hline$M_{\text {load,obs }}$ & kilograms & Mass of external total P loading to the lake, biweekly observations \\
\hline$M_{\text {rec }}$ & kilograms & Mass of $P$ recycled from the sediment \\
\hline
\end{tabular}


Table 5. Definitions of symbols used in this report-continued

[For definitions and values of parameters, see table 4 . All mass, concentration, and $\mathrm{pH}$ variables $\left(\right.$ except $\left.p H_{\text {site }}\right)$ in the water column are lakewide averaged quantities. -, no units; P, phosphorus]

\begin{tabular}{|c|c|c|}
\hline Symbol & Units & Description \\
\hline$M_{\text {rec }, o b s}$ & kilograms & Mass of $\mathrm{P}$ recycled from the sediment, biweekly observations \\
\hline$M_{\text {sed }}$ & kilograms & Mass of P settling from the water column \\
\hline$M_{\text {out }}$ & kilograms & Mass of total P flowing out of the lake \\
\hline$M_{\text {out, obs }}$ & kilograms & Mass of total P flowing out of the lake, biweekly observations \\
\hline$M_{S S}$ & kilograms & Steady state mass of water column total P calculated at each time step \\
\hline$M_{0}$ & kilograms & Initial mass of water column total $P$ for the time step \\
\hline$M_{14}$ & kilograms & Mass of water column total P at the end of the 14-day time step \\
\hline$M_{a v g}$ & kilograms & Average mass of total $P$ in the water column over the time step \\
\hline$M_{\text {rec_pH }}$ & kilograms & Mass of $\mathrm{P}$ recycled from the sediment, $\mathrm{pH}$-dependent mechanism \\
\hline$M_{\text {rec } T}$ & kilograms & $\begin{array}{l}\text { Mass of } P \text { recycled from the sediment, temperature-dependent mech- } \\
\text { anism }\end{array}$ \\
\hline$N$ & - & Number of observed samples used for calculation \\
\hline pH & - & Modeled pH \\
\hline$p H_{o b s}$ & - & Observed $\mathrm{pH}$ \\
\hline$p H_{\text {site }}$ & - & Site-specific observed $\mathrm{pH}$ \\
\hline$P_{\text {in }}$ & parts per billion & Inflow total $\mathrm{P}$ concentration \\
\hline$P_{n a}$ & parts per billion & Non-algal P concentration \\
\hline$P_{\text {alg }}$ & parts per billion & Algal $\mathrm{P}$ concentration \\
\hline$P_{a l g, o b s}$ & parts per billion & Algal P concentration, biweekly observations \\
\hline$P_{T}$ & parts per billion & Total $\mathrm{P}$ concentration \\
\hline$P_{T, o b s}$ & parts per billion & Total P concentration, biweekly observations \\
\hline$P_{S S}$ & parts per billion & Steady state $\mathrm{P}$ concentration \\
\hline$Q_{\text {in }}$ & cubic meters per day & Lake inflow rate \\
\hline$Q_{\text {out }}$ & cubic meters per day & Lake outflow rate \\
\hline$r_{\text {alg }}$ & - & Ratio of algal $\mathrm{P}$ to total $\mathrm{P}$ \\
\hline$r_{n a}$ & - & Ratio of non-algal $\mathrm{P}$ to total $\mathrm{P}$ \\
\hline$S$ & kilograms & Mass of total $\mathrm{P}$ in the sediment reservoir \\
\hline$S_{\text {bur }}$ & kilograms & Mass of $\mathrm{P}$ buried and removed from the active sediment reservoir \\
\hline$S_{s s}$ & kilograms & Steady state mass of sediment P calculated at each time step \\
\hline$S_{0}$ & kilograms & Initial mass of sediment $P$ for the time step \\
\hline$S_{14}$ & kilograms & Mass of total $\mathrm{P}$ in the sediment at the end of the 14-day time step \\
\hline$S_{a v g}$ & kilograms & Average mass of total $\mathrm{P}$ in the sediment reservoir over the time step \\
\hline
\end{tabular}


Table 5. Definitions of symbols used in this report-continued

[For definitions and values of parameters, see table 4. All mass, concentration, and $\mathrm{pH}$ variables $\left(\mathrm{except} p \mathrm{H}_{\text {site }}\right)$ in the water column are lakewide averaged quantities. -, no units; P, phosphorus]

\begin{tabular}{|c|c|c|}
\hline Symbol & Units & Description \\
\hline$S_{\text {init }}$ & kilograms & $\begin{array}{l}\text { Initial size of sediment reservoir calculated with original starting con- } \\
\text { centration } 1,000 \mathrm{mg} \mathrm{P} / \mathrm{kg} \text { sediment }\end{array}$ \\
\hline$S_{\text {init new }}$ & kilograms & $\begin{array}{l}\text { Initial size of sediment reservoir recalculated with starting concentra- } \\
\text { tion } 335 \mathrm{mg} \mathrm{P} / \mathrm{kg} \text { sediment }\end{array}$ \\
\hline$T_{\text {lake }}$ & degrees Celsius & Lake temperature \\
\hline$t$ & day & Time \\
\hline$V$ & cubic meters & Mean volume of the lake over the time step \\
\hline$Y_{P}^{\prime}$ & $\begin{array}{l}\text { milligrams phosphorus } \\
\text { per milligram chloro- } \\
\text { phyll } \boldsymbol{a}\end{array}$ & Minimum cell quota required for photosynthesis to occur \\
\hline$Z$ & meter & Average lake depth over the time step \\
\hline$\Delta t$ & day & Time step \\
\hline$M_{o b s}$ & kilograms & $\begin{array}{l}\text { Change in mass stored in the lake over the time step, biweekly obser- } \\
\text { vations }\end{array}$ \\
\hline$\Pi / \Pi_{\max }$ & - & $\begin{array}{l}\text { Photosynthesis rate at a particular depth divided by maximum photo- } \\
\text { synthesis rate }\end{array}$ \\
\hline
\end{tabular}

\section{Chlorophyll a Submodel}

The chlorophyll $a$ submodel is based on a mass balance in which it is assumed that chlorophyll $a$ is always at its maximum potential value based on phosphorus concentration and water temperature averaged over the time step:

$\frac{d B}{d t}=\left(G R O W T H-R E S P-S E T T L E-\frac{Q_{\text {out }}}{V}\right) \times B=0$,

where

GROWTH $=K_{G} F_{L} F_{T} F_{P}$,

$R E S P=K_{\text {resp }} F_{T}$, and

SETTLE $=\frac{u_{\text {alg }}}{z}$.

In the model, growth depends on water temperature, nutrient availability (phosphorus only), and light, whereas respiration depends on water temperature only (Walker, 2001). No mechanism for algal mortality that would bring on a midsea- son bloom decline is built into the model; therefore, the model overpredicts chlorophyll $a$ concentrations during and after August in most years, which leads to overpredicted $\mathrm{pH}$ and total phosphorus recycled from sediment. In the model, chlorophyll $a$ concentrations decrease in the autumn, when growth ceases largely because of temperature decreases, and settling and outflow dominate. The mass balance (eq. 10) can be rewritten in terms of model variables with temperature, nutrient, and light dependencies as:

$K_{G} F_{L} F_{T} F_{P} B-\left(K_{\text {resp }} F_{T}+\frac{u_{\text {alg }}}{z}+\frac{Q_{\text {out }}}{V}\right) B=0$

When lake temperature is greater than $14^{\circ} \mathrm{C}$, the algal growth rate in the model increases linearly with lake temperature between $T_{\min }$ and $T_{\max }$ (Bowie and others, 1985), so there is a steady increase in growth rate as lake temperatures increase followed by a steady decrease in growth rate as lake temperatures decrease: 
$F_{T}=\left(\frac{T_{l a k e}-T_{\min }}{T_{\max }-T_{\min }}\right)$

$T_{\min }$ and $T_{\max }$ were determined empirically to be 14 and $20^{\circ} \mathrm{C}$, respectively. When the lake temperature is less than $14^{\circ} \mathrm{C}$, the growth rate is set to zero and the chlorophyll $a$ concentration is set to a baseline value of $8 \mathrm{ppb}$. When the lake temperature is greater than $20^{\circ} \mathrm{C}$, the temperature adjustment factor, $F_{T}$, is equal to 1 .

The light limitation factor is based on an empirically determined equation relating photosynthesis (I) to light intensity $(I)$ at a particular depth (Talling, 1957):

$\frac{\Pi}{\Pi_{\max }}=\frac{\frac{I}{I_{K}}}{\left(1+\left(\frac{I}{I_{K}}\right)^{2}\right)^{1 / 2}}$

The light limitation factor in the model scales this relation to the entire water column by substituting the depth-averaged light intensity for the light intensity at a particular depth, and then multiplies by the photoperiod to represent integration over 24 hours:

$F_{L A V G}=\left(\frac{\frac{I_{\text {mean }}}{I_{K}}}{\left(1+\left(\frac{I_{\text {mean }}}{I_{K}}\right)^{2}\right)^{1 / 2}}\right) f_{p}$

Phosphorus limitation in the model is based on the results of Senft (1978) and Forsberg and Shapiro (1981). The limitation can be expressed in terms of a limiting cell quota and the ratio of chlorophyll $a$ concentration to total phosphorus concentration as (using model notation):

$F_{P F S}=\left(1-Y_{P}^{\prime} \frac{B}{P_{T}}\right)$,

where $Y_{P}^{\prime}$ is the minimum cell quota (mg P per mg chlorophyll a) required for photosynthesis to occur. In the model, the average, constant cell quota $Y_{P}$ is substituted for $Y_{P}^{\prime}$, so that the phosphorus limitation becomes the percent of available (nonalgal) phosphorus in the water column:

$F_{P 00}=\left(1-Y_{P} \frac{B}{P_{T}}\right)=\frac{P_{n a}}{P_{T}}$.

\section{pH Submodel}

The $\mathrm{pH}$ submodel is a linear regression that determines $\mathrm{pH}$ as a function of the natural logarithm of chlorophyll $a$ concentration and the Julian day $(J)$ :

$p H=7.93+0.534 \ln (B)-0.006 \max (J, 200)$.

The regression quantifies the high correlation between $\mathrm{pH}$ and chlorophyll $a$ during the typically major bloom months of June-July $\left(\mathrm{R}^{2}=0.87\right.$; Walker, 2001), the result of photosynthesis removing dissolved $\mathrm{CO}_{2}$ from the water column. The regression coefficients are determined empirically as part of the calibration process.

\section{Alternative Solution Method}

The water column and sediment phosphorus submodels were solved in the original TMDL model (and the R-script version of the original model) using the semi-analytical approach, in which the variables are assumed to respond with exponential decay over the time step in response to instantaneous changes in the boundary conditions and forcing functions at the beginning of each time step. Vollenweider (1975) proposed this solution to describe situations where the response to baseline loading could be described by the steady-state solution and the response to one or more anthropogenic loadings could be described by adding exponential decay terms to the steady-state solution. However, Vollenweider (1975) used an annual or seasonal time step as appropriate, and the steady-state solution was not recalculated at the beginning of each time step. Given the shorter 2-week time step of the TMDL model, the advantage of simplicity that the Vollenweider-based semi-analytical approach has for models with long time steps is reduced.

We developed a more efficient conventional numerical solution method that made it easier to create and modify a program in a logical and easy to follow sequence. A model that incorporated all the same submodels, but solved the water column and sediment phosphorus equations (which include a time derivative) using a Runge-Kutta 
order 4 numerical method (Burden and Faires, 1997), was developed as an R-script for comparison to the existing model. We quantitatively compared the concentrations of total phosphorus, sediment phosphorus, chlorophyll $a$, and $\mathrm{pH}$ simulated by the semi-analytical and Runge-Kutta models (table 6). The Runge-Kutta model reproduced the model results reported in Walker (2001) well, and became the basis for all the modified versions of the model used in this study. The Runge-Kutta model was used instead of the semi-analytical version because of reduced computational effort (due to removal of iterative solution convergence), confidence in using a traditional solution method, and simplified evaluation of alternative recycling mechanisms.

Table 6. Comparison of simulated model variables obtained from the original, semi-analytical and Runge-Kutta models used in the review of the original model used to establish a TMDL for Upper Klamath Lake, Oregon.

[Bias is calculated as the mean value of the semianalytical result minus the Runge-Kutta result at each time step. R, correlation coefficient; RMSE, root mean square error; NS, Nash-Sutcliffe statistic. P; phosphorus; $\mathrm{kg}$, kilogram; ppb, parts per billion]

\begin{tabular}{lcclc}
\hline \multicolumn{1}{c}{ Variable } & R & \multicolumn{1}{c}{ Bias } & \multicolumn{1}{c}{ RMSE } & NS \\
\hline Water column P & 1.00 & $0.86 \mathrm{ppb}$ & $2.44 \mathrm{ppb}$ & 1.00 \\
Sediment P & 1.00 & $-2.22 \mathrm{~kg}$ & $2.47 \mathrm{~kg}$ & 1.00 \\
Chlorophyll $a$ & 1.00 & $0.89 \mathrm{ppb}$ & $2.19 \mathrm{ppb}$ & 1.00 \\
$\mathrm{pH}$ & 1.00 & 0.00 & 0.01 & 1.00 \\
\hline
\end{tabular}

\section{Model Calibration}

As part of the model verification, we duplicated the process of calibration described in Walker (2001). This process proceeds in four steps: (1) calibration of the regression coefficients in the $\mathrm{pH}$ submodel using measured chlorophyll $a$ concentrations from June through August 1991-1998, (2) calibration of the algal settling velocity using observed chlorophyll $a$ concentrations from June through July 19941998, (3) calibration of the nonalgal phosphorus loss rate, which primarily represents the sedimen- tation of particulate phosphorus, based on observed lake phosphorus concentrations from March through May 1991-1998, when the algal compartment is assumed to be minimal, and (4) calibration of the parameters controlling phosphorus recycling using observed $\mathrm{pH}$ and concentrations of total phosphorus and chlorophyll $a$ from May through July 1994-1998.

\section{Step 1-pH Regression Model Parameters}

The multiple regression was carried out in Excel using the chlorophyll $a$ concentration and $\mathrm{pH}$ observations from the model. These datasets included June-August 1991-1998 and included 52 data points. The coefficient of determination $\mathrm{R}^{2}$ and standard error determined during the duplication of the calibration compared well to those provided in the TMDL model documentation (table 7; Walker, 2001). The regression in Walker (2001) was based on at least 54 data points, suggesting that our minimally different statistics result from the slightly shorter dataset provided with the model than was used in the original calibration.

Table 7. Comparison of $\mathrm{pH}$ model coefficients and statistics between the original TMDL model for Upper Klamath Lake, Oregon, and the model recalibration.

\begin{tabular}{llcc}
\hline \multicolumn{1}{c}{ Quantity } & $\begin{array}{c}\text { Original } \\
\text { value }\end{array}$ & $\begin{array}{c}\text { Recali- } \\
\text { bration } \\
\text { value }\end{array}$ & p-value \\
\hline $\begin{array}{l}\text { pH model: intercept } \\
\text { pH model: chl } a\end{array}$ & 7.931 & 7.829 & $1.973 \mathrm{E}-19$ \\
coefficient & 0.5338 & 0.5514 & $1.595 \mathrm{E}-17$ \\
$\begin{array}{l}\text { pH model: Julian } \\
\text { day coefficient }\end{array}$ & -0.006 & -0.006 & 0.0169586 \\
$\begin{array}{l}\text { Coefficient of de- } \\
\text { termination R }\end{array}$ & 0.80 & 0.78 & \\
\begin{tabular}{l} 
Standard error \\
\hline
\end{tabular} & 0.24 & 0.25 & \\
\hline
\end{tabular}

\section{Step 2-Algal Settling Rate}

We used trial and error to duplicate the algal settling rate $\left(u_{\text {alg }}\right)$ calibration. Parameter values were assumed to be between 0.001 and $0.2 \mathrm{~m} / \mathrm{d}$ 
(Bowie and others, 1985). The best value was determined by correlating chlorophyll $a$ as calculated by equation (14) (using observed phosphorus concentrations) with observed chlorophyll $a$ concentrations in June-July 1994-1998. The sum of squared errors was minimized at $u_{\text {alg }}=0.059 \mathrm{~m} / \mathrm{d}$, in close agreement with the original value $(0.05 \mathrm{~m} / \mathrm{d})$ provided in the model documentation. Using a value of $u_{\text {alg }}=0.059$ $\mathrm{m} / \mathrm{d}$, the correlation coefficient $\mathrm{R}$ between the simulated and observed chlorophyll $a$ values was $0.79(\mathrm{p}<0.0001)$.

\section{Step 3-Nonalgal Phosphorus Loss Rate}

The original model documentation does not specify the method used to calibrate the nonalgal phosphorus loss rate $K_{n a}$, but Kann and Walker (2001) discuss the general approach. The calibration of the nonalgal phosphorus loss rate uses the biweekly mass balance of Kann and Walker (2001) during March-May, when recycling from the sediments is assumed to be nonexistent and total phosphorus in the water column is assumed to be predominantly nonalgal. Under these assumptions, the mass lost to sedimentation can be calculated by rearranging equation (1). This provides a set of "observations" of mass lost to sedimentation, which was compared to a set of calculated values of mass lost to sedimentation. The calculated values were determined by assuming a value of $K_{n a}$ and calculating the mass lost to sedimentation from lake total phosphorus concentration and volume at each time step:

$M_{\text {sed }}=K_{n a} V P_{T} \Delta \mathrm{t}$.

We used a least-squares fit as a calibration criterion in the absence of other information and determined by trial and error that the value of $K_{n a}$ that resulted in the lowest sum of squared errors was $0.015 / \mathrm{d}$, compared to the value of $0.012 / \mathrm{d}$ that is supplied in Walker (2001). Using either value, the correlation coefficient between the "observed" and calculated values of mass lost to sedimentation is the same (and low: $R=0.19$ ), and the regression coefficient is not significant $(p=0.35)$, indicating that for practical purposes the regression model does not have predictive capability. This parameter is difficult to calibrate, likely because the model does not distinguish between different forms of nonalgal P. Particleassociated nonalgal phosphorus has a different loss rate from dissolved nonalgal $\mathrm{P}$. Both values of $K_{n a}$ result in lower average values and smaller standard deviations of $M_{\text {sed }}$ than characterize the observations (table 8). Even so, the model assumes that the loss rate determined in this way is applicable for all seasons and all nonalgal phosphorus concentrations throughout the year (Kann and Walker, 2001).

Table 8. Comparison of descriptive statistics between observed and calculated non-algal mass lost to sedimentation during March-May 1991-1998

\begin{tabular}{llc}
\hline \multicolumn{1}{c}{ Mass lost to sedimentation } & $\begin{array}{c}\text { Average } \\
\text { (kilo- } \\
\text { grams) }\end{array}$ & $\begin{array}{c}\text { Standard } \\
\text { Deviation } \\
\text { (kilo- } \\
\text { grams) }\end{array}$ \\
\hline Observed (from mass balance) & 9008 & 6608 \\
$\begin{array}{l}\text { Calculated with } K_{n a}=0.012 \mathrm{~d}^{-1} \\
\text { (original model value) }\end{array}$ & 6781 & 1813 \\
$\begin{array}{l}\text { Calculated with } K_{n a}=0.015 \mathrm{~d}^{-1} \\
\text { (recalibrated model value) }\end{array}$ & 8476 & 2267 \\
\hline
\end{tabular}

\section{Step 4-Internal Recycling Parameters}

The equation for the mass of phosphorus transferred from the sediments to the water column ("recycled," $M_{\text {rec_pH }}$ ) at any time step is an empirically derived function of the bottom sediment phosphorus concentration and the water column $\mathrm{pH}$ :

$M_{\text {rec_pH }}=S_{\text {avg }} K_{R} \operatorname{Prob}\left(\mathrm{pH}>p H^{*}\right) \Delta t$,

where

$\operatorname{Prob}\left(\mathrm{pH}>p H^{*}\right)=1-C N D F\left[\frac{p H^{*}-p H}{\sigma_{o b s}}\right]$

and CNDF is the cumulative standard normal distribution of the expression in the square brackets.

Equation 22 requires two calibration parameters: $p H^{*}$ and $K_{R}$. The parameter $p H^{*}$ is the calibrated threshold at which the calibrated recycle rate $K_{R}$ is halved. At $p H$ values much higher than $\mathrm{pH}^{*}, \operatorname{Prob}\left(\mathrm{pH}>p H^{*}\right)$ approaches 1 , and at 
$p H$ values much less than $p H^{*}, \operatorname{Prob}\left(\mathrm{pH}>p H^{*}\right)$ approaches zero. The best values of these calibration parameters were those that minimized the following objective function:

$O\left(P_{T}, B, p H\right)=$

$\min \left(\frac{\sum\left(P_{T, o b s}-P_{T}\right)^{2} \cdot \sum\left(B_{o b s}-B\right)^{2} \cdot \sum\left(p H_{o b s}-p H\right)^{2}}{N^{3}}\right)$,

where the summation is over all May-July 19941998 data. The calibration period was restricted to May-July, when bloom growth is most rapid, and to avoid later summer months, when the model overpredicts chlorophyll $a$. This approach relies on the model structure and calibrated parameters from steps $1-3$ being accurate. The parameters supplied with the original model were $p H^{*}=9.1$ and $K_{R}=0.53 /$ yr. The values obtained in the process of duplicating the calibration with the datasets supplied with the model were $p H^{*}=9.0$ and $K_{R}=0.47 / \mathrm{yr}$. While duplicating the calibration, however, it was noted that if the objective function (eq. 24) was modified to incorporate May-July data for 1991-1998, instead of just for 1994-1998, the parameters that minimized the objective function were $p H^{*}=9.1$ and $K_{R}=0.52 / \mathrm{yr}$, much closer to those supplied with the original model. One explanation, therefore, for the differences between the parameters obtained when the calibration was duplicated and the original values is that the original calibration may have been performed using more years of data than was documented in Walker (2001).

\section{Comparison of Original to Recalibrated Model Per- formance}

The recalibrated model differed from the original model in two ways: The calibrated recycling rate was 11 percent lower $(0.47$ versus 0.53 per year), resulting in lower peaks of phosphorus in the water column during the time of year when recycling was important (fig. 7A). Because chlorophyll $a$ is in equilibrium with available phosphorus at each time step, the lower watercolumn phosphorus translated to lower peaks in chlorophyll $a$ (fig. 7B). The recalibrated algal settling velocity was 15 percent higher $(0.059$ versus
$0.05 \mathrm{~m} / \mathrm{d}$ ) than the original, which acted to reinforce the lower peaks in chlorophyll $a$; lower peaks in chlorophyll $a$ resulted in lower $\mathrm{pH}$ (fig. 7C), which reinforced the lower recycling rate.

The original model was validated using data from all months in 1991-1993 and August-April in 1994-1998, which comprised the data set not used in the calibration. Although the documentation states a validation period, Walker (2001) presents no performance statistics for the final calibrated model. To fill this gap, we calculated several standard model statistics from simulations produced with the original model and the parameter values supplied with it. We compared these statistics to the same statistics calculated from simulations produced with the recalibrated model, which used parameter values determined by duplicating the entire calibration process and which differed in some cases from those supplied with the original model. This process was a means of quantifying the sensitivity of the model to the calibration parameters. The statistics considered are the correlation coefficient $(\mathrm{R})$, the coefficient of determination $\left(\mathrm{R}^{2}\right)$, the mean of simulated minus observed values (Bias), the Nash Sutcliffe statistic (NS; Nash and Sutcliffe, 1970), and the root mean square error (RMSE).

For all variables, the recalibrated model resulted in a slight improvement in model statistics: smaller bias, smaller RMSE, and increased NS (compare model versions $O$ and $A$, tables 9-11). Overall, both the original and recalibrated model simulated total phosphorus concentration more successfully than they simulated chlorophyll $a$ concentration. Both models showed a negative bias for all variables, indicating that the models tended to underpredict the observed values during the validation period. Neither model performed well based on standard measures: $\mathrm{R}^{2}$ varied from 0.35 for total phosphorus to 0.18 for chlorophyll $a$ in the recalibrated model; the NS statistic was negative or near zero for all variables in both models, indicating that the mean squared error was greater than or close to the variance in the dataset. 

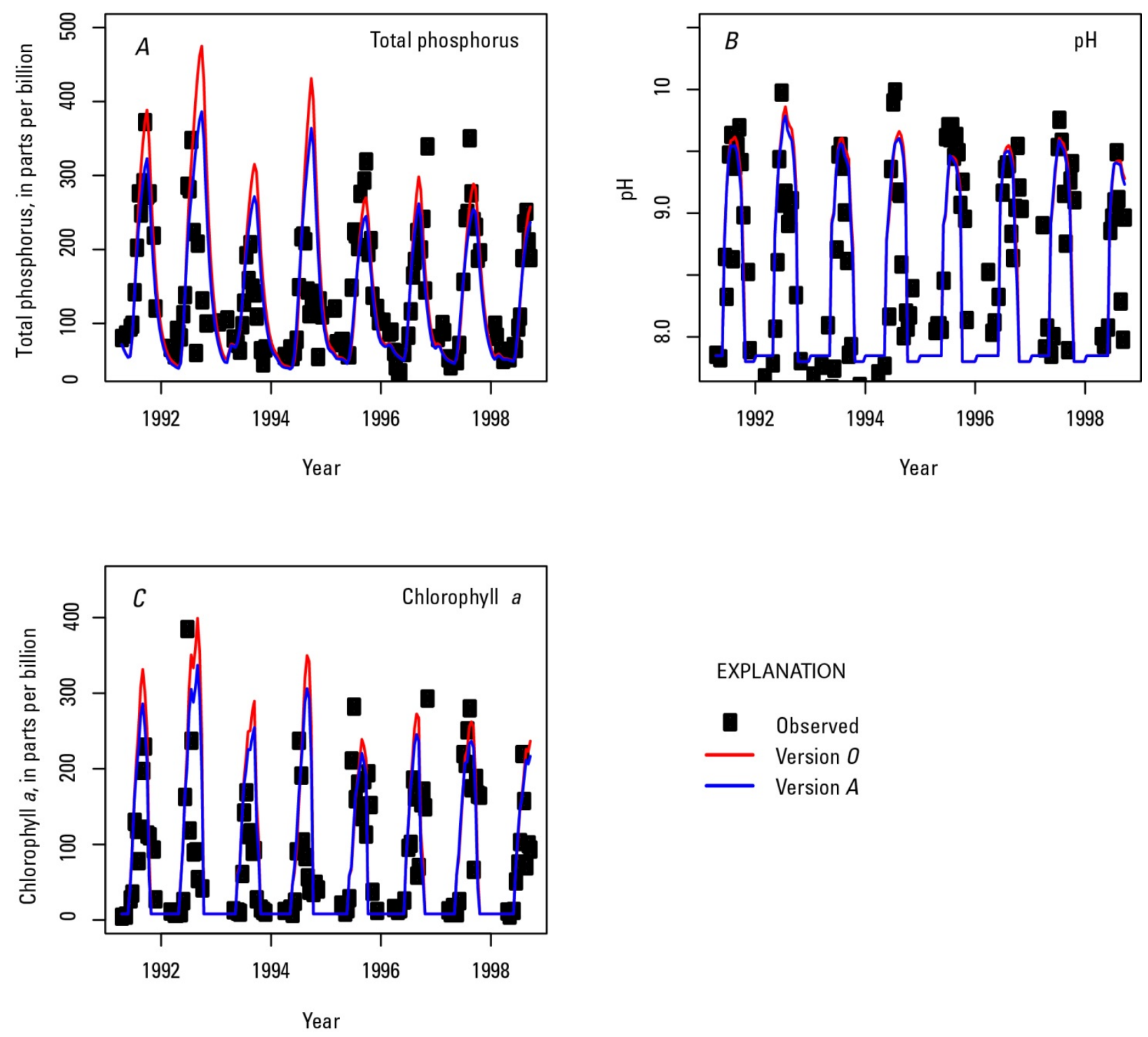

EXPLANATION

Observed

Version 0

Version $A$

Figure 7. Diagrams showing simulated and observed water column $(A)$ total phosphorus concentration, $(B)$ chlorophyll a concentration, and (C) pH, Upper Klamath Lake, Oregon, April 1991-September 1998. Model version $O$ is the original model with the original calibration parameters, and model version $A$ is the recalibrated version of the original model. 
Table 9. Comparison of performance statistics for total phosphorus obtained over a validation period including all months in 1991-1993 and AugustApril in 1994-1998 from model versions discussed in the report.

[The statistics are calculated over a validation period including all months in 1991-1993 and August-April in 1994-1998 (N=83). R=correlation coefficient; $\mathrm{R}^{2}=$ coefficient of determination; RMSE=root mean square error; $\mathrm{NS}=\mathrm{Nash}$-Sutcliffe statistic; $\mathrm{EQ}=$ Chlorophyll a concentration evaluated by setting $\mathrm{dB} / \mathrm{dt}$ to 0 ; $\mathrm{RK}=$ Chlorophyll a concentration evaluated using Runge-Kutta approach; INIT=Initial size of sediment reservoir calculated with original starting concentration $1,000 \mathrm{mg} \mathrm{P} / \mathrm{kg}$ sediment; INIT NEW=Initial size of sediment reservoir recalculated with starting concentration $335 \mathrm{mg} \mathrm{P} / \mathrm{kg}$ sediment; REC pH=Model relies on $\mathrm{pH}$-dependent recycle mechanism; $\mathrm{REC}_{-} \mathrm{T}=$ model relies on temperature-dependent recycle mechanism; $\mathrm{P} \_00=$ Phosphorus limitation factor calculated as the percent of non-algal P; P_MM=Phosphorus limitation factor calculated by Michaelis-Menten kinetics; L_AVG=Light limitation factor calculated using the average light intensity; L_DI=Average light limitation factor calculated by depth-integrating the light limitation equation. Model characteristics and parameters are defined in the text.]

\begin{tabular}{|c|c|c|c|c|c|c|c|c|c|c|c|c|c|c|c|c|c|}
\hline \multirow[b]{2}{*}{$\begin{array}{l}\text { Model } \\
\text { version }\end{array}$} & \multirow[b]{2}{*}{$\begin{array}{c}\text { Compare } \\
\text { to } \\
\text { version }\end{array}$} & \multicolumn{6}{|c|}{ Model Characteristics } & \multicolumn{5}{|c|}{ Model Calibration Parameters } & \multicolumn{5}{|c|}{ Performance Statistics } \\
\hline & & $\begin{array}{c}\text { Chlorophyll a } \\
\text { model }\end{array}$ & $\begin{array}{c}\text { Initial } \\
\text { sediment } \\
\text { reservoir }\end{array}$ & $\begin{array}{c}\text { Recycle } \\
\text { mechanism }\end{array}$ & $\begin{array}{l}\text { Phosphorus } \\
\text { limitation }\end{array}$ & $\begin{array}{c}\text { Light } \\
\text { limitation }\end{array}$ & $\begin{array}{c}U_{\text {alg }} \\
(\mathrm{m} / \mathrm{d})\end{array}$ & $\begin{array}{c}K_{R} \\
\text { (per yr) }\end{array}$ & $\mathrm{pH}^{*}$ & $\begin{array}{c}K_{T} \\
\text { (per yr) }\end{array}$ & $\begin{array}{c}T^{*} \\
\left({ }^{\circ} \mathrm{C}\right)\end{array}$ & $\begin{array}{c}k_{\text {half }} \\
(\mathrm{ppm})\end{array}$ & $\mathbf{R}$ & $\mathbf{R}^{2}$ & $\begin{array}{l}\text { Bias } \\
\text { (ppb) }\end{array}$ & $\begin{array}{l}\text { RMSE } \\
\text { (ppb) }\end{array}$ & NS \\
\hline \multicolumn{18}{|c|}{ Original model with original calibration } \\
\hline$O$ & & EQ & INIT & $\mathrm{REC} \_\mathrm{pH}$ & P_00 & L_AVG & 0.05 & 0.53 & 9.1 & NA & NA & NA & 0.56 & 0.32 & -48.6 & 109.6 & -0.58 \\
\hline$O^{\prime}$ & $O$ & EQ & INIT_NEW & $\mathrm{REC} \_\mathrm{pH}$ & P_00 & L_AVG & 0.05 & 1.33 & 9.0 & NA & NA & NA & 0.60 & 0.36 & -23.3 & 83.7 & 0.08 \\
\hline \multicolumn{18}{|c|}{ Recalibration of original model } \\
\hline$A$ & $O$ & EQ & INIT & REC_pH & P_00 & L_AVG & 0.059 & 0.47 & 9.0 & NA & NA & NA & 0.59 & 0.35 & -24.7 & 86.9 & 0.01 \\
\hline$A^{\prime}$ & $A$ & EQ & INIT_NEW & REC_pH & P_00 & L_AVG & 0.059 & 1.24 & 8.9 & NA & NA & NA & 0.61 & 0.38 & -10.4 & 75.1 & 0.26 \\
\hline \multicolumn{18}{|c|}{ Modifications to light and phosphorus limitation } \\
\hline$B$ & $A$ & EQ & INIT & REC_pH & P_MM & L_DI & 0.035 & 0.32 & 8.6 & NA & NA & 0.06 & 0.58 & 0.34 & -23.3 & 82.8 & 0.10 \\
\hline$B^{\prime}$ & $B$ & EQ & INIT_NEW & REC_pH & P_MM & L_DI & 0.035 & 1.05 & 8.7 & NA & NA & 0.06 & 0.60 & 0.35 & -23.4 & 83.1 & 0.10 \\
\hline \multicolumn{18}{|c|}{ Temperature-dependent recycling } \\
\hline$C$ & $B$ & EQ & INIT & REC_T & P_MM & L_DI & 0.035 & NA & NA & 0.54 & 12.8 & 0.06 & 0.59 & 0.35 & -31.8 & 90.7 & -0.08 \\
\hline$C^{\prime}$ & $C$ & EQ & INIT_NEW & REC_T & P_MM & L_DI & 0.035 & NA & NA & 1.62 & 12.8 & 0.06 & 0.60 & 0.36 & -25.1 & 84.8 & 0.06 \\
\hline \multicolumn{18}{|c|}{ Runge-Kutta solution of chlorophyll a } \\
\hline$D$ & $B$ & RK & INIT & REC_pH & P_MM & L_DI & 0.035 & 0.34 & 8.1 & NA & NA & 0.06 & 0.38 & 0.15 & -60.0 & 114.9 & -0.73 \\
\hline$D^{\prime}$ & $D$ & RK & INIT_NEW & REC_pH & P_MM & L_DI & 0.035 & 1.18 & 8.1 & NA & NA & 0.06 & 0.39 & 0.15 & -52.6 & 109.9 & -0.59 \\
\hline
\end{tabular}


Table 10. Comparison of performance statistics for chlorophyll a obtained over a validation period including all months in 1991-1993 and AugustApril in 1994-1998 from model versions discussed in the report.

[The statistics are calculated over a validation period including all months in 1991-1993 and August-April in 1994-1998 ( $\mathrm{N}=83$ ). $\mathrm{R}=$ correlation coefficient; $\mathrm{R}^{2}=$ coefficient of determination; RMSE=root mean square error; NS=Nash-Sutcliffe statistic; $\mathrm{EQ}=$ Chlorophyll a concentration evaluated by setting $\mathrm{dB} / \mathrm{dt}$ to 0 ; $\mathrm{RK}=$ Chlorophyll a concentration evaluated using Runge-Kutta approach; INIT=Initial size of sediment reservoir calculated with original starting concentration $1,000 \mathrm{mg}$ P/kg sediment; INIT_NEW=Initial size of sediment reservoir recalculated with starting concentration $335 \mathrm{mg} \mathrm{P} / \mathrm{kg}$ sediment; REC_pH=Model relies on pH-dependent recycle mechanism; REC_T=model relies on temperature-dependent recycle mechanism; $\mathrm{P} \_00=$ Phosphorus limitation factor calculated as the percent of non-algal P; P_MM=Phosphorus limitation factor calculated by Michaelis-Menten kinetics; $L_{-}$AVG $=$Light limitation factor calculated using the average light intensity; L_DI=Average light limitation factor calculated by depth-integrating the light limitation equation. Model characteristics and parameters are defined in the text.]

\begin{tabular}{|c|c|c|c|c|c|c|c|c|c|c|c|c|c|c|c|c|c|}
\hline \multirow[b]{2}{*}{$\begin{array}{l}\text { Model } \\
\text { version }\end{array}$} & \multirow[b]{2}{*}{$\begin{array}{c}\text { Compare } \\
\text { to } \\
\text { version }\end{array}$} & \multicolumn{5}{|c|}{ Model Characteristics } & \multicolumn{6}{|c|}{ Model Calibration Parameters } & \multicolumn{5}{|c|}{ Performance Statistics } \\
\hline & & $\begin{array}{c}\text { Chlorophyll a } \\
\text { model }\end{array}$ & $\begin{array}{c}\text { Initial } \\
\text { sediment } \\
\text { reservoir }\end{array}$ & $\begin{array}{c}\text { Recycle } \\
\text { mecha- } \\
\text { nism }\end{array}$ & $\begin{array}{l}\text { Phosphorus } \\
\text { limitation }\end{array}$ & $\begin{array}{c}\text { Light } \\
\text { limitation }\end{array}$ & $\begin{array}{c}u_{a l g} \\
(\mathrm{~m} / \mathrm{d})\end{array}$ & $\begin{array}{c}K_{R} \\
\text { (per yr) }\end{array}$ & $p H^{*}$ & $\begin{array}{c}K_{T} \\
\text { (per yr) }\end{array}$ & $\begin{array}{c}T^{*} \\
\left({ }^{\circ} \mathrm{C}\right)\end{array}$ & $\begin{array}{l}\text { Khalf } \\
\text { (ppm) }\end{array}$ & $\mathbf{R}$ & $\mathbf{R}^{2}$ & $\begin{array}{l}\text { Bias } \\
(\mathrm{ppb})\end{array}$ & $\begin{array}{l}\text { RMSE } \\
(\mathrm{ppb})\end{array}$ & NS \\
\hline \multicolumn{18}{|c|}{ Original model with original calibration } \\
\hline$O$ & & EQ & INIT & REC_pH & P_00 & L_AVG & 0.05 & 0.53 & 9.1 & NA & NA & NA & 0.42 & 0.17 & -56.5 & 129.6 & -1.77 \\
\hline$O^{\prime}$ & $O$ & EQ & INIT_NEW & REC_pH & P_00 & L_AVG & 0.05 & 1.33 & 9.0 & NA & NA & NA & 0.43 & 0.18 & -45.7 & 115.0 & -1.18 \\
\hline \multicolumn{18}{|c|}{ Recalibration of original model } \\
\hline$A$ & $A^{\prime}$ & EQ & INIT & REC_pH & P_00 & L_AVG & 0.059 & 0.47 & 9.0 & NA & NA & NA & 0.42 & 0.18 & -41.1 & 112.3 & -1.08 \\
\hline$A^{\prime}$ & A & EQ & INIT_NEW & REC_pH & P_00 & L_AVG & 0.059 & 1.24 & 8.9 & NA & NA & NA & 0.43 & 0.18 & -34.7 & 103.9 & -0.78 \\
\hline \multicolumn{18}{|c|}{ Modifications to light and phosphorus limitation } \\
\hline$B$ & $A$ & EQ & INIT & REC_pH & P_MM & L_DI & 0.035 & 0.32 & 8.6 & NA & NA & 0.06 & 0.40 & 0.16 & -51.1 & 127.5 & -1.68 \\
\hline$B^{\prime}$ & $B$ & EQ & INIT_NEW & REC_pH & P_MM & L_DI & 0.035 & 1.05 & 8.7 & NA & NA & 0.06 & 0.40 & 0.16 & -52.0 & 129.6 & -1.77 \\
\hline \multicolumn{18}{|c|}{ Temperature-dependent recycling } \\
\hline C & $B$ & EQ & INIT & REC_T & P_MM & L_DI & 0.035 & NA & NA & 0.54 & 12.8 & 0.06 & 0.36 & 0.13 & -59.2 & 143.3 & -2.39 \\
\hline$C^{\prime}$ & C & EQ & INIT_NEW & REC_T & P_MM & L_DI & 0.035 & NA & NA & 1.62 & 12.8 & 0.06 & 0.37 & 0.14 & -55.7 & 138.4 & -2.16 \\
\hline \multicolumn{18}{|c|}{ Runge-Kutta solution of chlorophyll a } \\
\hline$D$ & $B$ & RK & INIT & REC_pH & P_MM & L_DI & 0.035 & 0.34 & 8.1 & NA & NA & 0.06 & 0.48 & 0.23 & -61.0 & 114.4 & -1.16 \\
\hline$D^{\prime}$ & $D$ & RK & INIT_NEW & $\mathrm{REC} \_\mathrm{pH}$ & P_MM & L_DI & 0.035 & 1.18 & 8.1 & NA & NA & 0.06 & 0.48 & 0.23 & -57.2 & 112.3 & -1.08 \\
\hline
\end{tabular}


Table 11. Comparison of performance statistics for pH obtained over a validation period including all months in 1991-1993 and August-April in 19941998 from model versions discussed in the report.

[The statistics are calculated over a validation period including all months, 1991-1993 and August-April, 1994-1998 (N=83). R=correlation coefficient; $\mathrm{R}^{2}=$ coefficient of determination; RMSE=root mean square error; $\mathrm{NS}=$ Nash-Sutcliffe statistic; $\mathrm{EQ}=$ Chlorophyll $a$ concentration evaluated by setting $\mathrm{dB} / \mathrm{dt}$ to 0 ; $\mathrm{RK}=$ Chlorophyll $a$ concentration evaluated using Runge-Kutta approach; INIT=Initial size of sediment reservoir calculated with original starting concentration $1,000 \mathrm{mg}$ P/kg sediment; INIT_NEW=Initial size of sediment reservoir recalculated with starting concentration $335 \mathrm{mg} \mathrm{P} / \mathrm{kg}$ sediment; REC_pH=Model relies on $\mathrm{pH}$-dependent recycle mechanism; REC $\mathrm{T}=$ model relies on temperature-dependent recycle mechanism; $\mathrm{P} 00=$ Phosphorus limitation factor calculated as the percent of non-algal P; P_MM=Phosphorus limitation factor calculated by Michaelis-Menten kinetics; L_AVG=Light limitation factor calculated using the average light intensity; L_DI=Average light limitation factor calculated by depth-integrating the light limitation equation. Model characteristics and parameters are defined in the text.]

\begin{tabular}{|c|c|c|c|c|c|c|c|c|c|c|c|c|c|c|c|c|c|}
\hline \multirow[b]{2}{*}{$\begin{array}{l}\text { Model } \\
\text { version }\end{array}$} & \multirow[b]{2}{*}{$\begin{array}{c}\text { Compare } \\
\text { to } \\
\text { version }\end{array}$} & \multicolumn{5}{|c|}{ Model characteristics } & \multicolumn{6}{|c|}{ Model calibration parameters } & \multicolumn{5}{|c|}{ Performance statistics } \\
\hline & & $\begin{array}{c}\text { Chlorophyll a } \\
\text { model }\end{array}$ & $\begin{array}{c}\text { Initial } \\
\text { sediment } \\
\text { reservoir }\end{array}$ & $\begin{array}{c}\text { Recycle } \\
\text { mechanism }\end{array}$ & $\begin{array}{c}\text { Phosphorus } \\
\text { limitation }\end{array}$ & $\begin{array}{c}\text { Light } \\
\text { limitation }\end{array}$ & $\begin{array}{c}u_{a l g} \\
(\mathrm{~m} / \mathrm{d})\end{array}$ & $\begin{array}{c}K_{R} \\
\text { (per yr) }\end{array}$ & $p H^{*}$ & $\begin{array}{c}K_{T} \\
\text { (per yr) }\end{array}$ & $\begin{array}{c}T^{*} \\
\left({ }^{\circ} \mathrm{C}\right)\end{array}$ & $\begin{array}{c}K_{\text {half }} \\
\text { (ppm) }\end{array}$ & $\mathbf{R}$ & $\mathbf{R}^{2}$ & Bias & RMSE & NS \\
\hline \multicolumn{18}{|c|}{ Original model with original calibration } \\
\hline$O$ & & EQ & INIT & REC_pH & P_00 & L_AVG & 0.05 & 0.53 & 9.1 & NA & NA & NA & 0.57 & 0.32 & -0.195 & 0.716 & -0.09 \\
\hline$O^{\prime}$ & $O$ & EQ & INIT_NEW & REC_pH & P_00 & L_AVG & 0.05 & 1.33 & 9.0 & NA & NA & NA & 0.56 & 0.32 & -0.175 & 0.703 & -0.05 \\
\hline \multicolumn{18}{|c|}{ Recalibration of original model } \\
\hline$A$ & $A^{\prime}$ & EQ & INIT & REC_pH & P_00 & L_AVG & 0.059 & 0.47 & 9.0 & NA & NA & NA & 0.56 & 0.31 & -0.155 & 0.700 & -0.04 \\
\hline$A^{\prime}$ & $A$ & EQ & INIT_NEW & REC_pH & P_00 & L_AVG & 0.059 & 1.24 & 8.9 & NA & NA & NA & 0.55 & 0.31 & -0.143 & 0.694 & -0.02 \\
\hline \multicolumn{18}{|c|}{ Modifications to light and phosphorus limitation } \\
\hline$B$ & $A$ & EQ & INIT & REC_pH & P_MM & L_DI & 0.035 & 0.32 & 8.6 & NA & NA & 0.06 & 0.57 & 0.33 & -0.161 & 0.704 & -0.05 \\
\hline$B^{\prime}$ & $B$ & EQ & INIT_NEW & REC_pH & P_MM & L_DI & 0.035 & 1.05 & 8.7 & NA & NA & 0.06 & 0.58 & 0.33 & -0.157 & 0.699 & -0.04 \\
\hline \multicolumn{18}{|c|}{ Temperature-dependent recycling } \\
\hline$C$ & $B$ & EQ & INIT & REC_T & P_MM & L_DI & 0.035 & NA & NA & 0.54 & 12.8 & 0.06 & 0.57 & 0.32 & -0.175 & 0.716 & -0.09 \\
\hline$C^{\prime}$ & C & EQ & INIT_NEW & REC_T & P_MM & L_DI & 0.035 & NA & NA & 1.62 & 12.8 & 0.06 & 0.57 & 0.32 & -0.168 & 0.712 & -0.07 \\
\hline \multicolumn{18}{|c|}{ Runge-Kutta solution of chlorophyll a } \\
\hline$D$ & $B$ & RK & INIT & REC_pH & P_MM & L_DI & 0.035 & 0.34 & 8.1 & NA & NA & 0.06 & 0.64 & 0.41 & -0.247 & 0.622 & 0.18 \\
\hline$D^{\prime}$ & $D$ & RK & INIT_NEW & REC_pH & P_MM & L_DI & 0.035 & 1.18 & 8.1 & NA & NA & 0.06 & 0.65 & 0.42 & -0.235 & 0.612 & 0.21 \\
\hline
\end{tabular}

Several parameters in the model were calibrated using data from only May, June, and July, when the bloom is in a rapid growth phase; the performance of the model was tested over those months alone. Tables 12-14 compare model statistics for May-July 1991-1993 (years not used in the calibration). Model performance was better during this limited validation period than during the longer validation period included in the statistics presented in tables 9-11 for all variables and both models, as indicated by larger $\mathrm{R}^{2}$ values, smaller bias, and positive NS statistics. $\mathrm{R}^{2}$ was 0.89 or 0.86 for total phosphorus, 0.55 or 0.56 for 
chlorophyll $a$ (version $O$ and $A$, respectively), and 0.56 (both versions) for $\mathrm{pH}$. The NS statistic was 0.88 and 0.81 for total phosphorus, 0.28 or 0.40 for chlorophyll $a$, and 0.19 or 0.22 for $\mathrm{pH}$ (version $O$ and $A$, respectively). The bias was positive for total phosphorus and negative for chlorophyll $a$ and $\mathrm{pH}$ (both versions), indicating that over this limited validation period that included only spring through mid-summer months, the model overpredicted total phosphorus, but still underpredicted chlorophyll $a$ and $\mathrm{pH}$. Based on these statistics, the recalibrated model (version $A$ ) simulated total phosphorus concentration slightly worse than, and $\mathrm{pH}$ and chlorophyll $a$ concentration slightly better than, the original model and calibration (version $O$ ), but the differences in the performance statistics were small.

Table 12. Comparison of performance statistics for total phosphorus over a validation period including May-July 1991-1993 obtained from various model versions discussed in the report.

[The statistics are calculated over a validation period including May-July 1991-1993 ( $\mathrm{N}=16) . \mathrm{R}=$ correlation coefficient; $\mathrm{R}^{2}=$ coefficient of determination; RMSE=root mean square error; NS=Nash-Sutcliffe statistic; $\mathrm{EQ}=$ Chlorophyll $a$ concentration evaluated by setting $\mathrm{dB} / \mathrm{dt}$ to 0 ; RK=Chlorophyll $a$ concentration evaluated using Runge-Kutta approach; INIT=Initial size of sediment reservoir calculated with original starting concentration 1,000 mg P/kg sediment; INIT_NEW=Initial size of sediment reservoir recalculated with starting concentration $335 \mathrm{mg} \mathrm{P} / \mathrm{kg}$ sediment; REC_pH=Model relies on $\mathrm{pH}$-dependent recycle mechanism; REC_T=model relies on temperature-dependent recycle mechanism; $\mathrm{P}_{\mathbf{C}} 00=$ Phosphorus limitation factor calculated as the percent of non-algal $\mathrm{P}$; P $\_M M=$ Phosphorus limitation factor calculated by Michaelis-Menten kinetics; $L$ AVG=Light limitation factor calculated using the average light intensity;

L_DI=Average light limitation factor calculated by depth-integrating the light limitation equation. Model characteristics and parameters are defined in the text.]

\begin{tabular}{|c|c|c|c|c|c|c|c|c|c|c|c|c|c|c|c|c|c|}
\hline \multirow[b]{2}{*}{$\begin{array}{c}\text { Model } \\
\text { version }\end{array}$} & \multirow[b]{2}{*}{$\begin{array}{c}\text { Compare } \\
\text { to } \\
\text { version }\end{array}$} & \multicolumn{5}{|c|}{ Model characteristics } & \multicolumn{6}{|c|}{ Model calibration parameters } & \multicolumn{5}{|c|}{ Performance statistics } \\
\hline & & $\begin{array}{c}\text { Chlorophyll a } \\
\text { model }\end{array}$ & $\begin{array}{c}\text { Initial } \\
\text { sediment } \\
\text { reservoir }\end{array}$ & $\begin{array}{c}\text { Recycle } \\
\text { mechanism }\end{array}$ & $\begin{array}{l}\text { Phosphorus } \\
\text { limitation }\end{array}$ & $\begin{array}{l}\text { Light } \\
\text { limitation }\end{array}$ & $\begin{array}{c}u_{a l g} \\
(\mathrm{~m} / \mathrm{d})\end{array}$ & $\begin{array}{c}K_{R} \\
\text { (per yr) }\end{array}$ & $p H^{*}$ & $\begin{array}{c}K_{T} \\
\text { (per yr) }\end{array}$ & $\begin{array}{c}T^{*} \\
\left({ }^{\circ} \mathrm{C}\right)\end{array}$ & $\begin{array}{l}k_{\text {half }} \\
(\mathrm{ppm})\end{array}$ & $\mathbf{R}$ & $\mathbf{R}^{2}$ & $\begin{array}{l}\text { Bias } \\
\text { (ppb) }\end{array}$ & $\begin{array}{l}\text { RMSE } \\
(\mathrm{ppb})\end{array}$ & NS \\
\hline \multicolumn{18}{|c|}{ Original model with original calibration } \\
\hline$O$ & & EQ & INIT & REC_pH & P_00 & L_AVG & 0.05 & 0.53 & 9.1 & NA & NA & NA & 0.94 & 0.89 & 8.3 & 28.8 & 0.88 \\
\hline$O^{\prime}$ & $O$ & EQ & INIT_NEW & REC_pH & P_00 & L_AVG & 0.05 & 1.33 & 9.0 & NA & NA & NA & 0.92 & 0.85 & 9.7 & 35.9 & 0.82 \\
\hline \multicolumn{18}{|c|}{ Recalibration of original model } \\
\hline$A$ & $O$ & EQ & INIT & REC_pH & P_00 & L_AVG & 0.059 & 0.47 & 9.0 & NA & NA & NA & 0.93 & 0.86 & 14.9 & 36.5 & 0.81 \\
\hline$A^{\prime}$ & $A$ & EQ & INIT_NEW & REC_pH & P_00 & L_AVG & 0.059 & 1.24 & 8.9 & NA & NA & NA & 0.90 & 0.81 & 13.7 & 43.1 & 0.74 \\
\hline \multicolumn{18}{|c|}{ Modifications to light and phosphorus limitation } \\
\hline$B$ & $A$ & EQ & INIT & REC_pH & P_MM & L_DI & 0.035 & 0.32 & 8.6 & NA & NA & 0.06 & 0.94 & 0.88 & 17.4 & 39.3 & 0.78 \\
\hline$B^{\prime}$ & $B$ & EQ & INIT_NEW & REC_pH & P_MM & L_DI & 0.035 & 1.05 & 8.7 & NA & NA & 0.06 & 0.96 & 0.92 & 21.6 & 36.6 & 0.81 \\
\hline \multicolumn{18}{|c|}{ Temperature-dependent recycling } \\
\hline$C$ & $B$ & EQ & INIT & REC_T & P_MM & L_DI & 0.035 & NA & NA & 0.54 & 12.8 & 0.06 & 0.95 & 0.91 & 25.8 & 44.1 & 0.72 \\
\hline$C^{\prime}$ & $C$ & EQ & INIT_NEW & REC_T & P_MM & L_DI & 0.035 & NA & NA & 1.62 & 12.8 & 0.06 & 0.95 & 0.90 & 26.6 & 45.6 & 0.71 \\
\hline \multicolumn{18}{|c|}{ Runge-Kutta solution of chlorophyll a } \\
\hline$D$ & $B$ & RK & INIT & REC_pH & P_MM & L_DI & 0.035 & 0.34 & 8.1 & NA & NA & 0.06 & 0.94 & 0.88 & -6.8 & 34.4 & 0.83 \\
\hline$D^{\prime}$ & $D$ & RK & INIT_NEW & REC_pH & P_MM & L_DI & 0.035 & 1.18 & 8.1 & NA & NA & 0.06 & 0.94 & 0.88 & -14.3 & 35.5 & 0.82 \\
\hline
\end{tabular}


Table 13. Comparison of performance statistics for chlorophyll a obtained over a validation period including May-July 1991-1993 from model versions discussed in the report.

[The statistics are calculated over a validation period including May-July 1991-1993 ( $\mathrm{N}=16) . \mathrm{R}=$ correlation coefficient; $\mathrm{R}^{2}=$ coefficient of determination; RMSE=root mean square error; NS=Nash-Sutcliffe statistic; $\mathrm{EQ}=$ Chlorophyll $a$ concentration evaluated by setting $\mathrm{dB} / \mathrm{dt}$ to 0 ; RK=Chlorophyll $a$ concentration evaluated using Runge-Kutta approach; INIT=Initial size of sediment reservoir calculated with original starting concentration 1,000 mg P/kg sediment;

INIT_NEW=Initial size of sediment reservoir recalculated with starting concentration $335 \mathrm{mg}$ P/kg sediment; REC_pH=Model relies on pH-dependent recycle mechanism; REC T=model relies on temperature-dependent recycle mechanism; P $00=$ Phosphorus limitation factor calculated as the percent of non-algal $\mathrm{P}$;

P_MM=Phosphorus limitation factor calculated by Michaelis-Menten kinetics; $L_{-} \mathrm{AVG}=$ Light limitation factor calculated using the average light intensity;

L_DI=Average light limitation factor calculated by depth-integrating the light limitation equation. Model characteristics and parameters are defined in the text.R, correlation coefficient; $\mathrm{R}^{2}$, coefficient of determination; RMSE, root mean square error; NS, Nash-Sutcliffe statistic. Model characteristics and parameters are defined in the text.]

\begin{tabular}{|c|c|c|c|c|c|c|c|c|c|c|c|c|c|c|c|c|c|}
\hline \multirow[b]{2}{*}{$\begin{array}{c}\text { Model } \\
\text { version }\end{array}$} & \multirow[b]{2}{*}{$\begin{array}{c}\text { Compare } \\
\text { to } \\
\text { version }\end{array}$} & \multicolumn{5}{|c|}{ Model characteristics } & \multicolumn{6}{|c|}{ Model calibration parameters } & \multicolumn{5}{|c|}{ Performance statistics } \\
\hline & & $\begin{array}{c}\text { Chlorophyll a } \\
\text { model }\end{array}$ & $\begin{array}{c}\text { Initial } \\
\text { sediment } \\
\text { reservoir }\end{array}$ & $\begin{array}{c}\text { Recycle } \\
\text { mechanism }\end{array}$ & $\begin{array}{l}\text { Phosphorus } \\
\text { limitation }\end{array}$ & $\begin{array}{l}\text { Light } \\
\text { limitation }\end{array}$ & $\begin{array}{c}\text { Ualg } \\
(\mathrm{m} / \mathrm{d})\end{array}$ & $\begin{array}{c}K_{R} \\
\text { (per yr) }\end{array}$ & $\mathrm{pH}^{*}$ & $\begin{array}{c}K_{T} \\
\text { (per yr) }\end{array}$ & $\begin{array}{l}T^{*} \\
\left({ }^{\circ} \mathrm{C}\right)\end{array}$ & $\begin{array}{c}\begin{array}{c}k_{\text {half }} \\
(\mathrm{ppm})\end{array}\end{array}$ & $\mathbf{R}$ & $\mathbf{R}^{2}$ & $\begin{array}{l}\text { Bias } \\
\text { (ppb) }\end{array}$ & $\begin{array}{l}\text { RMSE } \\
(\mathrm{ppb})\end{array}$ & NS \\
\hline \multicolumn{18}{|c|}{ Original model with original calibration } \\
\hline$O$ & & EQ & INIT & REC_pH & P_00 & L_AVG & 0.05 & 0.53 & 9.1 & NA & NA & NA & 0.74 & 0.55 & -48.9 & 85.4 & 0.28 \\
\hline$O^{\prime}$ & $O$ & EQ & INIT_NEW & REC_pH & P_00 & L_AVG & 0.05 & 1.33 & 9.0 & NA & NA & NA & 0.75 & 0.56 & -48 & 82.3 & 0.33 \\
\hline \multicolumn{18}{|c|}{ Recalibration of original model } \\
\hline$A$ & $A^{\prime}$ & EQ & INIT & REC_pH & P_00 & L_AVG & 0.059 & 0.47 & 9.0 & NA & NA & NA & 0.75 & 0.56 & -39.6 & 77.8 & 0.40 \\
\hline$A^{\prime}$ & $A$ & EQ & INIT_NEW & REC_pH & P_00 & L_AVG & 0.059 & 1.24 & 8.9 & NA & NA & NA & 0.75 & 0.56 & -40.6 & 78.0 & 0.40 \\
\hline \multicolumn{18}{|c|}{ Modifications to light and phosphorus limitation } \\
\hline$B$ & A & EQ & INIT & REC_pH & P_MM & L_DI & 0.035 & 0.32 & 8.6 & NA & NA & 0.06 & 0.77 & 0.59 & -37.6 & 77.1 & 0.41 \\
\hline$B^{\prime}$ & $B$ & EQ & INIT_NEW & REC_pH & P_MM & L_DI & 0.035 & 1.05 & 8.7 & NA & NA & 0.06 & 0.77 & 0.59 & -33.4 & 76.2 & 0.43 \\
\hline \multicolumn{18}{|c|}{ Temperature-dependent recycling } \\
\hline C & $B$ & EQ & INIT & REC_T & P_MM & L_DI & 0.035 & NA & NA & 0.54 & 12.8 & 0.06 & 0.75 & 0.56 & -27.5 & 74.0 & 0.46 \\
\hline$C^{\prime}$ & C & EQ & INIT_NEW & REC_T & P_MM & L_DI & 0.035 & NA & NA & 1.62 & 12.8 & 0.06 & 0.75 & 0.56 & -26.6 & 73.1 & 0.47 \\
\hline \multicolumn{18}{|c|}{ Runge-Kutta solution of chlorophyll a } \\
\hline$D$ & $B$ & RK & INIT & REC_pH & P_MM & L_DI & 0.035 & 0.34 & 8.1 & NA & NA & 0.06 & 0.81 & 0.65 & 11.6 & 61.4 & 0.63 \\
\hline$D^{\prime}$ & $D$ & RK & INIT_NEW & REC_pH & P_MM & L_DI & 0.035 & 1.18 & 8.1 & NA & NA & 0.06 & 0.80 & 0.65 & 7.6 & 61.8 & 0.62 \\
\hline
\end{tabular}


Table 14. Comparison of performance statistics for pH obtained over a validation period including May-July 1991-1993 from various model versions discussed in the report.

[The statistics are calculated over a validation period including May-July, 1991-1993 ( $\mathrm{N}=16)$. $\mathrm{R}=$ correlation coefficient; $\mathrm{R}^{2}=$ coefficient of determination;

$\mathrm{RMSE}=$ root mean square error; NS=Nash-Sutcliffe statistic; $\mathrm{EQ}=$ Chlorophyll $a$ concentration evaluated by setting $\mathrm{dB} / \mathrm{dt}$ to 0 ; RK=Chlorophyll $a$ concentration evaluated using Runge-Kutta approach; INIT=Initial size of sediment reservoir calculated with original starting concentration $1000 \mathrm{mg}$ P/kg sediment; INIT_NEW=Initial size of sediment reservoir recalculated with starting concentration $335 \mathrm{mg}$ P/kg sediment; REC_pH=Model relies on pH-dependent recycle mechanism;

REC T=model relies on temperature-dependent recycle mechanism; P $00=$ Phosphorus limitation factor calculated as the percent of non-algal P; P MM=Phosphorus limitation factor calculated by Michaelis-Menten kinetics; $L_{-}$AVG $=$Light limitation factor calculated using the average light intensity; $L_{-}$DI=Average light limitation factor calculated by depth-integrating the light limitation equation. Model characteristics and parameters are defined in the text.]

\begin{tabular}{|c|c|c|c|c|c|c|c|c|c|c|c|c|c|c|c|c|c|}
\hline \multirow[b]{2}{*}{$\begin{array}{c}\text { Model } \\
\text { version }\end{array}$} & \multirow[b]{2}{*}{$\begin{array}{c}\text { Compare } \\
\text { to } \\
\text { version }\end{array}$} & \multicolumn{5}{|c|}{ Model characteristics } & \multicolumn{6}{|c|}{ Model calibration parameters } & \multicolumn{5}{|c|}{ Performance statistics } \\
\hline & & $\begin{array}{c}\text { Chlorophyll a } \\
\text { model }\end{array}$ & $\begin{array}{c}\text { Initial } \\
\text { Sediment } \\
\text { Reservoir }\end{array}$ & $\begin{array}{c}\text { Recycle } \\
\text { mechanism }\end{array}$ & $\begin{array}{l}\text { Phosphorus } \\
\text { limitation }\end{array}$ & $\begin{array}{c}\text { Light } \\
\text { limitation }\end{array}$ & $\begin{array}{c}\text { Ualg } \\
\text { (m/d) }\end{array}$ & $\begin{array}{c}K_{R} \\
\text { (per yr) }\end{array}$ & $\mathrm{pH}^{*}$ & $\begin{array}{c}K_{T} \\
\text { (per yr) }\end{array}$ & $\begin{array}{c}T^{*} \\
\left({ }^{\circ} \mathrm{C}\right)\end{array}$ & $\begin{array}{c}k_{\text {half }} \\
\text { (ppm) }\end{array}$ & $\mathbf{R}$ & $\mathbf{R}^{2}$ & Bias & RMSE & NS \\
\hline \multicolumn{18}{|c|}{ Original model with original calibration } \\
\hline$O$ & & EQ & INIT & REC_pH & P_00 & L_AVG & 0.05 & 0.53 & 9.1 & NA & NA & NA & 0.75 & 0.56 & -0.443 & 0.659 & 0.19 \\
\hline$O^{\prime}$ & $O$ & EQ & INIT_NEW & REC_pH & P_00 & L_AVG & 0.05 & 1.33 & 9.0 & NA & NA & NA & 0.73 & 0.54 & -0.456 & 0.677 & 0.14 \\
\hline \multicolumn{18}{|c|}{ Recalibration of original model } \\
\hline \multicolumn{18}{|c|}{ Modifications to light and phosphorus limitation } \\
\hline$B$ & $A$ & EQ & INIT & REC_pH & P_MM & L_DI & 0.035 & 0.32 & 8.6 & NA & NA & 0.06 & 0.74 & 0.55 & -0.320 & 0.589 & 0.35 \\
\hline$B^{\prime}$ & $B$ & EQ & INIT_NEW & REC_pH & P_MM & L_DI & 0.035 & 1.05 & 8.7 & NA & NA & 0.06 & 0.78 & 0.60 & -0.279 & 0.541 & 0.45 \\
\hline \multicolumn{18}{|c|}{ Temperature-dependent recycling } \\
\hline C & $B$ & EQ & INIT & REC_T & P_MM & L_DI & 0.035 & NA & NA & 0.54 & 12.8 & 0.06 & 0.77 & 0.60 & -0.300 & 0.551 & 0.43 \\
\hline
\end{tabular}


The primary reason for poorer model statistics when months outside of May-July were included in the calculation is the inability of the model to replicate algal decline in AugustOctober. Simulated values of chlorophyll $a$ and total phosphorus (of which algal phosphorus is the largest component) were much higher (as much as 4 times) than observed values during those months (fig. 7). A positive feedback inherent in the model contributes to the discrepancybecause there is no modeled midseason bloom decline, higher-than-observed chlorophyll $a$ values result in higher-than-observed $\mathrm{pH}$ values, according to the $\mathrm{pH}$ submodel (eq. 20). These higher-than-observed $\mathrm{pH}$ values induce more recycling (eq. 2), which elevates the amount of bioavailable phosphorus in the water column, which feeds back into the growth term in the chlorophyll $a$ model (eq. 11).

\section{Sensitivity of Calibration Parameters to Model Modifications}

In the process of reviewing the model equations, we identified a few easily implemented improvements. These included modifications to the mathematical forms of limitation factors (light and phosphorus) and elimination of the assumption that chlorophyll $a$ concentration is in instantaneous equilibrium with light, temperature, and nutrients.

Updated information regarding the size and forms of the phosphorus reservoir in the bed sediments prompted investigation of two additional modifications. The first modification was a change in the initial size of the sediment phosphorus reservoir. The second was a change in the form of the phosphorus recycling term to simulate a mechanism of recycling that would depend more on temperature than on $\mathrm{pH}$ and likely would draw on the sizable organic phosphorus fraction as a source. Each of the considered modifications to the model required that the calibrations of the algal settling rate and (or) internal recycling be revisited. One of the modifications (temperaturedependent recycling) replaced the calibration pa- rameters in the internal recycling component of the model with new parameters. We investigated the sensitivity of the calibration parameters to the various model modifications and compared the simulated results produced by the original and recalibrated model versions.

\section{Growth Limitation Factors}

Phosphorus and light availability limit algal growth in the original model (section "Chlorophyll a Submodel"). The phosphorus limitation is calculated as the percentage of available (nonalgal) phophorus in the water column, and light limitation is calculated with an application of Talling's (1957) equation, substituting average light intensity in the water column for light at a particular depth. As part of the validation process, we replaced these equations with other known and accepted equations (Bowie and others, 1985) using a Michaelis-Menten kinetics approach for phosphorus limitation and a depth-integrated Talling equation approach for light limitation.

In the original model, using the percentage of nonalgal phosphorus as $F_{P}$ (eq. 19) can result in little phosphorus limitation (even at very low concentrations) when nonalgal phosphorus is a large fraction of the total phosphorus, and much phosphorus limitation (even at very high concentrations) when nonalgal phosphorus is a small fraction of the total. As an alternative, MichaelisMenten kinetics is a well-known and accepted functionality between a reaction rate and the concentration of a substrate that allows the reaction rate (in this case, algal growth rate) to go to zero as the concentration of the substrate (in this case, nonalgal phosphorus concentration) goes to zero, and to approach a maximum value asymptotically as the concentration of the substrate becomes very large. The equation for $F_{P}$ presented in Bowie and others (1985), maintains MichaelisMenten kinetics for all values:

$F_{P M M}=\frac{P_{n a}}{k_{\text {half }}+P_{n a}}$. 
Equation 25 was substituted for equation 19 in a modified model, denoted version $B$ in tables 9 14.

The light-limitation function in the original model provides the light-limitation factor for whatever depth is associated with the average light intensity (eq. 17). Alternatively, integrating the Talling function over depth provides the average light limitation over the entire lake depth, $z$ :

$F_{L D I}=\frac{f_{p}}{E_{C} z} \ln \left[\frac{\frac{I_{0}}{I_{K}}+\left(1+\left(\frac{I_{0}}{I_{K}}\right)^{2}\right)^{\frac{1}{2}}}{\frac{I_{0}}{I_{K}} e^{-E_{C} z}+\left(1+\left(\frac{I_{0}}{I_{K}} e^{-E_{C} z}\right)^{2}\right)^{\frac{1}{2}}}\right]$

Equation 26 was substituted for equation 17 in version $B$ of the model (tables 9-14).

Because $F_{P}$ and $F_{L}$ are used in the chlorophyll $a$ submodel, we performed a recalibration of the settling parameter, $u_{\text {alg }}$ (table 4 ), as well as calibration of the new parameter, the halfsaturation constant $k_{\text {half }}$, followed by a recalibration of the recycling parameters (steps 2 and 4 of the calibration process). Calibration of $u_{a l g}$ and the new parameter $k_{\text {half }}$ was accomplished with a trial-and-error approach by evaluating combinations of these two parameters within the range of $0.001-0.2 \mathrm{~m} / \mathrm{d}$ and $0.01-0.06 \mathrm{ppm}$, respectively, based on literature values (Bowie and others, 1985). The effect of the modified limitation factors was to decrease the calibrated settling velocity $u_{\text {alg }}$ from 0.059 to $0.035 \mathrm{~m} / \mathrm{d}$, decrease the calibrated recycle rate $K_{R}$ from 0.47 to $0.32 / \mathrm{yr}$, and decrease the $\mathrm{pH}$ at which recycling is one-half the maximum $\left(p H^{*}\right)$ from 9.0 to 8.6 (tables 9-14). These changes in the calibration parameters are not the result of mechanistic, process-based changes, but rather are a consequence of a change in the balance of terms in equation 14 that was used to calibrate $u_{\text {alg }}$ in step 2 of the calibration process, which in turn changed the calibration of $K_{R}$ and $p H^{*}$ in step 4 of the calibration.

The combined effect of the modifications to the phosphorus and light limitation factors was to decrease the annual peak in total phosphorus concentration relative to the original, recalibrated model because the recycling rate was smaller; even so, the combination of lower algal settling and modification to growth limitation factors resulted in somewhat higher peaks in chlorophyll $a$ and $\mathrm{pH}$ (fig. 8).

Model performance was not substantially changed by the modification of the phosphorus and light limitation expressions, either when statistics were calculated over the full validation period, when performance was particularly poor based on low $\mathrm{R}^{2}$ values, high bias, and low NS values (tables 9-11), or over the limited MayJuly validation period, when performance improved (tables 12-14).

\section{Recycling Mechanism}

Several mechanisms likely contribute to the internal loading of phosphorus from the sediments, including diffusion, desorption, diffusion enhanced by bioturbation, and metabolic cycling. It is impossible to know which of these mechanisms dominates at any given point in time or location in the lake, but given the high density of benthic macroinvertebrates, mechanisms involving benthic macroinvertebrates probably are important at some times and locations. Furthermore, these mechanisms are more likely to depend on temperature than on $\mathrm{pH}$ and would likely draw on the sizable organic phosphorus fraction as a source. A well-developed mathematical description of recycling by the benthic macroinvertebrate community is outside the scope of this study, but one of the dominant features of such a description would include a dependence on temperature. To investigate the sensitivity of the calibration of recycling parameters to the form of the recycling term, we developed a temperature-dependent recycling mechanism analogous to the temperature dependency of cyanobacterial growth in the model. We substituted the temperature-dependent recycling mechanism for the $\mathrm{pH}$-dependent recycling mechanism in model version $B$, which, like the original model, incorporates an internal recycling 

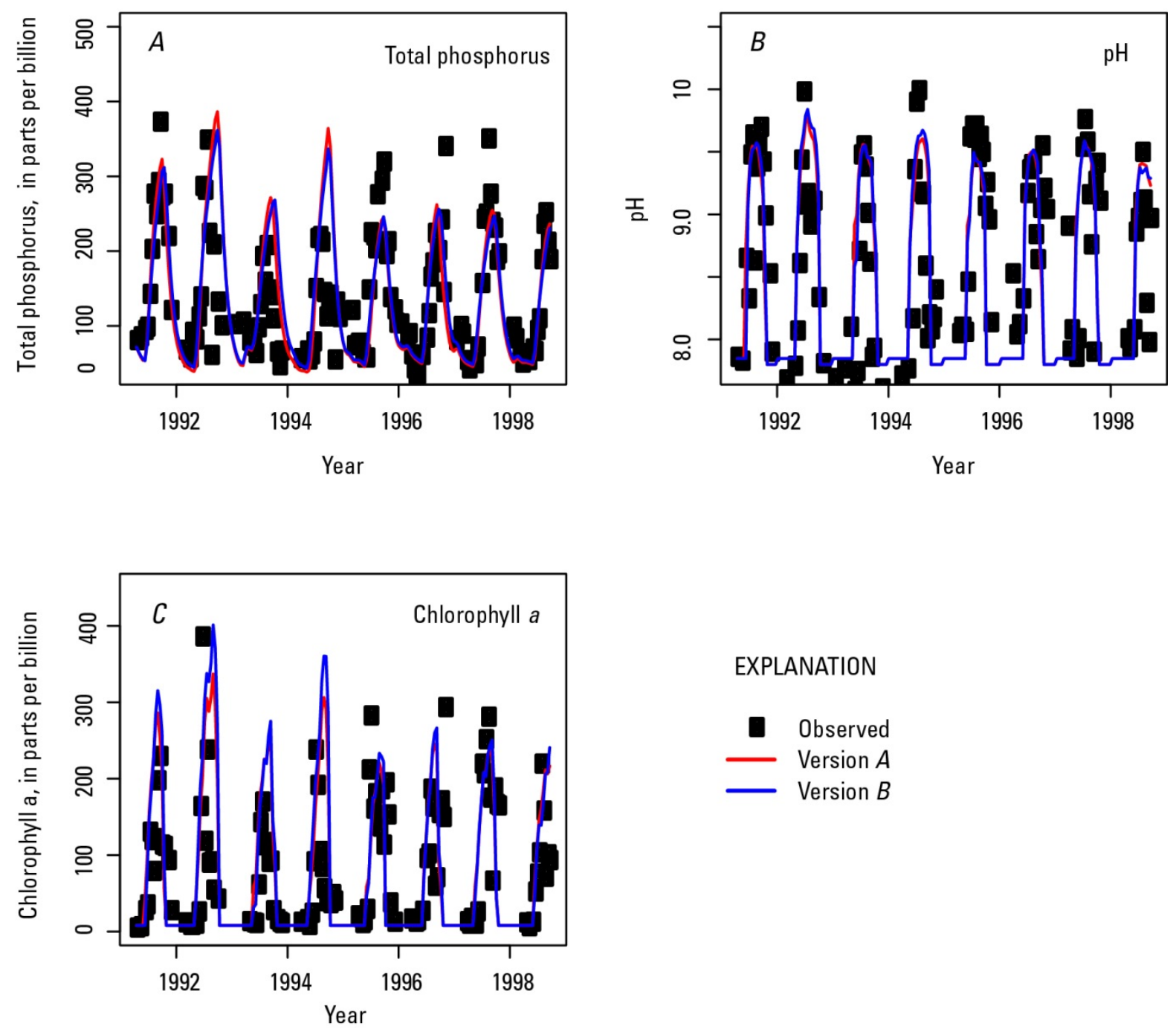

EXPLANATION

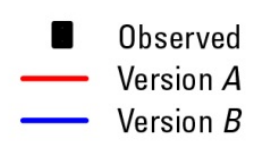

Figure 8. Diagrams showing simulated and observed water column $(A)$ total phosphorus concentration, $(B)$ chlorophyll a concentration, and (C) pH in Upper Klamath Lake, Oregon, April 1991-April 1998. Model version A is the original model (recalibrated) and model version $B$ incorporates modifications to the phosphorus and light limitations to algal growth.mechanism (eq. 22) that depends on $\mathrm{pH}$, the percentage of the lake (represented by percentage of sampling sites) exceeding a threshold $\mathrm{pH}$ denoted $\mathrm{pH}^{*}$ (the $\mathrm{pH}$ at which the recycle rate is one-half the maximum recycle rate, $K_{R}$ ), and the average mass of phosphorus in the sediment reservoir. Thus, equation 22 is a mathematical representation of $\mathrm{pH}$-dependent desorption of phosphorus from poorly crystalline iron oxides in the sediments.

The form of equation 22 derives from a demonstrated dependence of internal recycling on pH during May-July (Walker, 2001). The dependence of internal recycling on temperature can be similarly demonstrated. The calibrated sedimentation terms (nonalgal phosphorus loss rate $K_{n a}$ and the algal settling velocity $u_{a l g}$ from calibration steps 2 and 3 ) were substituted into a discretized version of the water column phosphorus mass balance (eq. 1), and the "observed" recycling at each time step was calculated as:

$$
\begin{aligned}
& M_{\text {rec }, \text { obs }}=\Delta M_{\text {obs }}+M_{\text {out }, o b s}+\left(K_{n a} P_{T, o b s} V \Delta t+\right. \\
& \left.u_{\text {alg }} P_{\text {alg }, o b s} A \Delta t\right)-M_{\text {load,obs }}
\end{aligned}
$$


When these observations of $M_{\text {rec }}$ were plotted against temperature, recycling was seen to increase with temperature, particularly above approximately $13^{\circ} \mathrm{C}$ (fig. 9). A relatively simple form for temperature-dependent recycling in which recycling is proportional to temperature above a threshold value describes the relation evident in figure 9, and also bears a functional resemblance to equation 22 :

$M_{\text {rec_T }}=$
$\left\{\begin{array}{c}\frac{T_{\text {lake }}-T_{\text {min }, \text { rec }}}{T_{\text {max }, \text { rec }}-T_{\text {min,rec }}} K_{T} S_{\text {avg }} \Delta t, \text { when } T_{\text {lake }} \geq T_{\text {min,rec }} \\ 0, \text { when } T_{\text {lake }}<T_{\text {min }, \text { rec }}\end{array}\right.$

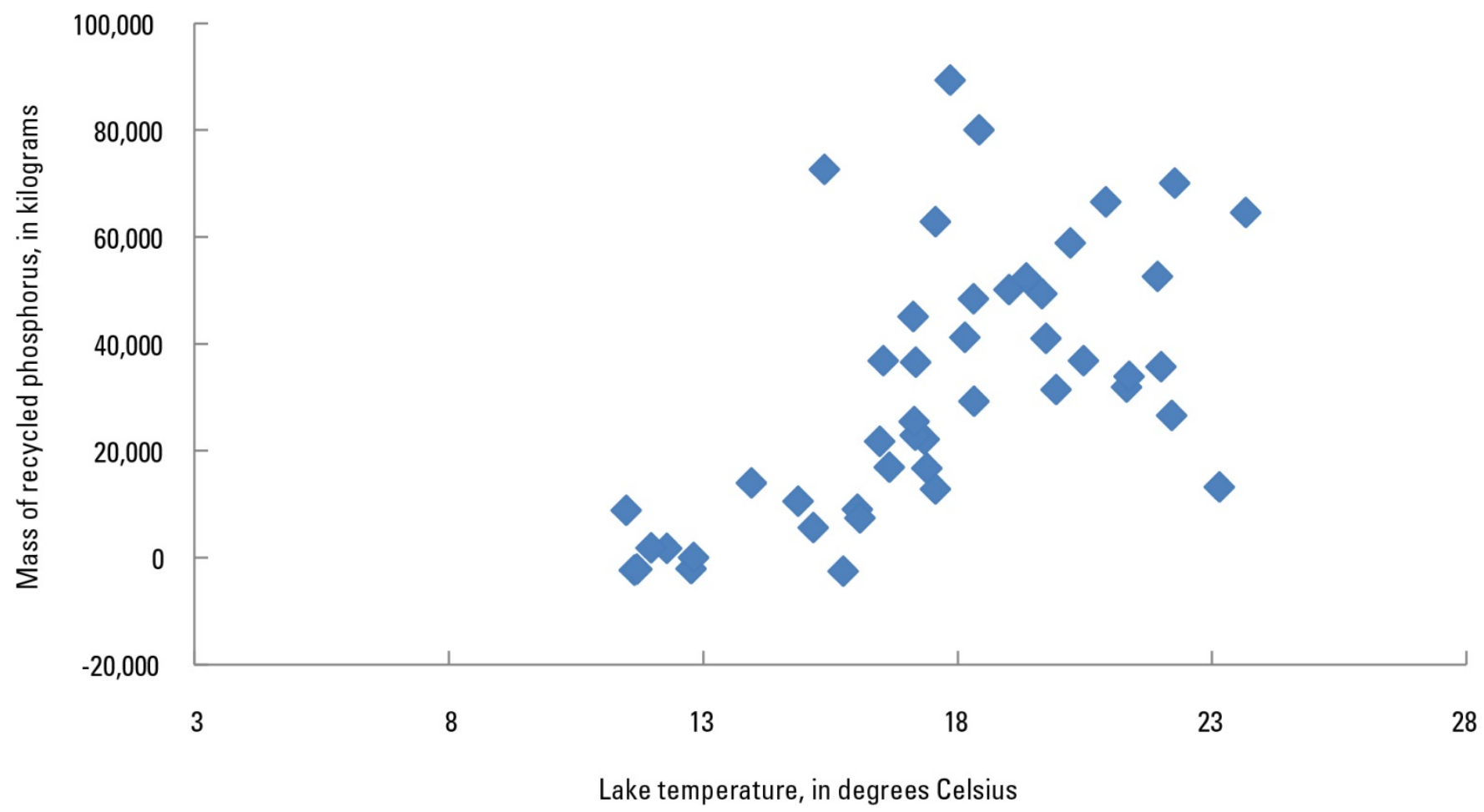

Figure 9. Graph showing mass of phosphorus recycled from sediments, calculated from observations of water column phosphorus and external loads, Upper Klamath Lake, Oregon, May-July 1991-1998, as a function of the lake temperature.

Replacing the $\mathrm{pH}$-dependent recycling mechanism with a temperature-dependent recycling mechanism resulted in an increase in most of the peak phosphorus and chlorophyll $a$ concentrations during the 7.5-year calibration period (fig. 10). The model modified with this simple temperature-dependent recycling mechanism has generally slightly worse performance statistics in which the rate constant $K_{T}$ and the minimum temperature at which recycling can occur $T_{\text {min,rec }}$ are calibration parameters. The calibration of these parameters proceeded, in analogy to the calibration of $K_{R}$ and $p H^{*}$, by trial and error. The values $K_{T}=0.54 / \mathrm{yr}$ and $T_{\text {min,rec }}=12.8^{\circ} \mathrm{C}$ were the values that minimized the objective function given in equation 24 (model version $C$ in tables 9-14). 
full validation period, $\mathrm{R}^{2}$ changed from 0.16 to 0.13 and NS changed from -1.68 to -2.39 , and over the limited validation period $\mathrm{R}^{2}$ changed from 0.59 to 0.56 and NS changed from 0.41 to 0.46 for chlorophyll $a$ (version $B$ to version $C$ ). Given the major conceptual change that this modification represented, these changes are small, and indicate that neither the $\mathrm{pH}$-dependent nor
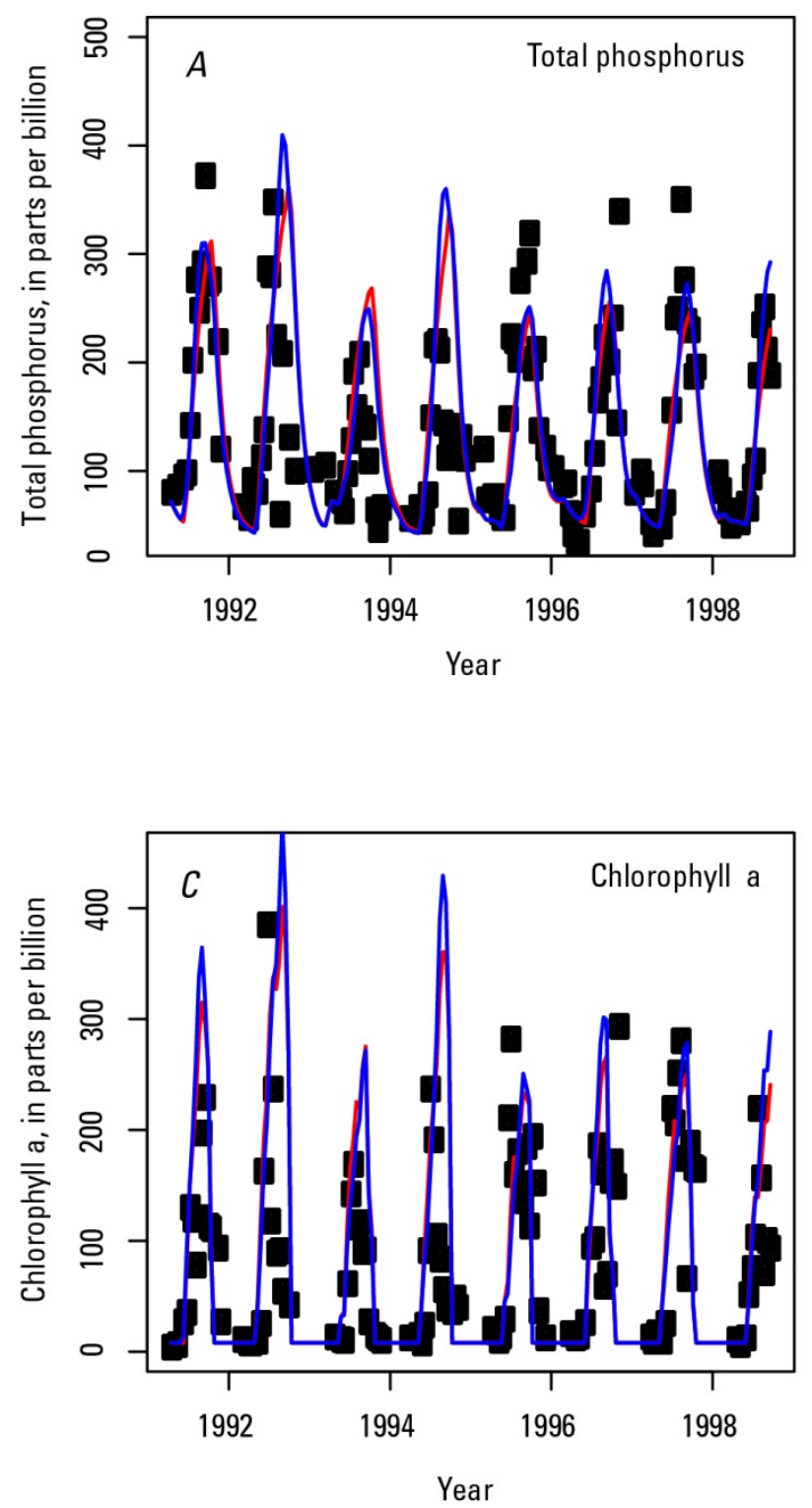

the temperature-dependent mechanism is uniquely suited to describing the observations; rather, any rate-dependent first-order term that generally increased through the spring and summer like $\mathrm{pH}$ and temperature would perform approximately equally well, and any such term probably would have generally poor performance statistics, particularly over the full validation period.

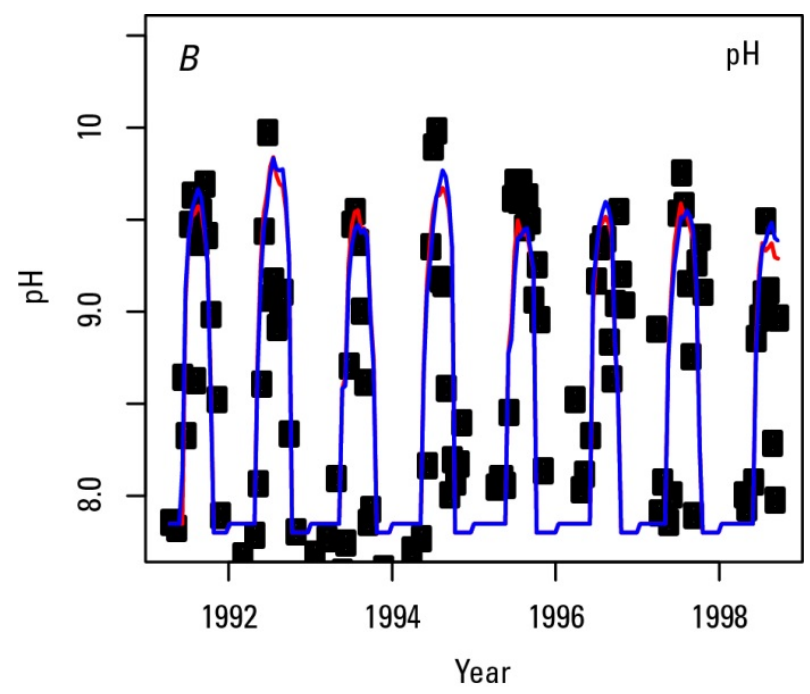

Figure 10. Graphs showing simulated and observed water column $(A)$ total phosphorus concentration, $(B)$ chlorophyll a concentration, and (C) pH, Upper Klamath Lake, Oregon, April 1991-September 1998. Model version $B$ incorporates modifications to the phosphorus and light limitations to algal growth, and model version $C$ has been modified to replace a pH-dependent recycling mechanism with a temperature-dependent recycling mechanism. 


\section{Numerical Solution of Chlorophyll a Equation}

In this sensitivity analysis, we examined the implications of the assumption of equilibration of chlorophyll $a$ concentration to temperature, light, and nutrients at each time step, which is, in effect, an assumption that the cyanobacterial bloom achieves maximum possible growth during each time step. The same chlorophyll $a$ mass balance (eq. 10) was used, but the assumption that the time derivative was zero was not made. A 4th order Runge-Kutta numerical method was used to solve the differential equation in an analogous manner to the solution of the water column and sediment phosphorus equations.

Model version $B$, which incorporated modifications to the phosphorus and light limitation factors was revisited using the Runge-Kutta solution for chlorophyll $a$. This version of the model was denoted version $D$ (tables 9-14). The calibration of the internal recycling parameters (step 4) was repeated, with the result that the calibration parameter $p H^{*}$ was lower by one-half $\mathrm{pH}$ unit, indicating accelerated recycling as a function of $\mathrm{pH}$, and that the newly calibrated recycle rate $K_{R}$ was nearly unchanged $(0.34 / \mathrm{yr}$ versus $0.32 / \mathrm{yr}$, comparing version $D$ to version $B$; tables 9-14). As a result, the modified model (version $D$ ) simulated higher baseline concentrations of water column phosphorus than version $B$; however, because chlorophyll $a$ was no longer required to achieve its maximum value in the 2 -week time interval, peaks in chlorophyll $a$ were uniformly reduced over the 7.5 -year calibration period (fig. 11).

The model modified with the Runge-Kutta solution for chlorophyll $a$ was the best performing model of all the models tested for all three variables during the limited validation period comprising May-July: highest correlation coefficients $(0.88,0.65$, and 0.73 for total phosphorus, chlorophyll $a$, and $\mathrm{pH}$, respectively), lowest RMSE, and NS closer to $1(0.83,0.63$, and 0.72 for total phosphorus, chlorophyll $a$, and $\mathrm{pH}$, respectively (tables 12-14). During the full validation period, this model gave the best results for chlorophyll $a\left(\mathrm{R}^{2}=0.23\right)$ and $\mathrm{pH}\left(\mathrm{R}^{2}=0.41\right.$; tables 10 and 11), but it did not simulate total phosphorus as well as the other models that were tested $\left(\mathrm{R}^{2}=0.15\right.$; table 9$)$. The winter spikes in $\mathrm{pH}$ (fig. 11C) resulted from discontinuity in the $\mathrm{pH}$ regression model (eq. 20) at the end of the calendar year and can be eliminated in future model revisions. 

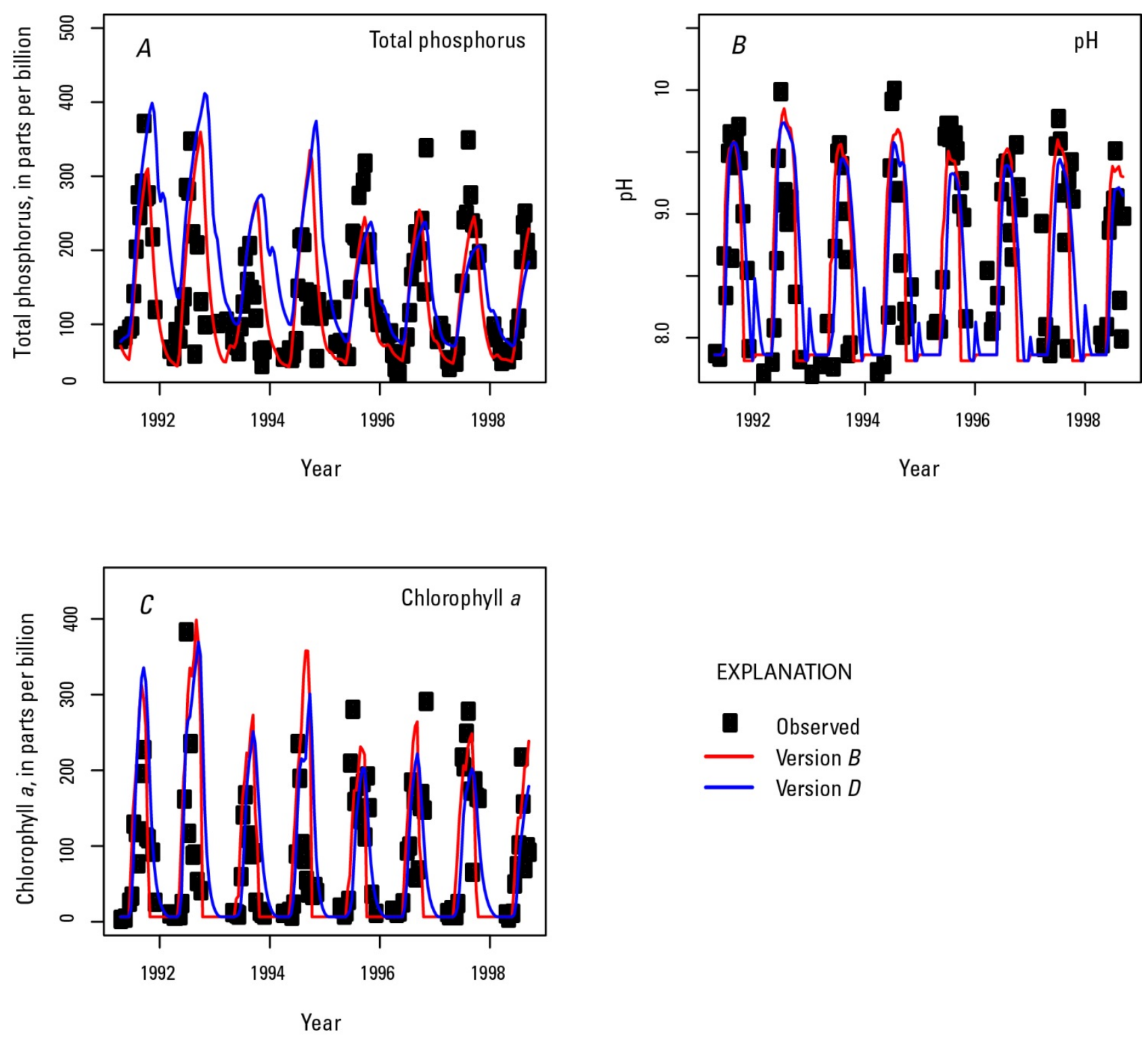

EXPLANATION

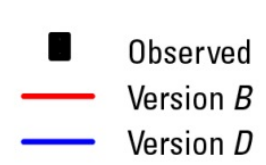

Figure 11. Graphs showing simulated and observed water column $(A)$ total phosphorus concentration, $(B)$ chlorophyll a concentration, and (C) pH, Upper Klamath Lake, Oregon, April 1991-September 1998. Model version $B$ incorporates modifications to the phosphorus and light limitations to algal growth, and model version $D$ incorporates a nonequilibrium approach to the solution of the chlorophyll a mass balance.

\section{Initial Sediment Reservoir}

One of two initial conditions of the model is the initial mass of total phosphorus in the sediment reservoir (the other being the initial mass of total phosphorus in the water column). The initial mass in the reservoir is calculated from

$S_{\text {init }}=\rho_{\text {bulk }} z_{\text {sed }} A P_{\text {sed }}$.
The sediment bulk density $\rho_{\text {bulk }}$ used was 0.12 $\mathrm{g} / \mathrm{cm}^{3}$ and the active sediment thickness $z_{\text {sed }}$ was $10 \mathrm{~cm}$, based on Eilers and others (2001). These values are consistent with more recent data ( $\mathrm{Si}$ mon and Ingle, 2011); however, the initial sediment phosphorus concentration used in the original model was $1,000 \mathrm{mg} / \mathrm{kg}$, based on the single core analyzed by Eilers and others (2001). Because more abundant core data have become available (Simon and Ingle, 2011), the average 
concentration of phosphorus in the sediments, $P_{\text {sed }}$, was recalculated based on the new information. The new average sediment concentration, $P_{\text {sed_new }}$, based on all 26 cores at depths to $10 \mathrm{~cm}$ was $335 \mathrm{mg} / \mathrm{kg}$, only about one-third of that reported by Eilers and others (2001), making it necessary to investigate sensitivity of the model calibration to initial sediment phosphorus concentration.

We ran each of the model versions again using the new initial condition for sediment phosphorus. Recalibration of algal settling velocity was not necessary, because the balance of terms used in that step did not change with this change to initial conditions. The calibration of the recycling parameters (step 4) was repeated, however, and the value of the calibration parameter $p H^{*}$ changed little-between 0 and $0.2 \mathrm{pH}$ units (tables 9-14) - but the newly calibrated recycle rate $K_{R}$ (or $K_{T}$ in version $C^{\prime}$ ) more than doubled in some cases (versions $O^{\prime}$ and $A^{\prime}$ ) or increased by over threefold (versions $B^{\prime}, C^{\prime}$, and $D^{\prime}$ ), indicating accelerated recycling at all values of $\mathrm{pH}$. Even so, the effect of the lower initial sediment reservoir was to reduce peaks in all of total phosphorus, $\mathrm{pH}$, and chlorophyll $a$ during the 7.5-year calibration period relative to original initial condition (fig. 12, model version $A$ as an example). Statistics indicated that the lower initial sediment reservoir generally did not greatly affect model performance, regardless of whether statistics were calculated over the full (tables 9-11) or limited (tables 12-14) validation period. Model performance increased marginally over the full validation period, particularly in the simulation of total phosphorus, as evidenced by small increases in $\mathrm{R}^{2}$ and NS, and decreases in RMSE (tables 911). Model performance decreased marginally over the limited validation period (tables 12-14) in the simulation of total phosphorus, and changes between un-primed and primed versions of the model were small and mixed in the simulation of chlorophyll $a$ and $\mathrm{pH}$. 

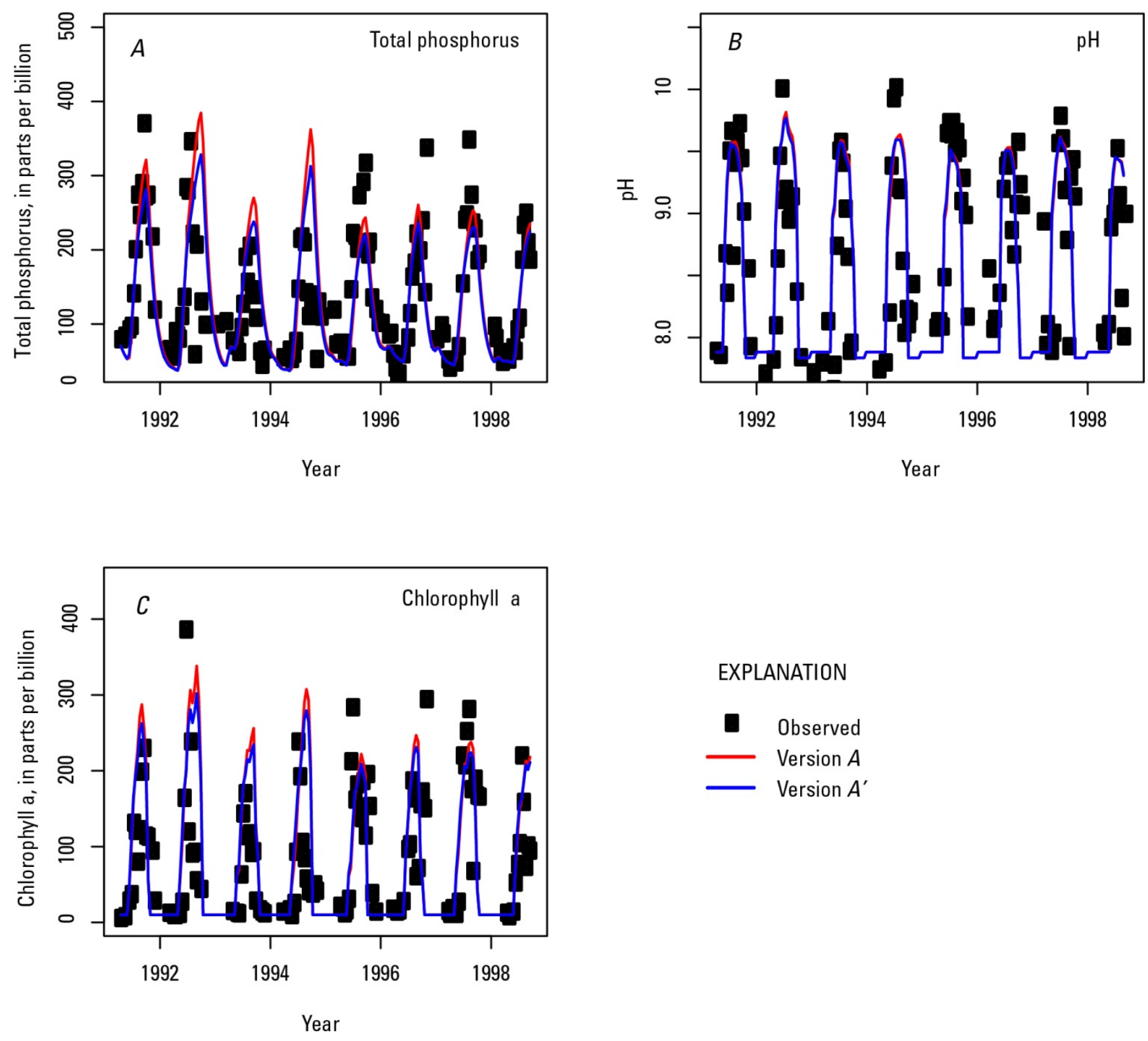

EXPLANATION

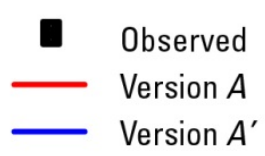

Figure 12. Graphs showing simulated and observed water column $(A)$ total phosphorus concentration, $(B)$ chlorophyll a concentration, and (C) pH, Upper Klamath Lake, Oregon, April 1991-September 1998. Model version $A$ is the original model (recalibrated), and model version $A$ ' is the original model recalibrated with a lower initial condition for the sediment phosphorus reservoir.

\section{Long-Term Model Simulation and Implications for TMDL}

The original model was used to address questions that preceded the implementation of the TMDL because of its ability to predict the response of water quality in Upper Klamath Lake to changes in management of the land and point sources of phosphorus in the Upper Klamath
Lake drainage basin. The CSTR is well-suited to addressing these questions because it is not computationally intensive and can provide simulations of conditions many decades into the future, consistent with the time frame for response to management changes. The 2-week time step and the input data requirements of the model were well-matched to the biweekly sampling strategy and the collected constituents of the 
long-term monitoring program that provided boundary conditions, observations for calibration of parameters, and mass balance terms for validation. The simplicity of the algorithms also allows insight into the factors that determine long-term system behavior that would be difficult to generate with a more complicated model.

The model predicts the response to a reduction in external loads of phosphorus to the lake. The original model included a "TMDL" option, which looped through the 7 years of input data (mid-April 1991-mid-April 1998) until a steady state (equilibrium) was achieved without storing interim values. The steady state was defined as the point at which the simulated water column and sediment phosphorus over the 7-year period were essentially unchanged with additional cycles through the input data. This method provided the end point, but did not indicate how long it took to achieve steady state (how many 7-year cycles) or how concentrations evolved during the transition period.

As part of the current validation process, we modified the R-script model to chain the 7 years of model input data to produce a continuous simulation of all the variables over 203 years (29 seven-year cycles), which brought the simulations to a steady state. These simulations were obtained with all versions of the model discussed previously. A second set of simulations was obtained with all versions of the model, but after first reducing the external load boundary condition by 40 percent, as recommended in the Upper Klamath Lake TMDL (Oregon Department of Environmental Quality, 2002). Thus, the simulations were arranged into four groups of five simulations each, defined by the four combinations of original or updated initial sediment reservoir and 0 or 40 percent reduction in the external load boundary condition.

Within a group of simulations, the behavior of each model can be summarized with the set of metrics compiled in table 15 . The ratio of the recycling term to the sedimentation term in the water column phosphorus balance
$\left(M_{\text {rec }} / M_{\text {sed }}\right.$, eq. 1) averaged over the first 7 years of simulation was positively correlated with the average water column phosphorus concentration over the last 7 years of the simulation (fig. $13 A$ ) and negatively correlated with the sediment reservoir averaged over the last 7 years of the simulation (fig. 13B). Given a set of boundary and initial conditions, more recycling relative to settling resulted in a steady state characterized by lower sediment phosphorus and higher water column phosphorus concentration as compared to less recycling relative to settling; thus, those two quantities were negatively correlated (fig. 13D). The ratio $M_{\text {rec }} / M_{\text {sed }}$ also was correlated with chlorophyll $a$ concentration within a group of simulations (fig. 13C), with the exception of model versions $D$ and $D^{\prime}$; those two versions of the model lack an assumption that chlorophyll $a$ (a surrogate for cyanobacterial biomass) achieves equilibrium with the available light and nutrients within a time step. 
Table 15. Comparison of metrics describing the long-term simulations for model versions discussed in the report.

[Shading indicates four groups of model simulations defined by four combinations of external loading and initial sediment reservoir. Mrec=mass of total phosphorus recycled from sediments to water column; Msed=mass of total phosphorus settled from water column to sediments; $\mathrm{EQ}=\mathrm{Chlorophyll}$ a concentration evaluated by setting $\mathrm{dB} / \mathrm{dt}$ to $0 ; \mathrm{RK}=$ Chlorophyll a concentration evaluated using Runge-Kutta approach; INIT=Initial size of sediment reservoir calculated with original starting concentration $1,000 \mathrm{mg}$ P/kg sediment; INIT NEW=Initial size of sediment reservoir recalculated with starting concentration $335 \mathrm{mg}$ P/kg sediment; REC_pH=Model relies on $\mathrm{pH}$-dependent recycle mechanism; REC_T $=$ model relies on temperature-dependent recycle mechanism; $\mathrm{P} \_00=\mathrm{Phosphorus} \mathrm{limitation}$ factor calculated as the percent of non-algal P; P_MM=Phosphorus limitation factor calculated by Michaelis-Menten kinetics; $L_{-}$AVG $=$Light limitation factor calculated using the average light intensity; $\mathrm{L}_{-} \mathrm{DI}=$ Average light limitation factor calculated by depth-integrating the light limitation equation.]

\begin{tabular}{|c|c|c|c|c|c|c|c|c|c|c|c|c|c|c|c|c|}
\hline \multirow[b]{4}{*}{$\begin{array}{c}\text { Model } \\
\text { version }\end{array}$} & \multirow[b]{4}{*}{$\begin{array}{l}\text { Compare } \\
\text { to } \\
\text { version }\end{array}$} & \multirow{3}{*}{\multicolumn{5}{|c|}{ Model Characteristics }} & \multicolumn{10}{|c|}{ Reduction in External Loading Boundary Condition Applied to the Model } \\
\hline & & & & & & & $0 \%$ & $40 \%$ & \multicolumn{2}{|c|}{$0 \% \quad 40 \%$} & $0 \%$ & $40 \%$ & $0 \%$ & $40 \%$ & $0 \%$ & $40 \%$ \\
\hline & & & & & & & \multirow{2}{*}{\multicolumn{2}{|c|}{$\begin{array}{l}\text { Ratio of recycling to } \\
\text { sedimentation, } \\
\text { Mrec/Msed, average } \\
\text { over first } 7 \text { years of } \\
\text { 203-year simulation }\end{array}$}} & \multicolumn{6}{|c|}{$\begin{array}{c}\text { Average concentration over last } 7 \text { years of 203- } \\
\text { year simulation }\end{array}$} & \multirow{2}{*}{\multicolumn{2}{|c|}{$\begin{array}{l}\text { Years with seasonal } \\
\text { chlorophyll a peak } \\
>100 \mathrm{ppb} \text { over last } 7 \\
\text { years of 203-year } \\
\text { simulation (out of } 7 \text { ) }\end{array}$}} \\
\hline & & $\begin{array}{l}\text { Chlorophyll a } \\
\text { model }\end{array}$ & $\begin{array}{l}\text { Initial } \\
\text { sediment } \\
\text { reservoir }\end{array}$ & $\begin{array}{l}\text { Recycle } \\
\text { mechanism }\end{array}$ & $\begin{array}{l}\text { Phospho- } \\
\text { rus } \\
\text { limitation }\end{array}$ & $\begin{array}{l}\text { Light } \\
\text { limitation }\end{array}$ & & & \multicolumn{2}{|c|}{ Total P (ppb) } & $\begin{array}{l}\text { Sedin } \\
\text { (metri }\end{array}$ & $\begin{array}{l}\text { lent } P \\
\text { tons) }\end{array}$ & \multicolumn{2}{|c|}{$\begin{array}{l}\text { Chlorophyll a } \\
\text { (ppb) }\end{array}$} & & \\
\hline \multicolumn{17}{|c|}{ Original model with original calibration } \\
\hline$O$ & & EQ & INIT & REC_pH & P_00 & L_AVG & 0.62 & 0.33 & 105.9 & 39.7 & 2,302 & 3,338 & 62.6 & 25.1 & 7 & 2 \\
\hline$O^{\prime}$ & $O$ & EQ & INIT_NEW & REC_pH & P_00 & L_AVG & 0.60 & 0.52 & 120.0 & 71.1 & 901 & 932 & 71.3 & 44.5 & 7 & 6 \\
\hline \multicolumn{17}{|c|}{ Recalibration of original model } \\
\hline$A$ & $O$ & EQ & INIT & REC_pH & P_00 & L_AVG & 0.57 & 0.42 & 102.8 & 42.6 & 2,441 & 3,018 & 60.9 & 27.1 & 7 & 3 \\
\hline$A^{\prime}$ & $A$ & EQ & INIT_NEW & REC_pH & P_00 & L_AVG & 0.57 & 0.53 & 118.4 & 69.4 & 980 & 897 & 69.1 & 44.0 & 7 & 6 \\
\hline \multicolumn{17}{|c|}{ Modifications to light and phosphorus limitation } \\
\hline$B$ & $A$ & EQ & INIT & REC_pH & P_MM & L_DI & 0.70 & 0.62 & 105.9 & 58.9 & 2,224 & 2,067 & 62.5 & 32.0 & 7 & 5 \\
\hline$B^{\prime}$ & $B$ & EQ & INIT_NEW & REC_pH & P_MM & L_DI & 0.69 & 0.43 & 121.5 & 73.0 & 871 & 1,028 & 72.0 & 39.8 & 7 & 4 \\
\hline \multicolumn{17}{|c|}{ Temperature-dependent recycling } \\
\hline$C$ & $B$ & EQ & INIT & REC_T & P_MM & L_DI & 0.69 & 0.79 & 106.3 & 65.0 & 2,117 & 1,299 & 63.6 & 39.5 & 7 & 7 \\
\hline$C^{\prime}$ & C & EQ & INIT_NEW & REC_T & P_MM & L_DI & 0.68 & 0.76 & 120.1 & 73.3 & 867 & 534 & 72.6 & 46.1 & 7 & 7 \\
\hline \multicolumn{17}{|c|}{ Runge-Kutta solution of chlorophyll a } \\
\hline$D$ & $B$ & RK & INIT & REC_pH & P_MM & L_DI & 1.09 & 1.18 & 116.8 & 70.2 & 1,569 & 1,061 & 54.4 & 33.9 & 7 & 4 \\
\hline$D^{\prime}$ & $D$ & RK & INIT_NEW & REC_pH & P_MM & L_DI & 1.06 & 1.13 & 129.0 & 78.4 & 518 & 355 & 60.3 & 38.4 & 7 & 6 \\
\hline
\end{tabular}

Table continues on next page. 
Table 15. Comparison of metrics describing the long-term simulations for model versions discussed in the report-continued [Shading indicates four groups of model simulations defined by four combinations of external loading and initial sediment reservoir.]

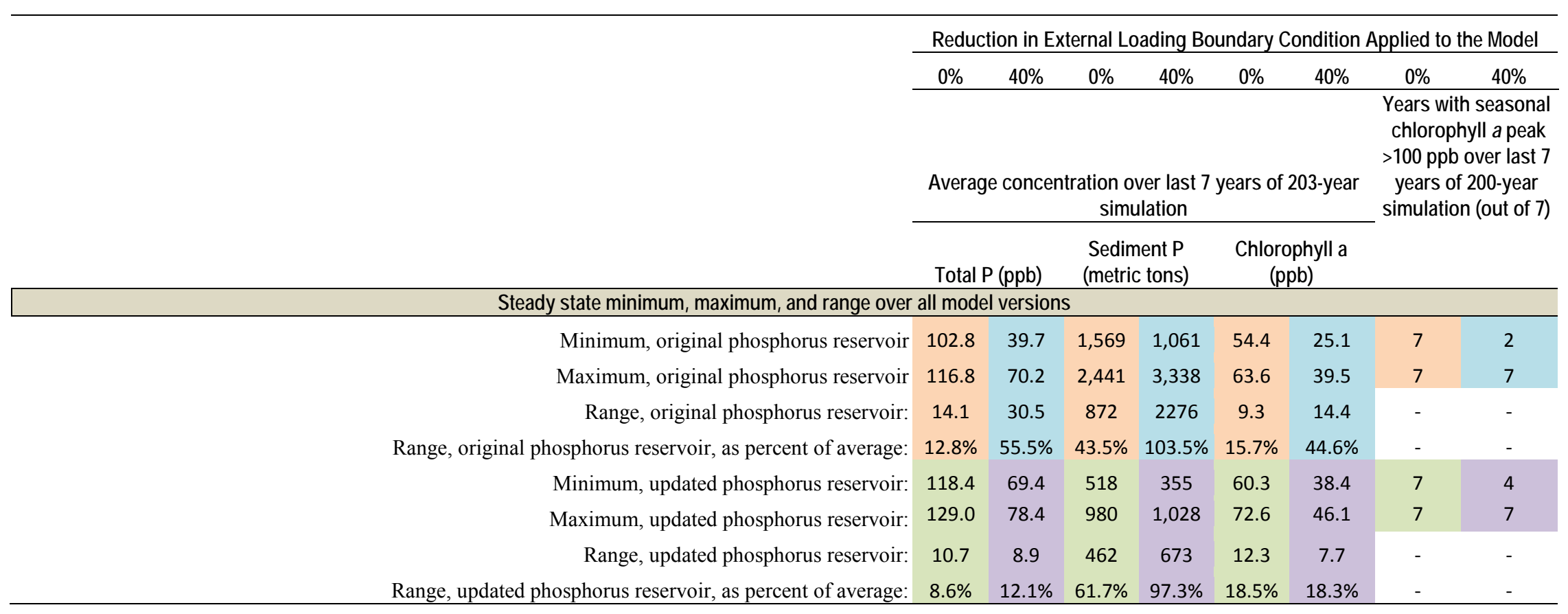



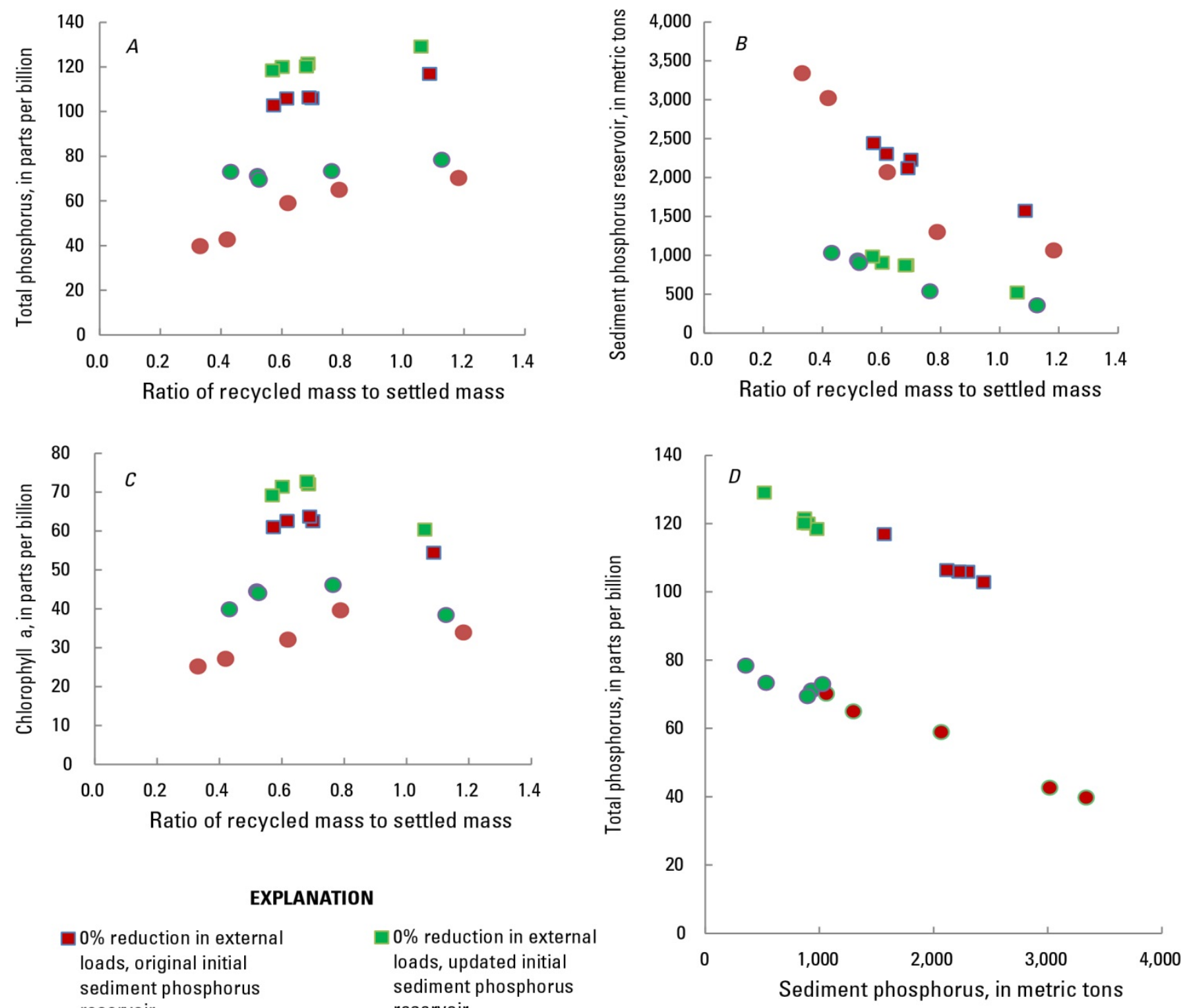

loads, original initial sediment phosphorus reservoir loads, updated initial sediment phosphorus reservoir

$40 \%$ reduction in external loads, original initial sediment phosphorus reservoir

$40 \%$ reduction in external loads, updated initial sediment phosphorus reservoir

Figure 13. Graphs showing average $(A)$ concentration of total phosphorus, $(B)$ size of the sediment reservoir, $(C)$ concentration of chlorophyll a during the final 7 years of a 203-year simulation for Upper Klamath Lake, Oregon, as a function of the average ratio of recycled mass to settled mass during the first 7 years of a 203-year simulation. (D) Total phosphorus concentration from graph $A$ as a function of the sediment reservoir from graph $B$.

All versions of the model produced simulations in which the steady-state phosphorus concentration was less than the initial concentration (fig. 14A, B). However, the steady-state concentration varied over a range of $14.0 \mathrm{ppb}$ (12.8 percent of the average), from 102.8 to
$116.8 \mathrm{ppb}$ when no reduction in external loads was applied as a boundary condition (table 15). When a reduction in external loads of 40 percent was applied, the steady-state phosphorus concentration was lower for all model versions than when no reduction in external loads was simulat- 
ed, but varied over a range of $30.5 \mathrm{ppb}$ (55.5 percent of the average), from 39.7 to $70.2 \mathrm{ppb}$ (table $15)$. When a 40 percent reduction in external loads was simulated, the range in steady-state concentration was larger and the effect of the difference in settling velocity $u_{\text {alg }}$ was apparent in the grouping of versions $O$ and $A\left(u_{a l g}=0.05\right.$ and $0.059 \mathrm{~m} / \mathrm{d}$, respectively) and the grouping of versions $B, C$ and $D\left(u_{a l g}=0.035 \mathrm{~m} / \mathrm{d}\right.$; therefore, lower settling relative to recycling than in versions $O$ and $A$ ) (fig. 14B).
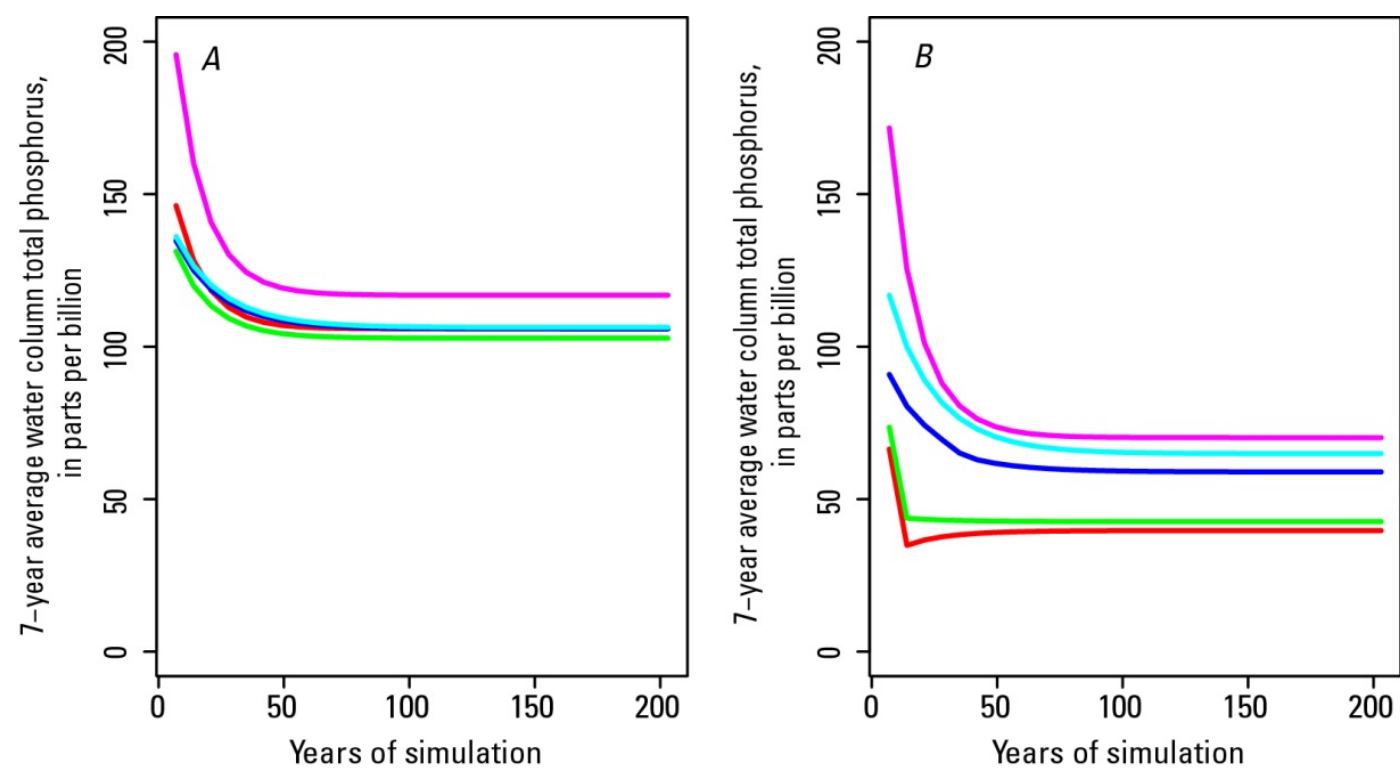

EXPLANATION

- Model version 0

- Model version A

- Model version B

- Model version C

- Model version D

Figure 14. Graphs showing comparison of long-term simulated concentration of water column phosphorus, under conditions of $(A) 0$ and $(B) 40$ percent reductions in external loads to Upper Klamath Lake, Oregon. Version $O=$ original model, original calibration; version $A=$ original model, recalibrated; version $B=$ modifications to light and phosphorus limitations to algal growth; version $C=$ version $B$ with replacement of $\mathrm{pH}$-dependent recycling with temperature-dependent recycling; version $D=$ version $B$ without assumption of maximum chlorophyll a growth during each time step.

Mechanistic connections between the assumptions that distinguish the model versions and the steady-state outcomes are not clear, however. For example, versions $B, C$, and $D$ share the corrections made to phosphorus and light limitations to cyanobacterial growth, making those limitation factors generally lower (data not shown). That led to a smaller value for $u_{\text {alg }}$ through the balance used to calibrate the algal settling velocity (eq. 14), even though there was no direct connection between how light and phosphorus limitation were calculated and the settling velocity. Thus, reasonable differences in model assumptions led to quite different values of calibration parameters. Over the 7.5 years for which observations were available, the differences between the calibrated model versions were barely perceptible (figs. 8, 10-12), and they all simulated the 7.5 years of available observations with roughly the same success (tables 9-14). However, when those same models were used to simulate conditions 203 years into the future, the differences in calibration parameters manifested themselves in potentially meaningful quantitative differences in steadystate conditions.

Like water column phosphorus concentration, the size of the sediment reservoir of phosphorus achieved equilibrium during the 203year simulations (fig. 15). When no reduction in external loading was applied as a boundary condition, the steady-state values were always less than the initial size of the reservoir, but the range 
was large ( 872 metric tons, or 43.5 percent of the average). Water column phosphorus concentration and the size of the sediment reservoir were inversely correlated, and the model versions that simulated the highest steady-state phosphorus concentration also simulated the smallest steadystate sediment phosphorus reservoir (fig. 13D). When a 40 percent reduction in external loads was applied as a boundary condition, the range in steady-state phosphorus reservoir from 1,061 to 3,338 metric tons (table 15, fig. 15B) encom- passed the range in the steady-state phosphorus reservoir that resulted when no reduction in external loads was applied (fig. 15A) and at 2,276 metric tons was more than twice as large (table 15). Under conditions of reduced external loading, model version $O$, which had the smallest $M_{\text {rec }} / M_{\text {sed }}$ ratio (table 15) and simulated the lowest overall steady-state water column phosphorus concentration (fig. 14B) simulated a steady-state phosphorus reservoir that was larger than the initial condition (fig. 15B).
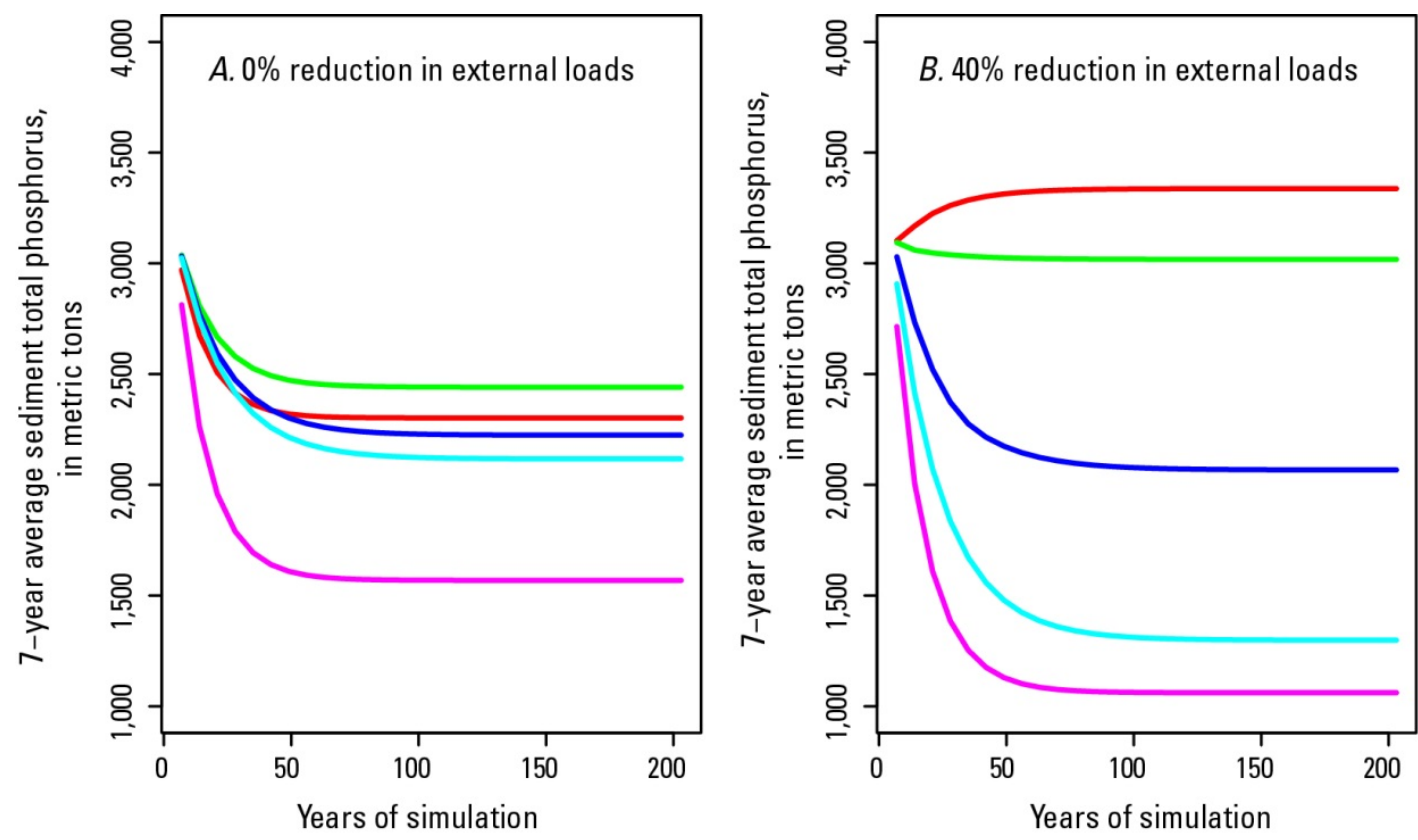

EXPLANATION

- Model version 0

- Model version A

Model version B

- Model version C

- Model version D

Figure 15. Graphs showing comparison of long-term simulated concentration of sediment phosphorus reservoir in Upper Klamath Lake, Oregon, under conditions of $(A) 0$ and $(B) 40$ percent reductions in external loads. Version $O=$ original model, original calibration; version $A=$ original model, recalibrated; version $B=$ modifications to light and phosphorus limitations to algal growth; version $C=$ version $B$ with replacement of $\mathrm{pH}$-dependent recycling with temperature-dependent recycling; version $D=$ version $B$ without assumption of maximum chlorophyll a growth during each time step.

When the updated estimate of the initial size of the sediment reservoir was used to start the simulations, the resulting range in steady-state phosphorus concentrations was smaller than when the original size of the sediment reservoir was used (fig. $16 A, B)-8.6$ percent and 12.1 percent of the average when no reductions and when 40 percent reductions in external loads were applied as a boundary condition, respectively. The steady-state values overall were, however, higher-118.4-129.0 ppb and 69.4-78.4 ppb when no reductions and 40 percent reductions in external loads were applied, respectively (fig. 13A, table 15). The updated phosphorus reservoir was smaller at the beginning of the simulations but also decreased less before achieving a steady state (fig. $17 A, B$ ). When a 40 percent reduction in external loads was applied, model version $C^{\prime}$, which was characterized by the smallest $M_{\text {rec }} /$ $M_{\text {sed }}$ in this group of models (table 15), produced a small increase in the phosphorus reservoir to achieve steady-state conditions. 

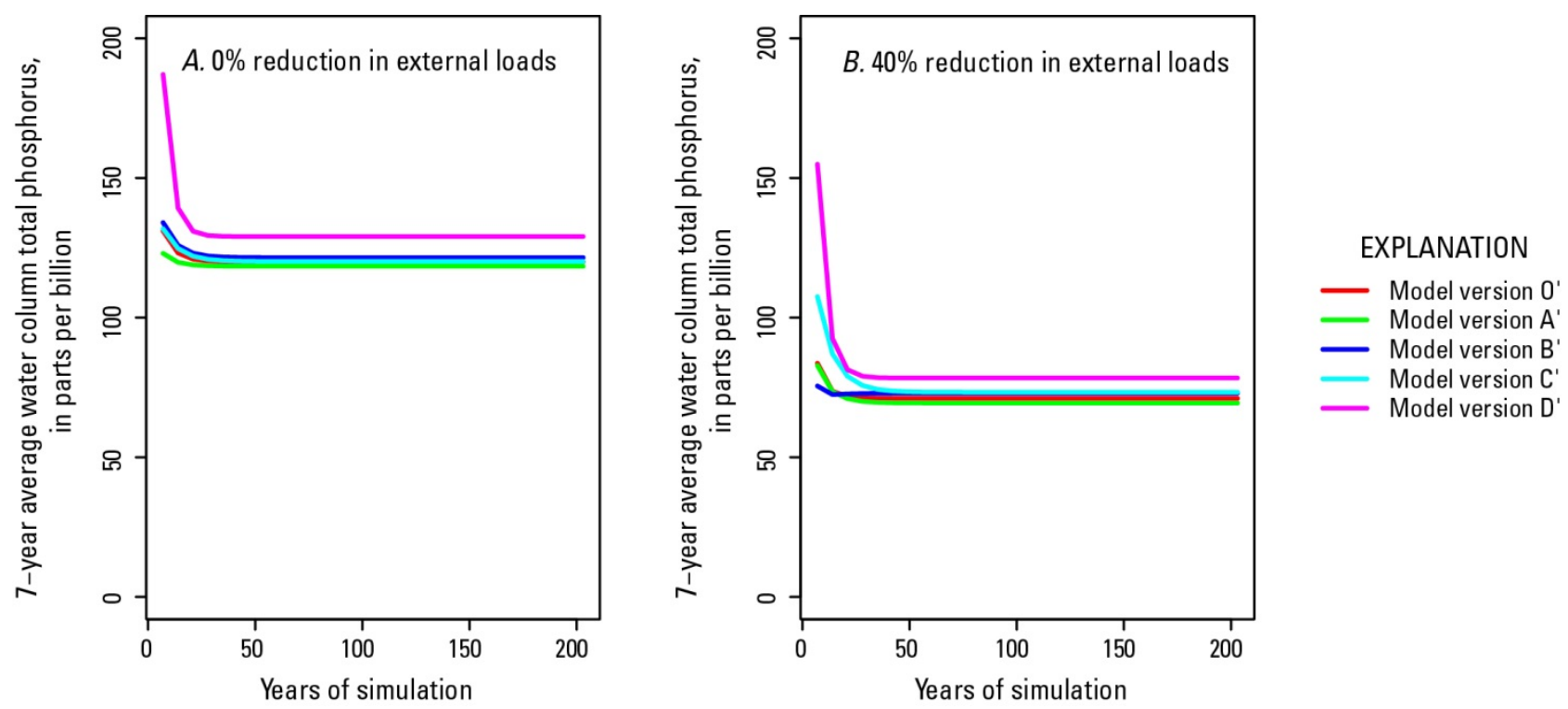

Figure 16. Graphs showing comparison of long-term simulated concentration of water column phosphorus in Upper Klamath Lake, Oregon, under conditions of $(A) 0$ and $(B) 40$ percent reductions in external loads. Versions of the model marked with a prime symbol $\left(O^{\prime}\right.$, for example) were calibrated using a lower initial condition of the sediment phosphorus reservoir than the corresponding versions without the prime symbol. Version $O^{\prime}=$ original model, original calibration; version $A^{\prime}=$ original model, recalibrated; version $B^{\prime}=$ modifications to light and phosphorus limitations to algal growth; version $C^{\prime}=$ version $B^{\prime}$ with replacement of $\mathrm{pH}$-dependent recycling with temperature-dependent recycling; version $D^{\prime}=$ version $B^{\prime}$ without assumption of maximum chlorophyll a growth during each time step.
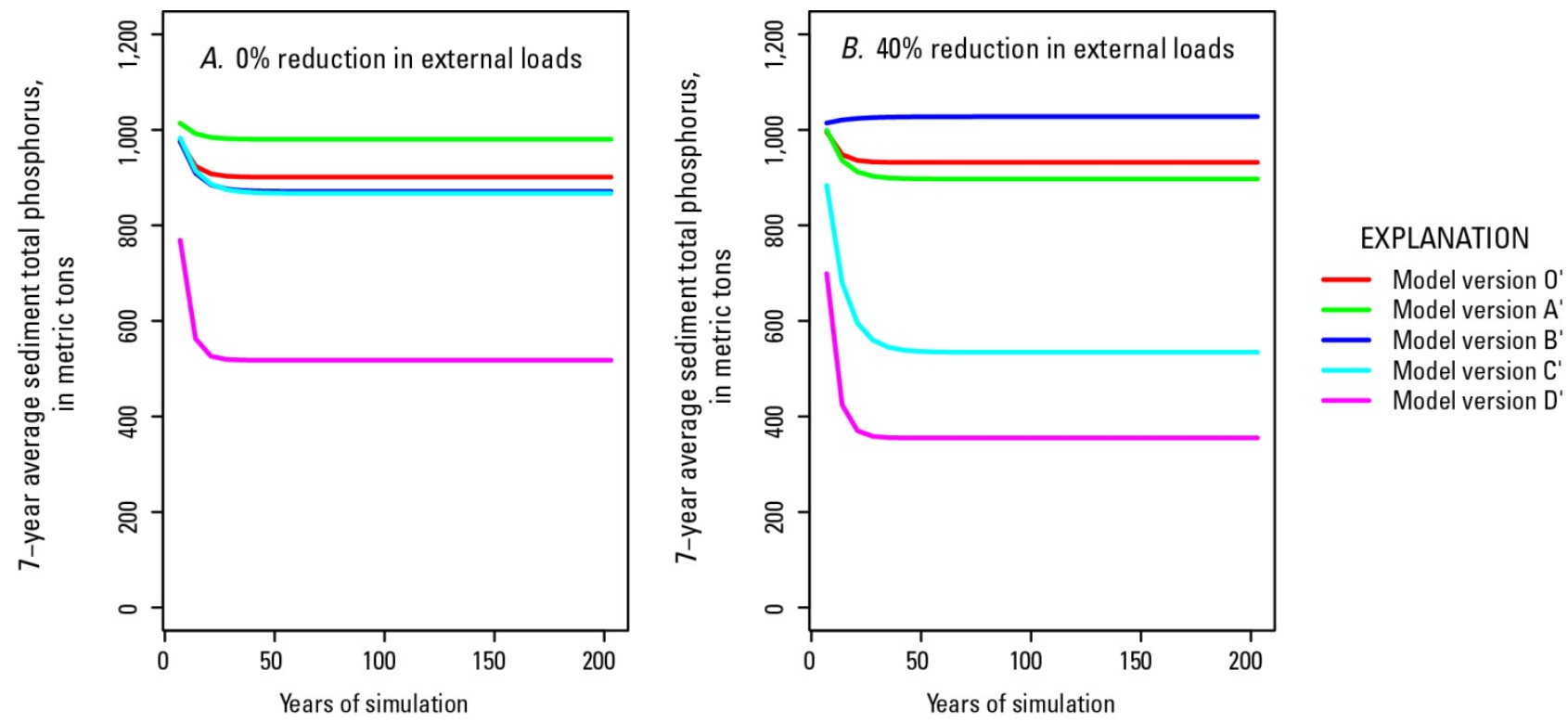

Figure 17. Graphs showing comparison of long-term simulated concentration of sediment phosphorus reservoir in Upper Klamath Lake, Oregon, under conditions of $(A) 0$ and $(B) 40$ percent reductions in external loads. Versions of the model marked with a prime symbol $\left(O^{\prime}\right.$, for example) were calibrated using a lower initial condition of the sediment phosphorus reservoir than the corresponding versions without the prime symbol. Version $O^{\prime}=$ original model, original calibration; version $A^{\prime}=$ original model, recalibrated; version $B^{\prime}=$ =modifications to light and phosphorus limitations to algal growth; version $C^{\prime}=$ =version $B^{\prime}$ with replacement of $\mathrm{pH}$-dependent recycling with temperaturedependent recycling; version $D^{\prime}=$ version $B^{\prime}$ without assumption of maximum chlorophyll a growth during each time step. 
The number of years in the final 7 years of the 203-year simulations in which maximum chlorophyll $a$ concentration exceeded $100 \mathrm{ppb}$ is another metric that can be used to characterize the long-term simulation (table 15; fig. 18). With no reduction in external loads, simulated chlorophyll $a$ exceeded $100 \mathrm{ppb}$ in each of 7 years regardless of the model version or the size of the initial sediment reservoir (fig. 18A, C). Consistent with Walker (2001), when a 40 percent reduction in external loads was applied as a boundary condition (fig 18B), model version $O$ showed simulated maximum chlorophyll $a$ exceeding 100 ppb in only 2 of 7 years. Other model versions simulated maximum chlorophyll $a$ exceeding 100 ppb in 3-7 of 7 years (fig. 18B). When the updated estimate of the initial sediment reservoir was used, the number of years in which maximum chlorophyll $a$ exceeded $100 \mathrm{ppb}$ was greater for each version of the model than when the larger, original initial sediment phosphorus reservoir was used (table 15, fig. 18D). Total water column phosphorus concentration simulated by each version of the model shows year-to-year variability in maximum phosphorus concentration that corresponds directly to the year-to-year variability in maximum chlorophyll $a$ (fig. 19).

Model versions $C$ and $C^{\prime}$ simulated maximum chlorophyll $a$ exceeding 100 ppb in 7 of 7 years, demonstrating an important difference between these model versions (in which a temperature-dependent recycling mechanism was substituted for a $\mathrm{pH}$-dependent one) and the others. Because of the proportionality between $\mathrm{pH}$ and chlorophyll $a$, the $\mathrm{pH}$-dependent mechanism has built-in positive feedback that the temperature-dependent mechanism does not. In model versions $O, O^{\prime}, A, A^{\prime}, B, B^{\prime}, D$ and $D^{\prime}$, if cyanobacterial growth does not exceed a threshold, $\mathrm{pH}$ remains below a critical value for recycling (roughly represented by $p H^{*}$ ) and recycling is constrained, whereas when the threshold is exceeded, recycling is accelerated. This results in uneven changes in peak chlorophyll $a$ from year to year when the external loading is reduced, with very large blooms in some years and very small blooms in others, depending on whether the threshold is exceeded (fig. 18). Total phosphorus concentration shows analogous year-to-year variability (fig. 19). Because the temperaturedependent mechanism has no built-in feedback, changes occur more evenly across years, leading to maximum chlorophyll $a$ being smaller in all years, but not less than $100 \mathrm{ppb}$ in any year.

The 203-year simulations provided insight into the length of time required to achieve steady state for each initial condition. Times were longer for the original sediment reservoir initial condition than for the updated sediment reservoir initial condition: about 50-70 years at the higher initial condition (figs. 14A, $B$ and 15A, B) and about 25-30 years at the lower initial condition (figs. 16A, $B$ and 17A, $B$ ). 

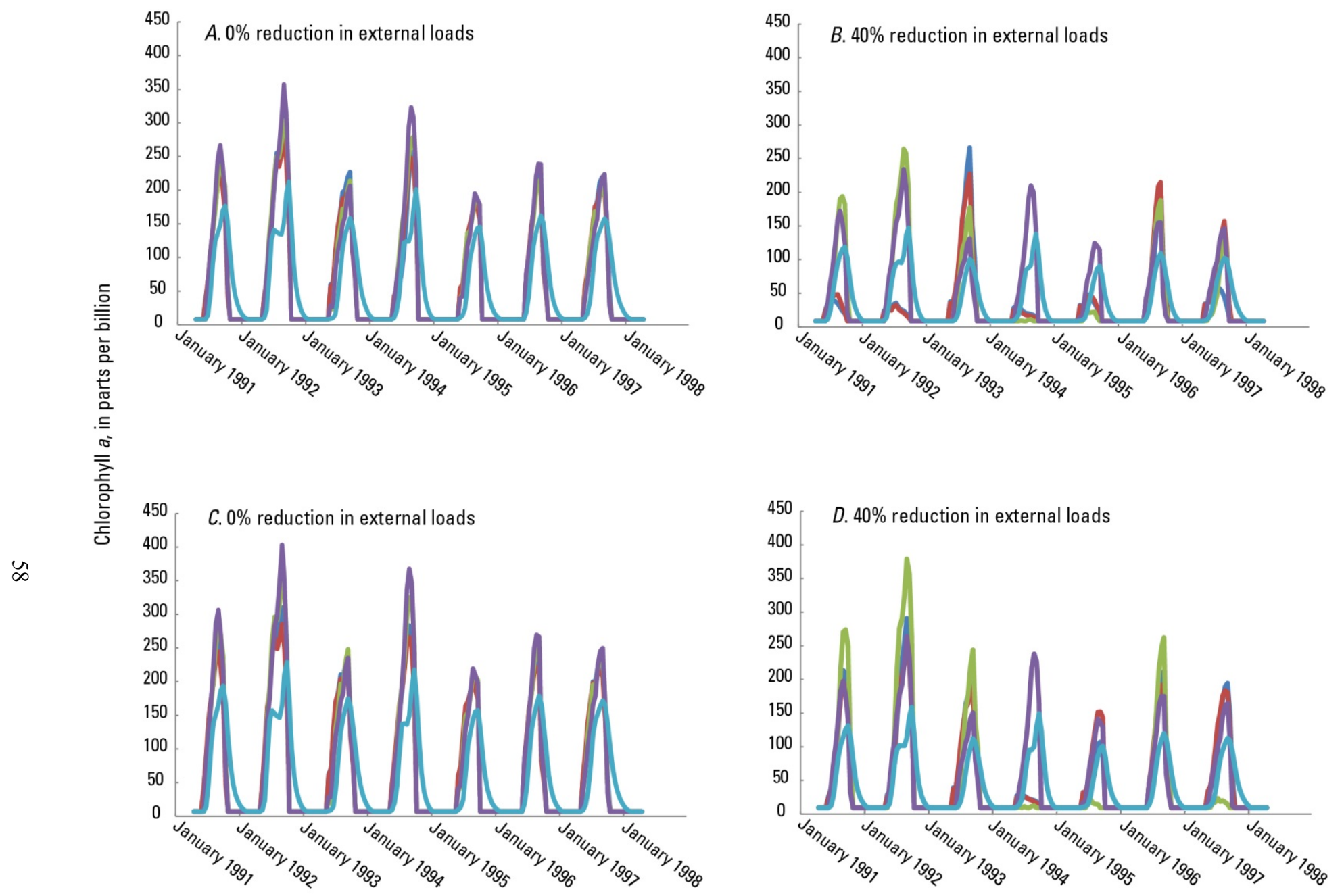

EXPLANATION
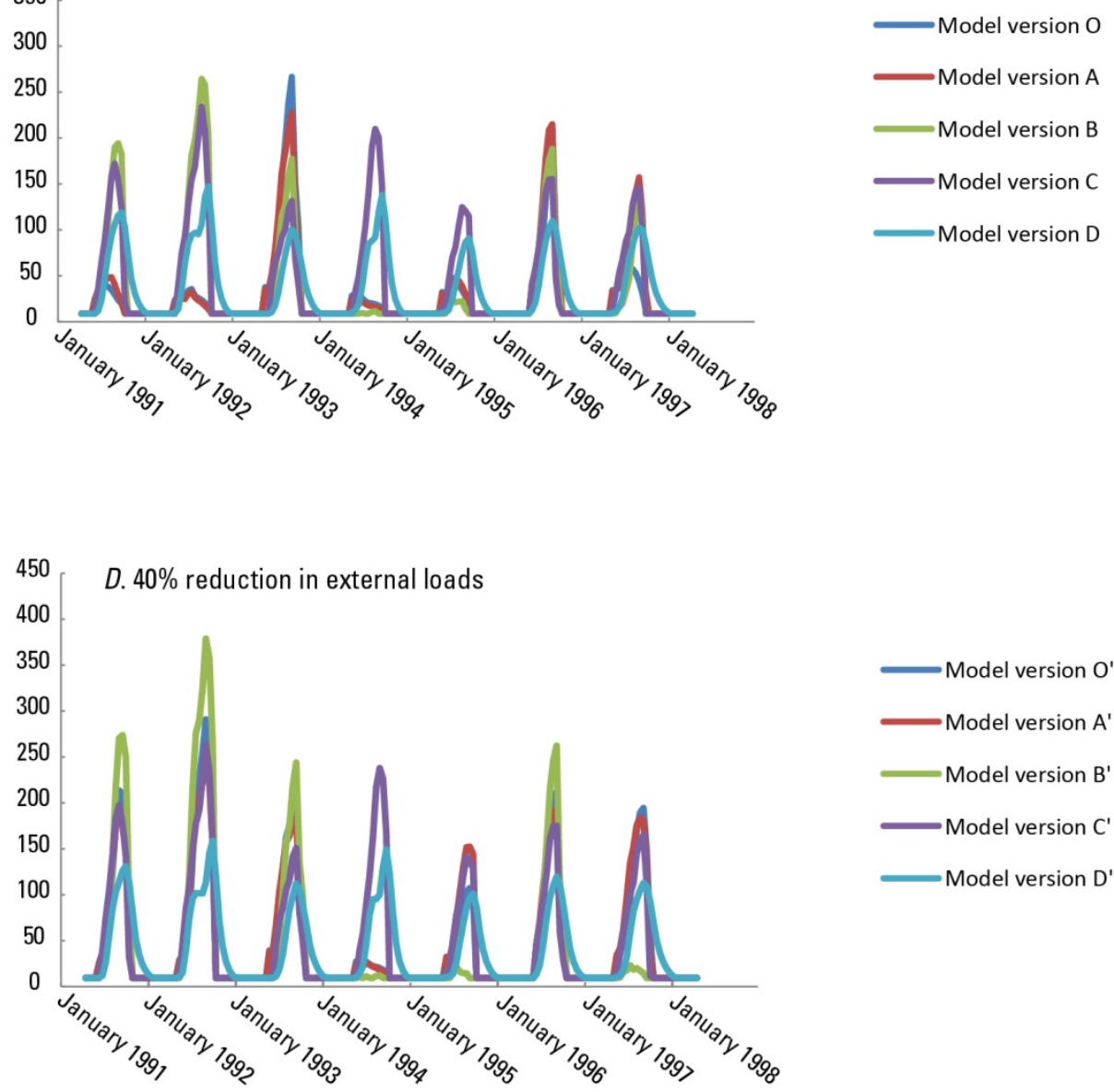

Figure 18. Graphs showing simulated chlorophyll a concentration during the last 7 years of a 203-year simulation under conditions of $(A$ and $C) 0$ percent and $(B$ and $D) 40$ percent reductions in external loads to Upper Klamath Lake, Oregon. The $x$-axis is labeled with the date in the 7-year cycle of observations that was merged end-to-end to create 203 years of boundary condition data to run the model. Versions of the model marked with a prime symbol ( $O^{\prime}$, for example) were calibrated using a lower initial condition of the sediment phosphorus reservoir than the corresponding versions without the prime symbol. Versions $O$ and $O^{\prime}=$ original model, original calibration; versions $A$ and $A^{\prime}=$ original model, recalibrated; versions $B$ and $B^{\prime}=$ =modifications to light and phosphorus limitations to algal growth; versions $C$ and $C^{\prime}=$ version $B$ with replacement of $\mathrm{pH}$-dependent recycling with temperature-dependent recycling; versions $D$ and $D^{\prime}=$ version $B$ without assumption of maximum chlorophyll a growth during each time step. 

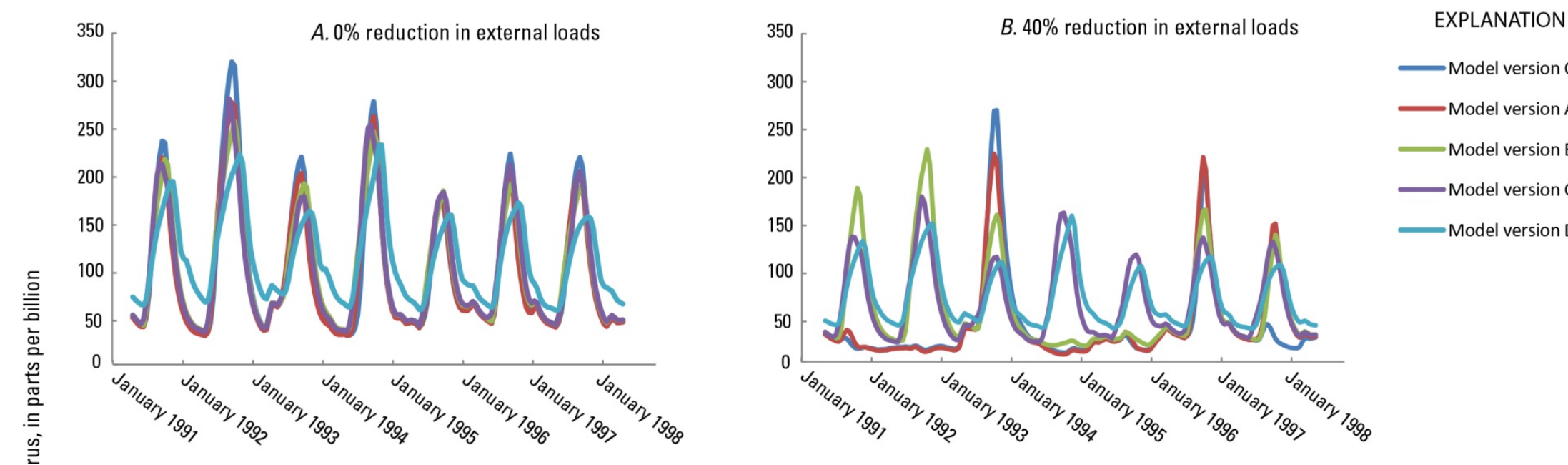

Model version 0

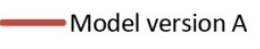

Model version B

- Model version D
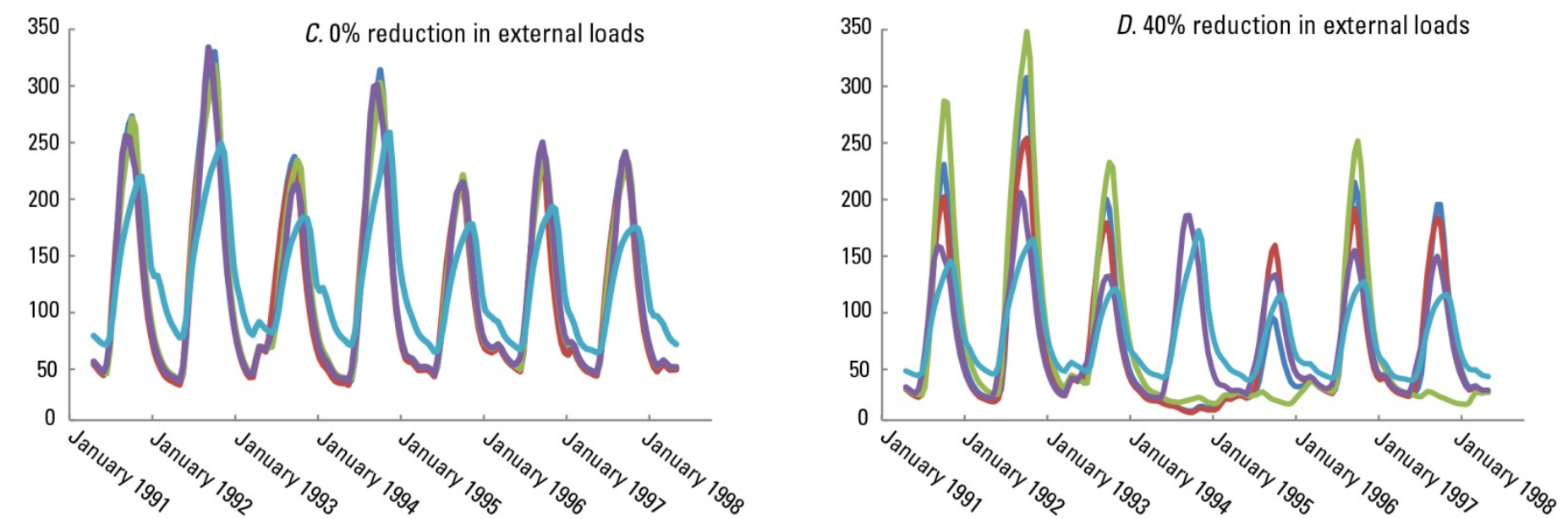

Model version $\mathrm{A}^{\prime}$

Model version B'

Model version C'

Model version D'

Figure 19. Graphs showing simulated total phosphorus concentration during the last 7 years of a 203-year simulation under conditions of $(A$ and $C)$ 0 percent and $(B$ and $D) 40$ percent reductions in external loads to Upper Klamath Lake, Oregon. The x-axis is labeled with the date in the 7-year cycle of observations that was merged end-to-end to create 203 years of boundary condition data to run the model. Versions of the model marked with a prime symbol $\left(O^{\prime}\right.$, for example) were calibrated using a lower initial condition of the sediment phosphorus reservoir than the corresponding versions without the prime symbol. Versions $O$ and $O^{\prime}=$ original model, original calibration; versions $A$ and $A^{\prime}=$ original model, recalibrated; versions $B$ and $B^{\prime}=$ modifications to light and phosphorus limitations to algal growth; versions $C$ and $C^{\prime}=$ version $B$ with replacement of $p H$-dependent recycling with temperature-dependent recycling; versions $D$ and $D^{\prime}=$ version $B$ without assumption of maximum chlorophyll a growth during each time step. 


\section{Summary, Conclusions, and Sugges- tions for Improvements to the TMDL Model}

\section{Verification of Model Algorithms}

Verification of the calibration of the original TMDL model revealed a few, minor discrepancies in calibration parameters; however, these could be explained by our interpretation of ambiguous descriptions of the calibration dataset in the model documentation. For the most part, the calibration of the model was duplicated closely with the original calibration dataset, which included phosphorus loading and water-quality data from 1991 through 1998. Because the semi-analytical approach in the original model was difficult to follow and modify, we developed an R-script version of the model that used a conventional numerical solution technique, and used that code for all the simulations reported herein. The R-script code is supplied as an appendix to this report.

The verification process identified three changes in model algorithms that would be helpful in improving the representation of lake processes in the model:

1. The light limitation function would better represent the available light for photosynthesis if it were integrated over depth, rather than substituting a depth-averaged light value into the light-limitation function defined for a specific depth.

2. The phosphorus limitation function would be more defensible if it were modified to incorporate a Michaelis-Menten formulation, rather than using a simple percentage of nonalgal phosphorus in the water column.

3. The assumption that chlorophyll a reaches equilibrium with light and nutrients over the time step does not accurately reflect the response time of the algal population to these factors, and the equation for chlorophyll $a$ would best be solved numerically, as are the equations for water column and sediment phosphorus. Implementation of change 3 would be facilitated by eliminating the discontinuity in the $\mathrm{pH}$ regression model at the end of the calendar year, which was not done in this study.

\section{Sensitivity of Calibration Parameters to Model Assumptions}

We developed a simple temperaturedependent recycling term based on a hypothesis that benthic invertebrate activity is an important driver of internal phosphorus loading and that such activity is stimulated by higher temperature. This term used a recycling rate analogous to the $\mathrm{pH}$-dependent recycling rate and a threshold temperature that also was treated as a calibration parameter. The temperature-dependent recycling term, therefore, required two calibration parameters, as did the $\mathrm{pH}$-dependent term. As a result, when this temperature-dependent recycling mechanism was substituted for the $\mathrm{pH}$-dependent mechanism in the original model, the total number of calibration parameters did not change.

We incorporated each of these three modifications to the original model-changes to the light and phosphorus limitation to growth, substitution of a temperature-dependent recycling term for the $\mathrm{pH}$-dependent term, and elimination of the assumption of maximum cyanobacterial growth during each time step - into new versions of the model. The algal settling velocity and recycling rate, or the algal settling velocity alone, as appropriate, were recalibrated using the same calibration dataset that was used in the calibration of the original model. The three new versions of the model, along with the original model and original calibration, as well as a recalibration of the original model done as part of this study, provided five calibrated versions of the model that could be compared by their performance over the validation dataset.

The calibrated settling velocity supplied with the original model was $0.05 \mathrm{~m} / \mathrm{d}$. The value of this parameter in the four versions of the model creat- 
ed as part of this study varied from $0.059 \mathrm{~m} / \mathrm{d}$ (+18 percent) to $0.035 \mathrm{~m} / \mathrm{d}(-30$ percent). The calibrated recycling rate supplied with the original model was $0.53 / y r$. The value of this parameter in three versions of the model created as part of this study that included the $\mathrm{pH}$-dependent recycling mechanism varied from $0.32 / \mathrm{yr}(-39.6$ percent) to $0.47 / \mathrm{yr}(-11.3$ percent). The value of the recycling rate in the version of the model that incorporated temperature-dependent recycling instead of $\mathrm{pH}$ dependent recycling was $0.54 / \mathrm{yr}(+1.9$ percent $)$. These represent substantial changes to calibration parameters that are not easily related mechanistically to the modifications that define the different versions of the model. For example, the 30 percent decrease in the settling velocity and 40 percent decrease in the recycling rate occurred when the light and phosphorus limitation factors were modified as indicated. Rather, these changes in calibration parameters are the consequence of repeating the calibration process after making seemingly unrelated changes to the model assumptions.

A final sensitivity analysis examined the consequences of changing the initialization of the sediment phosphorus reservoir. The most recent estimates, based on a set of 26 cores that provided a more complete coverage of the lake than was available when the TMDL was adopted, indicate that the previous initialization of the sediment phosphorus reservoir was too high by as much as 66 percent. The recycling rate in each of the five model versions was recalibrated using this new estimate. The calibrated recycling rate in each version of the model increased to compensate for the lower sediment concentration. (Because the recycled mass is proportional to both the size of the reservoir and the recycling rate, to achieve approximately the same balance in equation 1 , the rate must increase if the phosphorus content decreases.) The $\mathrm{pH}$-dependent recycling rate in this second set of five versions of the model varied from 1.05 to $1.33 / \mathrm{yr}$, and the temperaturedependent recycling rate was 1.62/ yr.

Although the changes in calibration parameters among all 10 versions of the model were substantial, the performance of the model based on statistics calculated over the full verification data set was not much changed, and was uniformly poor. Further, no model version consistently produced the best or worse results among the three state variables - total phosphorus, chlorophyll $a$, and $\mathrm{pH}$. When only May-July was considered in calculating statistics, performance was better. Generally, the differences among the various model versions were small, but the version of the model that did not assume maximum growth during the time step performed better overall in simulating chlorophyll $a$ and $\mathrm{pH}$. All versions of the model, therefore, performed better during months of rapid bloom expansion than during the other months of the year.

\section{Effect of Calibration Parameters on Long-Term Model Simulations}

Although the differences in model performance statistics among the various versions tested were small, when the models were used to examine the long-term steady-state conditions, the differences in the value of calibration parameters manifested themselves as sometimes large differences in concentration over time frames exceeding several decades. All versions of the model, when used to simulate water column concentrations characterizing a steady state 203 years into the future, produced lower total phosphorus concentrations over time, even when no reductions in the external load boundary condition were applied. When 40 percent reductions in the external load boundary condition were applied, the steady-state concentrations were always lower than when no reduction was applied. Within that broadly consistent result, however, there were large variations in the steady-state concentration that could be related to the ratio of the recycling term to the sedimentation term in the mass balance, with more recycling relative to sedimentation resulting in higher concentrations. The values of the recycling and sedimentation terms are directly dependent on the value of the calibration parameters - in particular the algal settling velocity and the recycling rate. 
The phosphorus stored in the sediment reservoir generally — although not always - decreased over time as well, and as with the water column concentrations, there was a wide range in the steady-state value that could be related to the ratio of the recycling term to the sedimentation term in the mass balance and the values of the calibration parameters that largely determine that ratio. The higher the ratio, indicating that there is more recycling relative to sedimentation, the lower the steady-state phosphorus reservoir. It follows that the steady-state water column phosphorus concentration was negatively correlated with the steadystate sediment reservoir - a lower steady-state sediment reservoir was associated with higher steady-state water column phosphorus concentration.

This last point became apparent when versions of the model that were calibrated to an updated, lower initial sediment reservoir were used to produce 203-year simulations. Models calibrated to the lower initial sediment reservoir simulated higher steady-state water column phosphorus concentrations than the counterpart calibrated to the higher sediment reservoir. For example, for models calibrated to a higher sediment reservoir, the steady-state phosphorus concentration ranged from about 103 to $117 \mathrm{ppb}$ when no reduction in the external load boundary condition was applied, and from about 40 to 70 ppb when a 40 percent reduction in the external load boundary condition was applied. For models calibrated to the lower sediment reservoir, the steady-state phosphorus concentration ranged from about 118 to $129 \mathrm{ppb}$ when no reduction in the external load boundary condition was applied and from about 69 to 78 ppb when a 40 percent reduction in the external load boundary condition was applied. Therefore, the sediment reservoir influences the long-term behavior of the modeled water column concentrations in an important and possibly counterintuitive way. These model results indicate that sediment phosphorus does not act as a supply that moves uniformly toward depletion over time. Rather, the model algorithms require the lake water column to reach a steady state in equilibrium with the sediments, and the steadystate conditions in the water column and sediments are determined by the calibration parameters. In some simulations, the size of the sediment phosphorus reservoir stayed mostly steady or increased slightly over time as that equilibrium state was approached. A corollary is that the initial size of the sediment reservoir is not as important in determining steady-state conditions as the rate of the lake processes that add phosphorus to the sediment through settling and recycle phosphorus from sediments to the water column.

Another metric that described steady-state conditions was the number of years in the final 7year cycle in which peak chlorophyll $a$ exceeded $100 \mathrm{ppb}$. This number was 7 out of 7 for all 10 model versions when no reduction in external load boundary conditions was applied - in other words, without a reduction in external loads, even though phosphorus and chlorophyll $a$ concentrations decreased over time, the peak chlorophyll $a$ concentration still exceeded 100 ppb every year. When a 40 percent reduction in external load was applied, however, the number of years in which peak chlorophyll $a$ exceeded $100 \mathrm{ppb}$ decreased to between 2 and 6 years out of 7, depending on the model version, and for only those versions that incorporated a $\mathrm{pH}$-dependent recycle mechanism.

Because $\mathrm{pH}$ is proportional to the logarithm of chlorophyll $a$, and recycling is in turn proportional to $\mathrm{pH}$ when a $\mathrm{pH}$-dependent recycle mechanism is used, reductions in chlorophyll $a$ are manifested as reductions in recycling, which lead to further reductions in chlorophyll $a$, and so on. This leads to a bimodal distribution of chlorophyll $a$, corresponding to very large blooms in some years and very small blooms in other years. Any recycling mechanism that does not have the same feedback would lead to a unimodal distribution. This was demonstrated in this study with a simple temperature-dependent recycling mechanism. Versions of the model in which a temperaturedependent recycle mechanism was substituted for a $\mathrm{pH}$-dependent mechanism simulated chlorophyll $a$ concentration maxima at steady state that were lower during large bloom years, but still exceeded 
$100 \mathrm{ppb}$ in every year because recycling was more even across all years. Because new evidence indicates that $\mathrm{pH}$-dependent desorption of phosphorus from iron oxyhydroxides is one of several mechanisms for the internal loading of phosphorus in the lake, and given that the form of the recycling term has a strong influence on the model outcome, efforts to improve the predictive power of the model likely will be most successful if they include a refinement of this recycling term.

\section{Suggestions for Improvements to the TMDL Model}

The goal of the sensitivity analysis was not to create a more "correct" model or to determine the "correct" calibration parameters, but rather to demonstrate sensitivity of the calibration parameters to model assumptions and initial conditions. If the comparison is limited to model versions that were calibrated with the updated initial phosphorus reservoir, calibrated values of the recycle rate over all the model modifications tested ranged from 1.05 to 1.62 per year. The settling velocity of algal phosphorus ranged from 0.035 to $0.059 \mathrm{~m} / \mathrm{d}$. The nonalgal phosphorus loss rate was not revisited as part of the sensitivity analysis because it was calculated based on observations of wintertime total phosphorus, but the linear model used to determine the nonalgal phosphorus loss rate did not have predictive power and, therefore, confidence in the parameter value was low. Such a wide range in calibrated values indicates that the parameter calibration is not converging on a value that represents a true physical or chemical process. Rather, it indicates that the parameter calibration is compensating for imprecise formulations of those processes and that some of the streamlined equations in the model are not adequate placeholders for the more complex phenomena that occur in the lake.

The model could be improved by reducing uncertainty in the recycling and sedimentation terms. One approach would be to undertake a field program to directly measure or estimate by other means the parameters required for the recycling and sedimentation terms in the model, and in the process to either determine appropriate constant values (as are used in the original model for algal settling rate and nonalgal loss rate) or develop new algorithms that can be implemented within the model to predict these terms as functions of other environmental variables that are available as input data. In the case of macro-invertebratedependent recycling, for example, two important explanatory variables might be water temperature and time elapsed since the start of the growing season, which would be related to the timing of increased invertebrate growth and activity in the spring and the progression of species cohorts.

The contribution of benthic invertebrates to nutrient cycling in Upper Klamath Lake has begun to be quantified; however, much remains to be learned regarding their role. For example, leeches (functionally biodiffusers) represent a significant fraction of the benthic assemblage at all spatial and temporal scales thus far examined, but we have yet to consider their roles in phosphorus release. Additionally, the rate at which nutrients are released by a species possibly changes at different life stages. Given the synchronicity of many invertebrate life stages, this effect, if present, could be important relative to nutrient recycling both spatially and temporally. Further, trophic interactions likely affect $A$. flos-aquae, Microcystis, tubificid worm, leech, midge, and fish population dynamics in ways that influence phosphorus cycling in Upper Klamath Lake. Additionally, the influence of zooplankton on nutrient cycling has yet to be studied in the lake. Better defining the interactions between climate, hydrodynamics, chemistry, and biology would greatly enhance our understanding of the ecology of Upper Klamath Lake. It is not within the scope of this study to provide a detailed plan for making such measurements/estimates; however, some tools and techniques that likely would be useful can be identified.

Quantitative assessment of the contribution of metabolic cycling and excretion by benthic invertebrates to the recycling of phosphorus from the sediments through a season would require collection of density, body-size, and body-stoichiometry data for the most dominant taxa at representative 
sites in the lake on at least a biweekly time scale (the time step of the model) and over a few growing seasons to capture intra-annual variability. Inverse modeling techniques combined with pore water profiles can be used to determine bioturbation and bio-irrigation parameters (Meile and others, 2001) that define the enhancement of diffusion processes by bioturbation and bioirrigation. Such techniques could be used in combination with silica profiles (silica acts like a conservative tracer) that already have been collected in the lake and wetlands with a pore water profiler (Kuwabara and others, 2007). A calibrated early diagenesis sediment model in combination with pore water profiles of reacting solutes, such as redox sensitive species and $\mathrm{pH}$ (Berg and others, 2003), could be used to infer degradation rates of settled organic material. Because recycling can be expected to vary spatially around the lake, as does sediment phosphorus, benthic invertebrate density, and the sedimentation of fresh organic material, a spatially explicit phosphorus transport model of the lake could be used to appropriately "scale up" the spatial variability from sitedependent estimates for use in a CSTR model.

A fundamental problem regarding sedimentation is that the model uses sedimentation to account for the process of removal of algal phosphorus from the water column, but no mortality term in the equations moves algal phosphorus from a viable (largely non-settling) to a detrital (settling) physiological state. Uniform settling of the large buoyant colonies that dominate the cyanobacterial population in Upper Klamath Lake through the season is unlikely. Rather, more settling likely occurs during bloom declines. Experimentation with sediment traps in Upper Klamath Lake (Eldridge and others, 2013) determined that settling algal material was partially degraded, not bright green and healthy, which supports the idea that settling increases when the bloom is declining. Large, net negative internal loading based on mass balance calculations also indicates that large quantities of suspended material settle during periods of algal decline (Kann and Walker, 2001). This is the reason that the per- formance of the model degrades when it is validated with data from outside May-July, when the bloom is usually growing rapidly. A rapid decline in the bloom that the model cannot simulate occurs at some point after the second week in July in most years, roughly coincident with the seasonal maximum temperature (Lindenberg and others, 2009). Consequently, the model consistently overpredicts total phosphorus (by overpredicting the algal phosphorus component) and particularly chlorophyll $a$ concentrations after the bloom decline, as noted by Walker (2001).

To address this problem, the model could be improved by incorporating a mortality term. As noted by Walker (2001), the reason for the seasonal rapid bloom decline was not known when the model was developed, so no term was developed to describe the phenomenon. Although the cause still remains largely unknown, 20 years of biweekly profiles collected by the Klamath Tribes and 8 years of continuous monitor data collected by the USGS provide a description of the seasonal bloom dynamics over a wide range of conditions. An adequate empirical description of the midseason bloom decline possibly could be developed for incorporation into the TMDL model with the use of those data.

The previously noted difficulty with calibration of the nonalgal phosphorus loss rate is caused by the inability of the model to distinguish different forms of nonalgal phosphorus that have substantially different loss rates. For example, the principal components analysis of bed sediment cores provided evidence that particle-associated inorganic phosphorus settles out of the water column downstream of the Williamson River mouth. The model could be improved by tracking particle-associated and dissolved nonalgal phosphorus separately. This would require information about the distribution of phosphorus between the two fractions at the tributary boundaries.

Finally, the TMDL model parameters, and consequently the character of the simulations (particularly the long-term 203-year response), are likely to be dependent on the dataset used during 
calibration. Several simulations of the long-term behavior of the model have been presented in this report, and these simulations generally indicate that a steady state is achieved within about 50 years. All the calibrated models were consistent in that they resulted in a final steady-state in which total phosphorus concentration in the lakes was reduced, and most models simulated severe blooms ( $>100 \mathrm{ppb}$ ) happening less often by the time steady state was reached. However, the calibration process essentially fits the early part of the simulation to the available data, but the long-term response is an extrapolation that depends on the form of the model and its fitting parameters. In this case, the water-quality data from 1991 through 1998 that were used to calibrate the model showed decreasing trends in the average inflow and lake concentrations by about 2.8 percent per year and 8.2 percent per year, respectively (Walker, 2001). Those decreasing trends are incorporated into the fitting parameters. An updated mass balance dataset was not available for updating the model, but when a longer term dataset becomes available, the potential changes to calibrated parameters based on a longer calibration dataset and the performance of the model over a longer validation dataset can be evaluated.

\section{References Cited}

Aldous, A.R., Craft, C.B., Stevens, C.J., Barry, M.J., and Bach, L.B., 2007, Soil phosphorus release from a restoration wetland, Upper

Klamath Lake, Oregon: Wetlands, v. 27, no. 4, p. 1025-1035.

Aldous, A., McCormich, P., Ferguson, C., Graham, S., and Craft, C., 2005, Hydrologic regime controls soil phosphorus fluxes in restoration and undisturbed wetlands: Restoration Ecology, v. 13, no. 2, p. 341-347.

Alves, J.M., Caliman, A., Guariento, R.D., Figueiredo-Barros, M.P., Carneiro, L.S., Farjalla, V.F., Bozelli, R.L., and Esteves, F.A., 2010, Stoichiometry of benthic invertebrate nutrient recycling-Interspecific variation and the role of body mass: Aquatic Ecology, v. 44, p. 421-430.

Andersson, G., Graneli, W., and Stenson, J., 1988, The influence of animals on phosphorus cycling in lake ecosystems: Hydrobiologia, v. 170, p. 267-284.

Banish, N.P., Adams, B.J., and Shively, R.S., 2009, Distribution and habitat associations of radio-tagged adult Lost River suckers and shortnose suckers in Upper Klamath Lake, Oregon: Transactions of the American Fisheries Society, v. 138, p. 153-168.

Barbiero, R.P., and Kann, J., 1994, The importance of benthic recruitment to the population development of Aphanizomenon flos-aquae and internal loading in a shallow lake: Journal of Plankton Research, v. 16, p. 1581-1588.

Berg, P., Rysgaard, S., and Thamdrup, B., 2003, Dynamic modeling of early diagenesis and nutrient cycling - A case study in an arctic marine sediment: American Journal of Science, v. 303, p. 905-955.

Bowie, G.L., Mills, W.B., Porcella, D.B., Campbell, C.L., Pagenkopf, J.R., Rupp, G.L., Johnson, K.M., Chan, P.W.H., Gherini, S.A., and Chamberlin, C.E., 1985, Rates, constants, and kinetics formulations in surface water quality modeling: U.S. Environmental Protection Agency, EPA/600/3-85/040, 455 p.

Bradbury, J.P., Colman, S.M., and Reynolds, R.L., 2004, The history of recent limnological changes and human impact on Upper Klamath Lake, Oregon: Journal of Paleolimnology, v. 31, p. 151-165.

Burden, R.L., and Faires, J.D., 1997, Numerical analysis: Pacific Grove, California, Brooks/Cole Publishing Co., 811 p.

Devine, J.A., and Vanni, M.J., 2002, Spatial and seasonal variation in nutrient excretion by benthic invertebrates in a eutrophic reservoir: Freshwater Biology, v. 47, p. 1107-1121.

Eilers, J.M., Kann, J., Cornett, J., Moser, K., St. Amand, A., and Gubala, C., 2001, Recent paleo- 
limnology of Upper Klamath Lake, Oregon: Roseburg, Oreg., JC Headwaters, Inc., 44 p.

Eilers, J.M., Kann, J., Cornett, J., Moser, K., and St. Amand, A., 2004, Paleolimnological evidence of change in a shallow, hypereutrophic lake-Upper Klamath Lake, Oregon, USA: Hydrobiologia, v. 520, p. 7-18.

Eldridge, S.L., Wood, T.M., Echols, K.R., and Topping, B.R., 2013, Microcystins, nutrient dynamics, and other environmental factors during blooms of non-microcystin-producing Aphanizomenon flos-aquae in Upper Klamath Lake, Oregon, 2009: Lake and Reservoir Management, v. 29 , p. $68-81$. DOI: 10.1080/10402381.2013.775199.

Eldridge, D.B., Caldwell Eldridge, S.L., Schenk, L.S., and Wood, T.M., 2012, Water quality data from Upper Klamath and Agency Lakes, Oregon, 2009-10: U.S. Geological Survey OpenFile Report 2012-1142, 32 p. (Also available at http://pubs.usgs.gov/of/2012/1142.)

Elsroad, A., Rudd, N., and Hendrixson, H., 2011, Williamson River Delta Preserve vegetation monitoring - Tulana third-year post-breaching results: Klamath Falls, Oregon, The Nature Conservancy, 14 p., accessed August 26, 2013, at http://conserveonline.org/library/williamsonriver-delta-preserve-vegetation-2/@@view.html.

Fisher, L.H., and Wood, T.M., 2004, Effect of water-column $\mathrm{pH}$ on sediment-phosphorus release rates in Upper Klamath Lake, Oregon, 2001: U.S. Geological Survey Water-Resources Investigations Report 03-4271, 25 p.

Forsberg, B.R., and Shapiro, J., 1981, The effects of artificial destratification on algal populations, in Stefan, H.G., ed., Proceedings of the Symposium on Surface Water Impoundments, June 25, 1980, Minneapolis, Minnesota: New York, American Society of Civil Engineers, p. 851864.

Fukuhara, H., and Sakamoto, M., 1987, Enhancement of inorganic nitrogen and phosphate release from lake sediment by tubificid worms and chironomid larvae: Oikos, v. 38, p. 312320 .
Fukuhara, H., and Yasuda, K., 1985, Phosphorus excretion by some zoobenthos in a eutrophic freshwater lake and its temperature dependency: Japanese Journal of Limnology, v. 46, p. 287296.

Gardner, W.S., Nalepa, T.F., Quigley, M.A., and Malczyk, J.M., 1981, Release of phosphorus by certain benthic invertebrates: Canadian Journal of Fisheries and Aquatic Science, v. 38, p. 978981.

Graham, S.A., Craft, C.B., McCormick, P.V., and Aldous, A., 2005, Forms and accumulation of soil $\mathrm{P}$ in natural and recently restored peatlands-Upper Klamath Lake, Oregon, USA: Wetlands, v. 25, no. 3, p. 594-606.

Hansen, K., Mouridsen, S., and Kristensen, E., 1998, The impact of Chironomus plumosus larvae on organic matter decay and nutrient $(\mathrm{N}, \mathrm{P})$ exchange in a shallow eutrophic lake sediment following a phytoplankton sedimentation: Hydrobiologia, v. 364, p. 65-74.

Haykin, S., 1999, Neural Networks: A Comprehensive Foundation 2nd Edition, Prentice Hall, Upper Saddle River, New Jersey.

Hoilman, G.R., Lindenberg, M.K., and Wood, T.M., 2008, Water quality conditions in Upper Klamath and Agency Lakes, Oregon, 2005: U.S. Geological Survey Scientific Investigations Report 2008-5026, $44 \mathrm{p}$.

Jacoby, J.M., Lynch, D.D., Welch, E.B., and Perkins, M.A., 1982, Internal phosphorus loading in a shallow eutrophic lake: Water Research, v. 16, p. 911-919.

Kaiser, H.F., 1958, The varimax criterion for analytic rotation in factor analysis: Psychometrika, vol. 23 , no. 3, p. 187-200.

Kaiser, H.F., 1960, The application of electronic computers to factor analysis: Educational and Psychological Measurement, vol. 20, 141-151.

Kann, J., 1998, Ecology and water quality dynamics of a shallow hypereutrophic lake dominated by cyanobacteria (Aphanizomenon flos-aquae): Chapel Hill, University of North Carolina, PhD dissertation, $110 \mathrm{p}$. 
Kann, J., 2011a, Upper Klamath Lake 2010 data summary report: Ashland, Oregon, Aquatic Ecosystem Sciences LLC, 54 p.

Kann, J., 2011b, Upper Klamath Lake tributary loading — 2010 data summary report: Ashland, Oregon, Aquatic Ecosystem Sciences, LLC, 31 p.

Kann, J., and Smith, V.H., 1999, Estimating the probability of exceeding elevated $\mathrm{pH}$ values critical to fish populations in a hypereutrophic lake: Canadian Journal of Fisheries and Aquatic Sciences, v. 56, p. 2,262-2,270.

Kann, Jacob, and Walker, W.W., 2001, Nutrient and hydrologic loading to Upper Klamath Lake: Klamath Tribes Natural Resource Department, U.S. Bureau of Reclamation Cooperative Studies, $48 \mathrm{p}$.

Kann, Jacob, and Welch, J.B., 2005, Wind control on water quality in shallow, hypereutrophic Upper Klamath Lake, Oregon: Lake and Reservoir Management, v. 21, no. 2, p. 149-158.

Koski-Vahala, J., and Hartikainen, H., 2001, Assessment of the risk of phosphorus loading due to resuspended sediment: Journal of Environmental Quality, v. 30, p. 960-966.

Kuwabara, J.S., Lynch, D.D., Topping, B.R., Murphy, F., Carter, J.L., Simon, N.S., Parchaso, F., Wood, T.M., Lindenberg, M.K., Wiese, K., and Avanzino, R.J., 2007, Quantifying the benthic source of nutrients to the water column of Upper Klamath Lake, Oregon: U.S. Geological Survey Open-File Report 2007-1276, 39 p. (Also available at http://pubs.usgs.gov/of/2007/1276/)

Kuwabara, J.S., Topping, B.R., Carter, J.L., Wood, T.M., Parchaso, F., Cameron, J.M., Asbill, J.R., Carlson, R.A., Fend, S.V., 2012a, Time scales of change in chemical and biological parameters after engineered levee breaches adjacent to Upper Klamath and Agency Lakes, Oregon: U.S. Geological Survey Open-File Report 2012-1057, 26 p. (Also available at http://pubs.usgs.gov/of/2012/1057/)

Kuwabara, J.S., Topping, B.R., Carter, J.L., Wood, T.M., Cameron, J.M., Asbill-Case, J.R.,
Carlson, R.A., 2012b, Changes in benthic nutrient sources within a wetland after hydrologic reconnection: Environmental Toxicology and Chemistry, v. 31, no. 9, p. 1995-2013.

Kuwabara, J.S., Topping, B.R., Lynch, D.D., Carter, J.L., and Essaid, H.I., 2009, Benthic nutrient sources to hypereutrophic Upper Klamath Lake, Oregon, USA: Environmental Toxicology and Chemistry, v. 28, p. 516-524.

Laenen, A., and LeTourneau, A.P., 1996, Upper Klamath basin nutrient-loading study-Estimate of wind-induced resuspension of bed sediment during periods of low lake elevation: U.S. Geological Survey Open File Report 95-414, 11 p. (Also available at http://pubs.er.usgs.gov/publication/ofr95414.)

Lindenberg, M.K., Hoilman, Gene, and Wood, T.M., 2009, Water quality conditions in Upper Klamath and Agency Lakes, Oregon, 2006: U.S. Geological Survey Scientific Investigations Report 2008-5201, $54 \mathrm{p}$. (Also available at http://pubs.usgs.gov/sir/2008/5201/.)

Meile, C., Koretsky, C.M., and Van Cappellen, P., 2001, Quantifying bioirrigation in aquatic sediments-An inverse modeling approach: Limnology and Oceanography, v. 46, p. 164177.

Mermillod-Blondin, F., 2011, The functional significance of bioturbation and biodeposition on biogeochemical processes at the water-sediment interface in freshwater and marine ecosystems: Journal of the North American Benthological Society, v. 30, no. 3, p. 770-778.

Mermillod-Blondin, F., and Rosenberg, R., 2006, Ecosystem engineering: the impact of bioturbation on biogeochemical processes in marine and freshwater benthic habitats: Aquatic Science, v. 68, p. 434-442.

Michaud, E., Desrosiers, G., Mermillod-Blondin, F., Sundby, B., and Stora, G., 2005, The functional group approach to bioturbation-The effects of biodiffusers and gallery-diffusers of the Macoma balthica community on sediment oxygen uptake: Journal of Experimental Marine Biology and Ecology, v. 326, p. 77-88. 
Michaud, E., Desrosiers, G., Mermillod-Blondin, F., Sundby, B., and Stora, G., 2006, The functional group approach to bioturbation-II. The effects of the Macoma balthica community on fluxes of nutrients and dissolved organic carbon across the sediment-water interface: Journal of Experimental Marine Biology and Ecology, v. 337, p. 178-189.

Morace, J.L., 2007, Relation between selected water-quality variables, climatic factors, and lake levels in Upper Klamath and Agency Lakes, Oregon, 1990-2006: U.S. Geological Survey Scientific Investigations Report 2007-5117, 54 p. (Also available at http://pubs.usgs.gov/sir/2007/5117/.)

Nash, J.E. and Sutcliffe, J.V., 1970, River flow forecasting through conceptual models part I A discussion of principles: Journal of Hydrology, v. 10, no. 3, p. 282-290.

Niemisto, J., Holmroos, H., and Horppila, J., 2011, Water $\mathrm{pH}$ and sediment resuspension regulating internal phosphorus loading in a shallow lakeField experiment on diurnal variation: Journal of Limnology, v. 70, no. 1, p. 3-10.

Nogaro, G., Mermillod-Blondin, F., Valett, M.H., Francois-Carcaillet, F., Gaudet, J.-P., Lafont, M., and Gibert, J., 2009, Ecosystem engineering at the sediment-water interface-Bioturbation and consumer-substrate interaction: Oecologia, v. 161, p. $125-138$.

Oregon Department of Environmental Quality, 2002, Upper Klamath Lake drainage Total Maximum Daily Load (TMDL) and Water Quality Management Plan (WQMP): Oregon Department of Environmental Quality, 188 p., accessed August 8, 2013, at http://www.deq.state.or.us/WQ/TMDLs/klamath. htm.

Oregon Department of Environmental Quality, 2010, Upper Klamath and Lost River subbasins total maximum daily load (TMDL) and water quality management plan (WQMP): Oregon Department of Environmental Quality, 231 p., plus app., accessed August 8, 2013, at
http://www.deq.state.or.us/WQ/TMDLs/klamath. htm.)

Perkins, D.L., Kann, J., and Scoppettone, G.G., 2000, The role of poor water quality and fish kills in the decline of endangered Lost River and shortnose suckers in Upper Klamath Lake, U. S. Geological Survey, Biological Resources Division Report submitted to the U. S. Bureau of Reclamation, Contract 4-AA-29-12160: Klamath Falls, Oregon, U.S. Geological Survey, Klamath Falls Project Office.

Quintana, C.O., Tang, Min, and Kristensen, Erik, 2007, Simultaneous study of particle reworking, irrigation transport and reaction rates in sediment bioturbated by the polychaetes

Heteromastus and Marenzelleria: Journal of Experimental Marine Biology and Ecology, v. 352, p. 392-406.

$\mathrm{R}$ Core Team, 2012, R-A language and environment for statistical computing: Vienna, Austria, R Foundation for Statistical Computing, ISBN 3-900051-07-0, accessed August 20, 2013, at http://www.R-project.org/.

Redfield, A.C., 1934, On the proportions of organic derivations in sea water and their relation to the composition of plankton, in Daniel, R.J., ed., James Johnstone Memorial Volume: University Press of Liverpool, p. 177-192.

Rounds, S.A., and Sullivan, A.B., 2009, Review of Klamath River total maximum daily load models from Link River Dam to Keno Dam, Oregon: U.S. Geological Survey Administrative Report, 37 p., accessed August 20, 2013, at http://www.usbr.gov/mp/kbao/waterquality/klamath _river_model_review_final.pdf.

Rounds, S.A., and Sullivan, A.B., 2013, Review of revised Klamath River Total Maximum Daily Load models from Link River Dam to Keno Dam, Oregon: U.S. Geological Survey OpenFile Report 2013-1136, 31 p. (Also available at http://pubs.usgs.gov/of/2013/1136/.)

Senft, W.H., 1978, Dependence of light-saturated rates of algal photosynthesis on intra-cellular concentrations of phosphorus: Limnology and Oceanography, v. 23, p. 709-718. 
Sereda, J.F., and Hudson, J.J., 2011, Empirical models for predicting the excretion of nutrients $(\mathrm{N}$ and P) by aquatic metazoans-Taxonomic differences in rates and element ratios: Freshwater Biology, v. 56, p. 250-263.

Simon, N.S., Lynch, D., and Gallaher, T.N., 2009, Phosphorus fractionation in sediment cores collected in 2005 before and after onset of an Aphanizomenon flos-aquae bloom in Upper Klamath Lake, OR, USA: Water, Air, and Soil Pollution, v. 204, p. 139-153, accessed August 20, 2013, at http://springerlink.com/content/06580113p6q415v 7/fulltext.pdf.

Simon, N.S., and Ingle, S.N., 2011, Physical and chemical characteristics including total and geochemical forms of phosphorus in sediment from the top 30 centimeters of cores collected in October 2006 at 26 sites in Upper Klamath Lake, Oregon: U.S. Geological Survey Open File Report 2011-1168, 49 p. (Available at http://pubs.usgs.gov/of/2011/1168/.)

Sondergaard, M., 1988, Seasonal variations in the loosely sorbed phosphorus fraction of the sediment of a shallow and hypereutrophic lake: Environmental Geology and Water Sciences, v. 11, p. 115-121.

Sondergaard, M., Kristensen, P., and Jeppesen, E., 1992, Phosphorus release from resuspended sediment in the shallow and wind exposed Lake Arreso, Denmark: Hydrobiologia, v. 228, p. 9199.

Talling, J.F., 1957, Photosynthetic characteristics of some freshwater plankton diatoms in relation to underwater radiation: New Phytologist, v. 56, no. 1, p. 29-50.

Vannote, R.L., and Sweeney, B.W., 1980, Geographic analysis of thermal equilibria-A conceptual model for evaluating the effect of natural and modified thermal regimes on aquatic insect communities: The American Naturalist, v. 115 , no. 5, p. 667-693.

Vollenweider, R.A., 1975, Input-output models with special reference to the phosphorus loading concept in limnology: Schweizererische Zeitschrift für Hydrologie, v. 37, p. 53-84.

Walker, W.W., Jr., 2001, Development of a phosphorus TMDL for Upper Klamath Lake, Oregon: prepared for Oregon Department of Environmental Quality, Bend, Oregon, 80 p., accessed August 26, 2013, at http://www.deq.state.or.us/wq/tmdls/docs/klama thbasin/ukldrainage/devphostmdl.pdf.

Wetzel, R.G., 1975, Limnology: W.B. Saunders, $743 \mathrm{p}$.

Wildung, R.E., and Schmidt, R.L., 1973, Phosphorus release from lake sediments, prepared for Office of Research and Monitoring, U.S. Environmental Protection Agency, Washington, D.C.: U.S. Environmental Protection Agency report EPA-R3-73-024, $185 \mathrm{p}$.

Wildung, R.E., Schmidt, R.L., and Routson, R.C., 1977, The phosphorus status of eutrophic lake sediments as related to changes in limnological conditions-Phosphorus mineral components: Journal of Environmental Quality, v. 6, no. 1, p. 100-104, accessed August 9, 2013, at http://dx.doi.org/10.2134/jeq1977.0047242500060 0010022x.

Wong, S.W., Barry, M.J., Aldous, A.R., Rudd, N.T., Hendrixson, H.A., and Doehring, C.M., 2011, Nutrient release from a recently flooded delta wetland-Comparison of field measurements to laboratory results: Wetlands, v. 31, p. 433-443.

Wong, S., and Hendrixson, H., 2011, Water quality conditions in the Williamson River delta, Oregon-Three years post-restoration: Klamath Falls, Oregon, The Nature Conservancy Klamath Basin Field Office, 2010 Annual Data Report, 38 p.

Wood, T.M., Fuhrer, G.J., and Morace, J.L., 1996, Relation between selected water-quality variables and lake level in Upper Klamath and Agency Lakes, Oregon: U.S. Geological Survey WaterResources Investigations Report 96-4079, 57 p. (Also available at http://pubs.er.usgs.gov/publication/wri964079)

Wood, T.M., 2001, Sediment oxygen demand in Upper Klamath and Agency Lakes, Oregon, 1999: U.S. Geological Survey Water-Resources Investigations Report 01-4080, 13 p. 
Wood, T.M., Hoilman, G.R., and Lindenberg, M.K., 2006, Water-quality conditions in Upper Klamath Lake, Oregon, 2002-2004: U.S. Geological Survey Scientific Investigations Report 2006-5209, 52 p. (Also available at http://pubs.usgs.gov/sir/2006/5209/.)

Wood, T.M., Cheng, R.T., Gartner, J.W., Hoilman, G.R., Lindenberg, M.K., and Wellman, R.E., 2008, Modeling hydrodynamics and heat transport in Upper Klamath Lake, Oregon, and implications for water quality: U.S. Geological Survey Scientific Investigations Report 2008-5076, 48 p. (Also available at $h t t p: / / p u b s . u s g s . g o v / s i r / 2008 / 5076 /)$

Zhang, L., Gu, X., Fan, C., Shang, J., Shen, Q., Wang, Z., and Shen, J., 2010, Impact of different benthic animals on phosphorus dynamics across the sediment-water interface: Journal of Environmental Sciences, v. 22, no. 11, p. 1674-1682. 


\title{
Appendix A. R-Script Code for Upper Klamath Lake Phosphorus Model
}

\author{
\#Load observed, bi-weekly input data \\ setwd("E:/users/swherry/UKL_TMDL_Project/TMDL_model/TMDL_model_R/") \\ input<-read.csv( "input_data.csv", header=TRUE) \\ \#Convert input Date column to date class \\ input\$Date<-as. Date (input\$Date, "\%m/\%d/\%Y") \\ \#Define iterative Chlorophyll a model termination criteria \\ iteration<-50 \\ difference $<-10^{\wedge}-16$
}

\#Define model parameters

$\mathrm{kg}<-0.012$

umn (1/day)

ph_sigma<- 0.25

ph2_int<-7.93101869324701

ph2_chla<- 0.533758530498359

ph2_julian<- - 0.00596604468236423

jdmin<-200

ph_min<-7.8

beta<- 0.0097

alpha<-1. 2

ihalf $<-214$

$\operatorname{gmax}<-1.2$

$r \max <-0.06$

topt $<-20$

tzero $<-14$

ур $<-0.6$

chla_min<-8

zsed $<-10$

sed_dens $<-0.12$

uburial<-1.4

latitude $<-42.5$

reflect<-0.1

par<- 0.714285714285714

wC_p $\odot<-74$

deltat $<-14$

area $<-271$

$v \odot<-622$

khalf<- $\odot .06$

\#Gross removal (sedimentation) rate of non-algal $\mathrm{P}$ from water col-

\#pH spatial standard deviation

\#pH vs chlorophyll a intercept

$\#$ pH vs chlorophyll a slope

\#pH vs Julian day slope

\#Minimum Julian day for model

\#Minimum predicted $\mathrm{pH}$

\#Algal light extinction coefficient $(1 / \mathrm{m} / \mathrm{ppb})$

\#Background light extinction $(1 / \mathrm{m})$

\#Onset of light saturation (uE/m2-sec)

\#Max algal growth rate (1/day)

\#Max algal respiration rate (1/day)

\#0ptimum temp for algal growth (deg-C)

\#Temperature when zero algal growth (deg-C)

\#Algal cell $\mathrm{P}$ quota (mg $\mathrm{P} / \mathrm{mg}$ chlorophyll a)

\#Minimum predicted chlorophyll a (ppb)

\#Active sediment thickness $(\mathrm{cm})$

\#Sediment bulk density $(\mathrm{g} / \mathrm{cm} 3)$

\#Burial velocity ( $\mathrm{mm} / \mathrm{yr}$ )

\#Latitude

\#Light reflection fraction

\#PAR/langley conversion

\#Initial water column total $\mathrm{P}$ concentration ( $\mathrm{ppb}$ )

\#Time increment (days)

\#Total lake area $(\mathrm{km} 2)$

\#Initial lake volume (hm3)

\#Phosphorus half saturation constant for Michaelis-Menten kinetics

\#Request inputs from the model user

reduc<-as.numeric(readline("How much load reduction (\%) is there? "))/100 \#Watershed load Reduction (\%)

ualgae<-as.numeric(readline("What is the algal settling velocity $(\mathrm{m} / \mathrm{d})$ ? ")) \#Algal settling rate $(\mathrm{m} / \mathrm{d})$

ph_threshold<-as.numeric(readline("What is $\mathrm{pH}^{*}(\mathrm{pH}$ at half max recycle)? ")) $\# \mathrm{pH}$ at half the max recycle rate

ks_ph<-as.numeric(readline("What is the maximum total $P$ recycle rate, KR? ")) \#Maximum total $P$ recycle rate (1/yr)

sed_po<-as.numeric(readline("What is the initial sediment total P concentration (0riginal=1000; Recalc=335)?

") \#Initial sediment total $\mathrm{P}$ concentration $(\mathrm{mg} / \mathrm{kg})$

\#Basic lake characteristics calculations

tmdl_load<-input\$Load* $(1-$ reduc)

load_tot<-(tmdl_load+input\$Precip_load)

v_0<-input\$End_Storage-input\$Change_Storage

v_mean<-input\$End_Storage-(input\$Change_Storage/2)

$z \quad 0<-v \_/$input $\$$ Area

$z \_m e a n<-v \_m e a n / i n p u t \$ A r e a$

q_out<-input\$outflow/deltat
\#Phosphorus load for given TMDL reduction \#Total P load from inflow and precip \#Initial lake volumes for each time step \#Mean lake volume for each time step \#Initial lake depth for each time step \#Mean lake depth for each time step \#Lake outflow for each time step

\#Calculated parameters from defined parameters

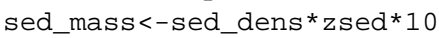

\#Sediment soil mass $(\mathrm{kg} / \mathrm{m} 2)$ 
sinit<-sed_mass*area*sed_po

minit<-wc_p $0^{*} v \_$mean [1]

step<-deltat $/ 365.25$

kb<-uburial/10/zsed
\#Initial sediment total $\mathrm{P}$ reservoir $(\mathrm{kg})$

\#Initial water column total $P(\mathrm{~kg})$

\#Time step (year)

\#Burial rate (1/yr)

\#Define the unknown variables the model will be solving for Mo<-vector $($ mode="numeric", length=nrow(input) $)$ step

Mt<-vector $($ mode="numeric", length=nrow(input $))$ \#Initial water column total $\mathrm{P}$ mass for each time (14 days later) Mavg<-vector $($ mode="numeric", length=nrow(input)) step

Cavg<-vector $($ mode="numeric", length=nrow(input $)$ )

time step

C_NA<-vector $($ mode="numeric", length=nrow(input) $)$ the time step

C_alg<-vector (mode="numeric", length=nrow(input) )

Sed_alg<-vector (mode="numeric", length=nrow(input))

Sed_NA<-vector $($ mode="numeric", length=nrow(input))

umn

Mout $<-\operatorname{vector}($ mode $=$ "numeric", length=nrow(input $))$

Mrec<-vector $($ mode="numeric", length=nrow (input))

the sediment

delM<-vector $($ mode="numeric", length=nrow(input))

So<-vector $($ mode="numeric", length=nrow (input) )

St<-vector (mode="numeric", length=nrow(input) )

days later)

Savg $<-\operatorname{vector}($ mode="numeric", length=nrow(input $))$

$\mathrm{Sb}<-\operatorname{vector}($ mode="numeric", length=nrow (input))

Chla<-vector $($ mode="numeric", length=nrow(input) $)$

$\mathrm{pH}<-\operatorname{vector}($ mode="numeric", length=nrow (input))

W_check<-vector (mode="numeric", length=nrow(input))

S_check<-vector $(\operatorname{mode}=$ "numeric", length=nrow(input))

\#Final water column total $\mathrm{P}$ mass for each time step \#Average water column total $P$ mass over the time \#Average water column total $\mathrm{P}$ concentration over the \#Non-algal water column total $\mathrm{P}$ concentration over

\#Algal water column total $\mathrm{P}$ concentration \#Mass of algal $P$ settling out of the water column \#Mass of non-algal $P$ settling out of the water col-

\#Mass of total $\mathrm{P}$ flowing out of the lake \#Mass of total $P$ recycled into the water column from

\#Change in mass of total $P$ over the time step \#Initial sediment total $P$ mass for each time step \#Final sediment total $P$ mass for each timstep (14

\#Average sediment total $P$ mass over the time step \#Mass of buried total $P$ in the sediment \#Chlorophyll-a concentration $\# \mathrm{pH}$

\#Request nutrient and light limitation information from model user fp_method<-as.numeric(readline("Which phosphorus limitation approach should be used (1=\%Non-alg P; 2=MichaelisMenten)? "))

fl_method<-as.numeric(readline("Which light limitation approach should be used (1=Average; 2=Depth-integrated)? "))

\#Define a function that runs the chlorophyll a model with a water column total $\mathrm{P}$ mass input

chla_model<-function $(m)\{$

$\mathrm{n}<-1$

while(n<iteration) \{

if $(n==1) \quad\{$

chla<-chla_min

chla_calc<-chla_min $\}$ else $\left\{\right.$ chla<-mean $\left.\left(c\left(c h l a, c h l a \_c a l c[n-1]\right)\right)\right\}$

\#Calculate the average water column total $\mathrm{P}$ concentrations (total and non-algal)

cavg<-m/v_mean[i]

na<-cavg-yp*chla

\#Calculate the light extinction coefficient

Ec $<-$ alpha+beta* ${ }^{*}$ la

\#Calculate the amount of daylight, in hours, based on Julian day and geography

if(input\$Julian[i]<8) $d<-365+$ input\$Julian[i]-7 else $d<-$ input\$Julian[i]

declin<- $0.4102^{*} \sin ((2 * \mathrm{pi} / 365) *(\mathrm{~d}-80.25))$

day_length<-7.72*acos $\left(-\tan \left(\left(2^{*} \mathrm{pi} / 360\right){ }^{*}\right.\right.$ latitude $\left.){ }^{\star} \tan (\operatorname{declin})\right)$

\#Calculate light intensity at the lake surface

Io<-input\$SolarRad [i] * $\operatorname{par}^{*}$ (24/day_length) * (1-reflect)

\#Determine average light intensity over the water column

$\operatorname{Im}<-\left(\right.$ Io-Io* $\left.\exp \left(-z \_m e a n[i]{ }^{*} \mathrm{EC}\right)\right) /\left(z_{-}\right.$mean $\left.[i]^{*} \mathrm{EC}\right)$

\#Calculate the temperature adjustment factor 
$\mathrm{ft}<-\max (\odot,($ input\$WtrTemp $[$ i] -tzero $) /($ topt -tzero $))$

\#Determine the growth rate

gt $<-\max \left(\odot, \operatorname{gmax}{ }^{*} \min (1, \mathrm{ft})\right)$

\#Determine the combination respiration, settling and outflow term

$r<-\max \left(0.01, r \max { }^{*} \mathrm{ft}+(\right.$ ualgae/z_mean $[i])+\left(q \_\right.$out $\left.\left.[i] / v \_m e a n[i]\right)\right)$

\#Determine the light and nutrient limitation factors based on the user-specified methods

fl<-

ifelse (fl_method==1, (Im/ihalf)/sqrt $\left(1+(\operatorname{Im} / \text { ihalf })^{\wedge} 2\right)^{*}($ day_length/24), ((day_length/24)/(Ec*z_mean [i] $\left.)\right)^{*}$ log $((($ Io/i

half $\left.)+\operatorname{sgrt}\left(1+\left((\text { Io/ihalf })^{\wedge} 2\right)\right)\right) /\left(\left(\right.\right.$ Io*exp $\left(-z\right.$ mean $\left.[i]^{*} E c\right) /$ ihalf $)+\operatorname{sgrt}\left(1+\left(\left(\right.\right.\right.$ Io* $\left.\left.\left.\left.\left.\exp \left(-z \_m e a n[i]{ }^{\star} E c\right) / i h a l f\right) \wedge 2\right)\right)\right)\right)$

$\mathrm{fp}<-$ ifelse $\left(\mathrm{fp} \_\mathrm{method}==1, \min (1, \mathrm{na} / \operatorname{cavg}), \max (0, \min (1,(\mathrm{na} / 1000) /((\mathrm{na} / 1000)+\mathrm{khalf})))\right)$

\#Calculate the chlorophyll a concentration such that its minimum is never less than 8 ppb

\#and its maximum never exceeds the cell quota with respect to available phosphorus

chla_calc $[\mathrm{n}]<-\min \left(\max \left(\mathrm{chla} \_\mathrm{min}, \mathbf{i f e l s e}\left(\mathrm{gt}==0, \mathrm{chla}\right.\right.\right.$ min, gt* $\left.\left.\mathrm{fl}^{*} \mathrm{fp}^{*} \mathrm{chla} / \mathrm{r}\right)\right)$, cavg/yp)

\#If chlorophyll concentration hasn't changed by more than the threshold since the last iteration, \#finish the iterative process otherwise continue

if (abs (chla-chla_calc $[\mathrm{n}])<$ difference) $n<-$ iteration else $n<-n+1$

\}

chla_calc[length(chla_calc)]

\}

\#Begin the model loop, the outer loop runs through each time step "i"

for(i in 1:nrow(input)) \{

\#Set the initial water column and sediment total $P$ masses, the calculated values for the first

\#time step $i=1$, and end values from the previous timstep for $i>1$

if $(i==1) \quad\{$

m_o<-minit

s_o<-sinit $\}$ else \{

m_o $<-$ Mt $[i-1]$

S_o<-St $[i-1]\}$

\#Determine the corresponding chlorophyll a concentration for m_o

chla@<-chla_model $\left(m \_o\right)$

$\#$ pH Model (Dependent on chlorophyll a concentration)

ph<-max (ph_min, ph2_int+ph2_chla* $\log (\operatorname{chla} \odot)+p h 2 \_j u l i a n * \max (j \mathrm{dmin}$, input\$Julian [i] ))

\#Calculate the recycled mass of total $P$ from the sediment at $t=0$

m_reco<- ( (1-pnorm $\left.\left(\left(p h \_t h r e s h o l d-p h\right) / p h \_s i g m a\right)\right)^{*} k s \_p h{ }^{*} s \_{ }^{*}$ step $) / d e l t a t$

\#Calculate the average water column non-algal $P$ concentration at $t=0$

c_na<-m_o/v_mean[i]-chla@*yp

\#Calculate the mass of algal $P$ settling out of the water column

sed_na<-c_na*v_mean $[i]{ }^{*} \mathrm{~kg}$

\#Calculate the mass of non-algal $P$ settling out of the water column

sed_alg<-chla0*yp*input\$Area[i]*ualgae

\#Calculate the mass of total $P$ flowing out of the lake

m_out<- $\left(\left(m \_o / v \_m e a n[i]\right) *\right.$ input $\$$ Outflow $\left.[i]\right) /$ deltat

\#Sediment Model

\#Calculate the mass of buried total $\mathrm{P}$ in the sediment

s_b<- $\left(k b * s \_o * s t e p\right) /$ deltat

\#Calculate the first set of Runge-Kutta factors, k11 and k12, or the first

\#approximated change in mass

k11<-(load tot $[i] /$ deltat $+m$ reco-sed_alg-sed_na-m_out $) *$ deltat

k12<- (sed_alg+sed_na-m_reco-s_b)*deltat 
\#Calculate the variables modified by k11 and k12

\#Determine the corresponding chlorophyll a concentration for m_o

chla1<-chla_model $\left(\mathrm{m} \_0+0.5 * \mathrm{k} 11\right)$

ph1<-max (ph_min, ph2_int+ph2_chla* $\log ($ chla1 $)+p h 2 \_j u l i a n * m a x(j d m i n$, input\$Julian [i] $\left.)\right)$

m_rec1<- ( (1-pnorm ( (ph_threshold-ph1)/ph_sigma $)){ }^{*} k s \_p h *\left(s \_0+0.5 * k 12\right)$ *step $) / d e l t a t$

sed_na1<- $\mathrm{kg}{ }^{*}\left(\left(\mathrm{~m} \_0+0.5^{*} \mathrm{k} 11\right)-\mathrm{yp}{ }^{*} \mathrm{chla1}{ }^{*} \mathrm{v} \_\right.$mean $\left.[\mathrm{i}]\right)$

sed_alg1<-chla1*yp*input\$Area [i]*ualgae

m_out1<- $(($ m_o+0.5*k11)/v_mean [i] $) *$ input\$outflow $[i] /$ deltat

s_b1<-kb* (s_o+0.5*k12)*step/deltat

\#Calculate the second set of Runge-Kutta factors, k21 and k22, or the second

\#approximated change in mass

k21<-(load_tot [i]/deltat+m_rec1-sed_alg1-sed_na1-m_out1)*deltat

k22<-(sed_alg1+sed_na1-m_rec1-s_b1) ${ }^{\star}$ deltat

\#Calculate the variables modified by k21 and k22

\#Determine the corresponding chlorophyll a concentration for m_o

chla2<-chla_model (m_0+0.5*k21)

ph2<-max (ph_min, ph2_int+ph2_chla* $\log (\mathrm{chla2})+$ ph2_julian*max (jdmin, input\$Julian [i] $))$

m_rec2<- ( (1-pnorm ( (ph_threshold-ph2)/ph_sigma $))^{*} k s \_p h *\left(s \_0+0.5^{*} k 22\right){ }^{*}$ step $) / d e l t a t$

sed_na2<-kg* $\left(\left(m \_0+0.5^{*} \mathrm{k} 21\right)-\mathrm{yp}{ }^{*} \mathrm{chla} 2^{*} \mathrm{v} \_\right.$mean $\left.[i]\right)$

sed_alg2<-chla2*yp*input\$Area $[i]{ }^{*}$ ualgae

m_out $2<-\left(\left(m \_0+0.5 * k 21\right) / v \_m e a n[i]\right) *$ input\$Outflow $[i] /$ deltat

s_b2<-kb* (s_o+0.5*k22)*step/deltat

\#Calculate the third set of Runge-Kutta factors, k31 and k32, or the third

\#approximated change in mass

k31<-(load_tot [i]/deltat+m_rec2-sed_alg2-sed_na2-m_out2)*deltat

k32<-(sed_alg2+sed_na2-m_rec2-s_b2)*deltat

\#Calculate the variables modified by $k 31$ and $k 32$

\#Determine the corresponding chlorophyll a concentration for m_o

chla3<-chla_model $\left(\mathrm{m} \_0+\mathrm{k} 31\right)$

ph3<-max (ph_min,ph2_int+ph2_chla* $\log (\operatorname{chla3})+p h 2 \_j u l i a n * \max (j \mathrm{dmin}$, input\$Julian [i] $\left.)\right)$

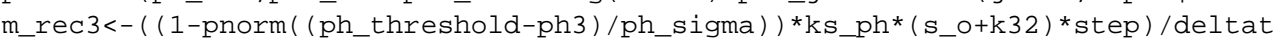

sed_na3<- $\mathrm{kg}^{*}\left(\left(\mathrm{~m} \_0+\mathrm{k} 31\right)-\mathrm{yp}{ }^{*} \mathrm{chla3}{ }^{*} \mathrm{v} \_\right.$mean $\left.[i]\right)$

sed_alg3<-chla3*yp*input\$Area[i]*ualgae

m_out3<- $\left(\left(\mathrm{m} \_0+\mathrm{k} 31\right) / \mathrm{v} \_\right.$mean $\left.[i]\right) *$ input\$Outflow $[\mathrm{i}] / \mathrm{deltat}$

s_b3 $<-k b *\left(s \_0+k 32\right) *$ step/deltat

\#Calculate the first set of Runge-Kutta factors, k41 and k42, or the fourth

\#approximated change in mass

k41<-(load_tot [i]/deltat+m_rec3-sed_alg3-sed_na3-m_out3)*deltat

k42<-(sed_alg3+sed_na3-m_rec3-s_b3) ${ }^{*}$ deltat

\#Calculate the final water column total $\mathrm{P}$ mass 14 days later based on the four approximations; \#the second and third approximations are given the greatest weight

$m \_t<-m \_0+(1 / 6) *(k 11+2 * k 21+2 * k 31+k 41)$

\#Calculate the average water column total $P$ mass over the time step

$\mathrm{m} \_$avg $<-$mean $\left(\mathrm{c}\left(\mathrm{m} \_\mathrm{o}, \mathrm{m} \_\mathrm{t}\right)\right)$

\#Calculate the average water column total $\mathrm{P}$ concentration over the time step

c_avg<-m_avg/v_mean[i]

\#Calculate the final sediment total $\mathrm{P}$ mass 14 days later

s_t $<-s \_0+(1 / 6) *(k 12+2 * k 22+2 * k 32+k 42)$

\#Calculate the change in mass of total $\mathrm{P}$ over the time step

delm<-m_t-m_o

\#Sediment Model

\#Calculate the change in mass of total $\mathrm{P}$ over the time step

dels<-s_t-s_o

\#Calculate the average sediment total $\mathrm{P}$ mass over the time step

s_avg<-mean $\left(c\left(s \_o, s \_t\right)\right)$ 


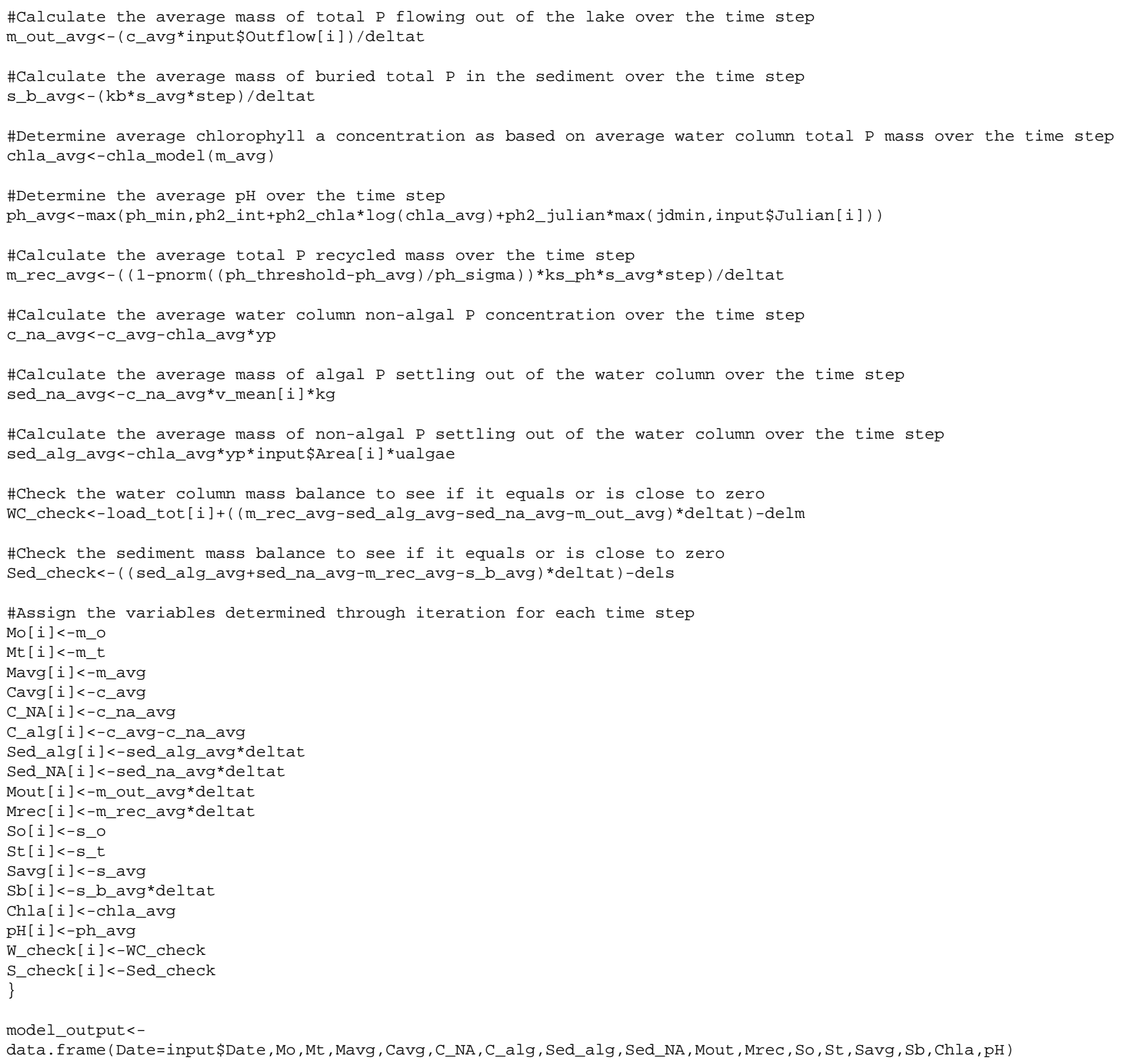


